Florida International University FIU Digital Commons

$11-8-2010$

\title{
A Phenomenological Exploration Of How West Indian Professionals In South Florida Perceive Their Career Construction
}

Judith D. Bernier

Florida International University, Jbni01@yahoo.com

DOI: $10.25148 /$ etd.FI10120604

Follow this and additional works at: https://digitalcommons.fiu.edu/etd

Part of the Adult and Continuing Education and Teaching Commons

\section{Recommended Citation}

Bernier, Judith D., "A Phenomenological Exploration Of How West Indian Professionals In South Florida Perceive Their Career Construction" (2010). FIU Electronic Theses and Dissertations. 299.

https://digitalcommons.fiu.edu/etd/299 


\section{FLORIDA INTERNATIONAL UNIVERSITY}

Miami, Florida

\section{A PHENOMENOLOGICAL EXPLORATION OF HOW WEST INDIAN PROFESSIONALS IN SOUTH FLORIDA PERCEIVE THEIR CAREER CONSTRUCTION}

A dissertation submitted in partial fulfillment of the requirements for the degree of DOCTOR OF EDUCATION

in

ADULT EDUCATION AND HUMAN RESOURCE DEVELOPMENT by

Judith Debbie Bernier

2010 
To: Interim Dean Delia C. Garcia

College of Education

This dissertation, written by Judith Debbie Bernier and entitled A Phenomenological Exploration of how West Indian Professionals in South Florida Perceive their Career Construction, having been approved in respect to style and intellectual content, is referred to you for judgment.

We have read this dissertation and recommend that it be approved.

$\overline{\text { Dawn Addy }}$

$\overline{\text { Dionne Stephens }}$

Hilary Landorf

Tonette Rocco, Major Professor

Date of Defense: November 8, 2010

The dissertation of Judith Debbie Bernier is approved.

Interim Dean Delia C. Garcia College of Education

Interim Dean Kevin O’ Shea University Graduate School

Florida International University, 2010 
(C) Copyright 2010 by Judith Debbie Bernier

All rights reserved. 


\section{DEDICATION}

I dedicate this dissertation to my parents, Catherine and Alphonsus Bernier, for their desire and courage to migrate to the United States to create a better life for themselves and their five children: Marcia, Carol, Judith, Sharon, and Tenji. My parents and sisters' love and encouragement have been invaluable throughout my life. You have all made this academic journey possible. I appreciate your dedication to my life goals and achievements. I love you and look forward to spend more time in your presence. 


\section{ACKNOWLEDGMENTS}

The completion of this dissertation was made possible because of an invaluable community of scholars, peers, friends, and participants. Dr. Rocco, my major professor, has been an outstanding mentor and academic and career advisor from the inception of my doctoral studies. Her enthusiasm for and dedication to research and scholarly writing is infectious. I appreciate her encouragement and devotion to ensure that I seized many scholarly writing and presentation opportunities throughout my doctoral studies. These experiences helped to inform my research agenda and have been some of the most enriching and rewarding experiences of this process.

My dissertation committee's commitment to my educational growth and achievement has been both sincere and inspirational. Each member's expert knowledge is reflected throughout various aspects of my dissertation. Dr. Addy, who has served on both my program of study and dissertation committees, has been instrumental in guiding and focusing my doctoral studies and dissertation content. Dr. Landorf has been instrumental in providing valuable feedback and guidance that allowed me to expand my knowledge and deepen my insight. Dr. Stephens has been instrumental in providing insightful and scholarly feedback and value resources that enhanced the significance of this study. Your collective commitment to educational excellence is admirable.

The Office of Graduate Studies has been both supportive and diligent in their commitment to serve the students of the College of Education. Drs. Barbetta, Bliss, Newman and the OGS team, I appreciate your scholarly feedback and administrative guidance. 
My dissertation peer group has been an endless circle of friendship and support system. Masha, Greg, and Claire, I appreciate your support and friendship. Your friendship and support have made this journey bearable when at times it became unbearable. Your milestones and achievements have also been great motivators.

My dear friend Wanda has been a true friend as I journeyed through this process. I appreciate your interest in and support of my educational pursuit. I adore our friendship. Henry, my beloved friend, has been a great motivator and supporter. I appreciate your patience and support.

This study would not have been possible without the participants, who were candid, forthcoming, and generous with their time. I appreciate your commitment and interest in this study. Your shared experiences will provide valuable insights on how West Indian professionals in South Florida construct their careers and integrate into the U.S occupational structures. Thanks for your dedication and participation. 


\begin{abstract}
OF THE DISSERTATION
A PHENOMENOLOGICAL EXPLORATION OF HOW WEST INDIAN PROFESSIONALS IN SOUTH FLORIDA PERCEIVE THEIR CAREER CONSTRUCTION
\end{abstract}

by

Judith Debbie Bernier

Florida International University, 2010

Miami, Florida

Professor Tonette Rocco, Major Professor

This phenomenological study explored how West Indian professionals in South Florida perceive their career construction. The study used Savickas's (2005) theory of career construction as its theoretical framework. Semi-structured interviews were conducted, transcribed, and analyzed for 15 West Indian professionals, who selfidentified as West Indians and met all the criteria for this study.

Interview data were analyzed using inductive, deductive, and comparative analyses. Five themes emerged from the inductive analysis of the data: (a) vocational influences, (b) adjustment challenges, (c) employment patterns, (d) career mobility patterns, and (d) career success perceptions. The theory of career construction guided the deductive analysis. The deductive analysis revealed that both extrinsic and intrinsic influences were equally influential in shaping the participants' vocational personalities. The deductive analysis also revealed that the participants used three of the career adaptive dimensions: career concern, control, and confidence. Career concern manifested as planning for the future through educational attainment and performing meaningful 
work. Career control manifested as continuous learning and maintaining secondary careers. Career confidence manifested as self-efficacy expectations, beliefs about one's ability to perform a behavior that produces desired outcomes. The participants' life themes or challenges included navigating their identity, starting over, and adjusting to their environment. The comparative analysis revealed that all five themes from the inductive analysis were evident in each of the three tenets of Savickas's (2005) career construction theory (i.e., vocational personality, career adaptability, and life themes). Career compromises emerged as coping behavior to facilitate the participants' social and occupational integration.

The findings of this study imply that the participants constructed their sense of self in relation to those around them and that their vocational behaviors tend to mobilize and reinforce a mixture of personality and ability. The findings also imply that the participants' decision-making style and habitual pattern of decision making, may be embedded in their culturally norms, producing a specific cognitive style. Finally, the findings imply that the participants' career adaptive dimensions were grounded in their attitudes, beliefs, and competencies and overall self-concept. Recommendations for further research are given. 


\section{TABLE OF CONTENTS}

\section{CHAPTER}

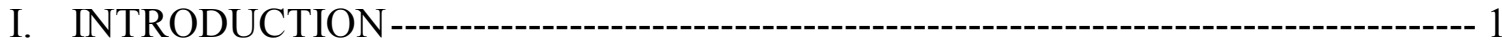

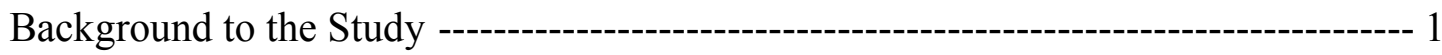

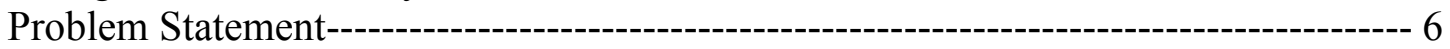

Purpose of the Study -----_-_- 8

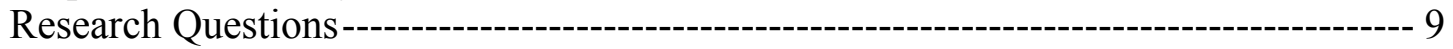

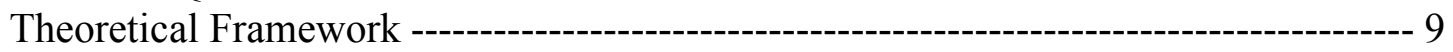

Significance of the Study ---_-_-

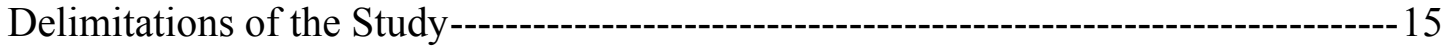

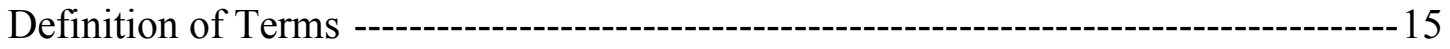

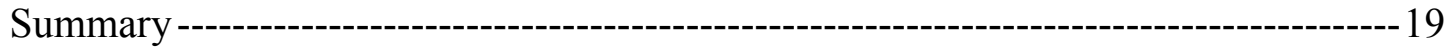

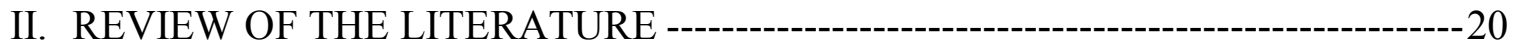

Organizational Context of Career: A Human Resource Development Perspective ---21

Social Context of Career----_---_.

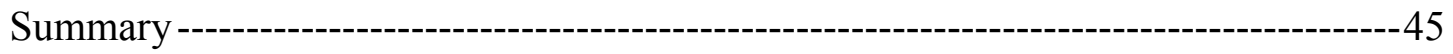

III. METHODS ---------

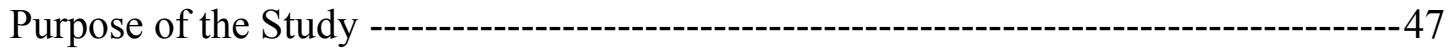

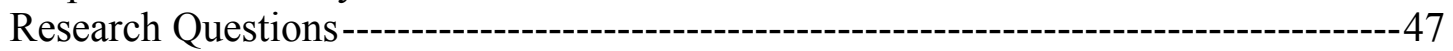

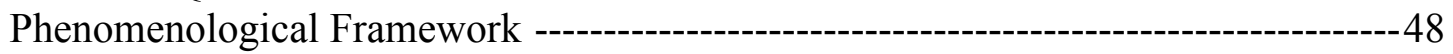

Researcher's Autobiography, Assumptions, and Journaling Process ------------------49

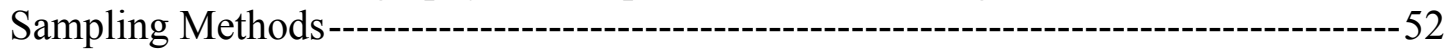

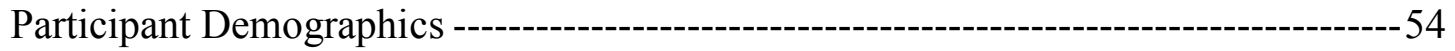

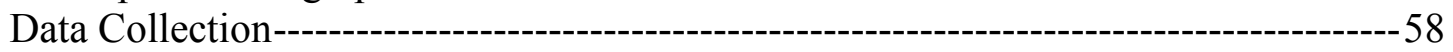

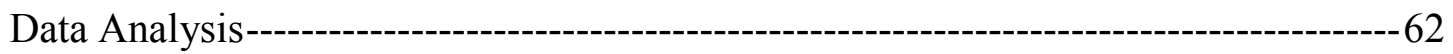

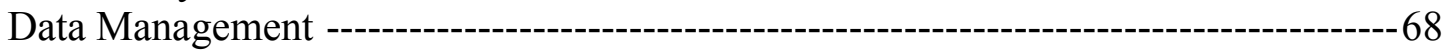

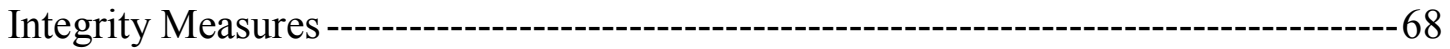

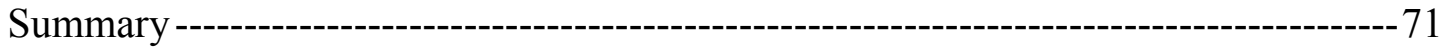

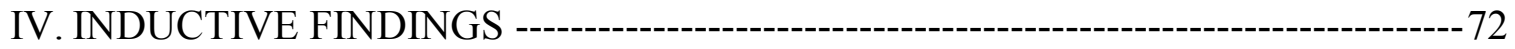

Vocational Influences -----------------------------------------------------------------72

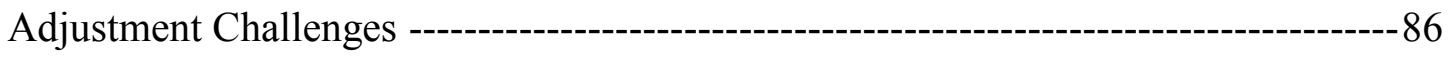

Employment Patterns--------------------------------------------------------95

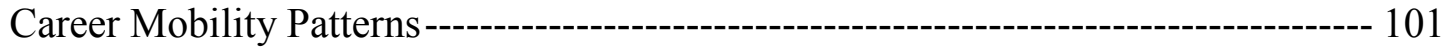

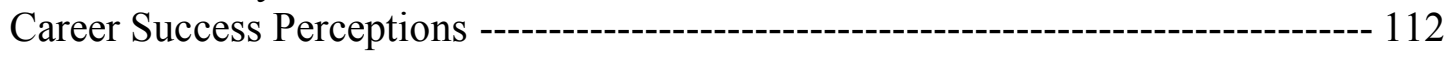

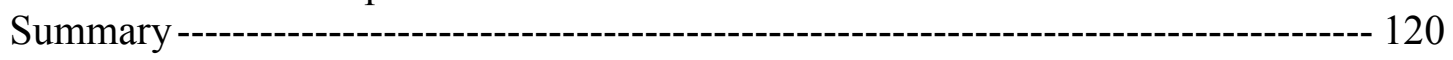

V. DEDUCTIVE AND COMPARATIVE FINDINGS ---_--- 121

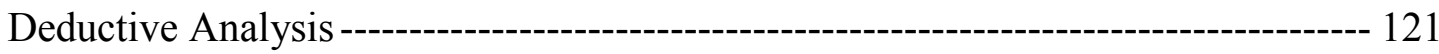

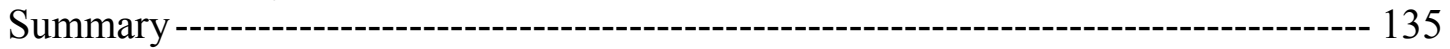


Comparative Analysis----------------------------------------------------------------------------- 136

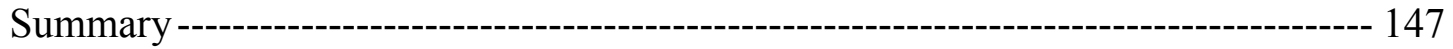

VI. DISCUSSION ---------------------------------------------------------------------------------- 148

Responses to the Research Questions------------------------------------------------------- 148

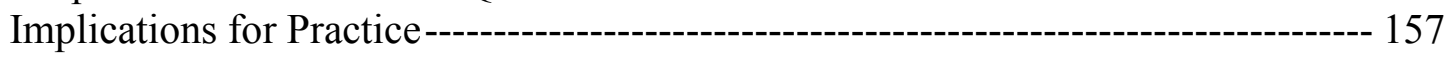

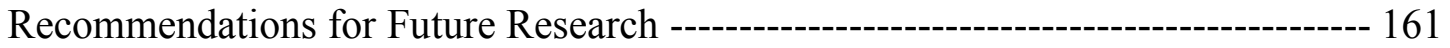

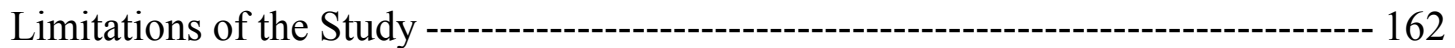

Summary ------------------------------------------------------------------------------------------- 162

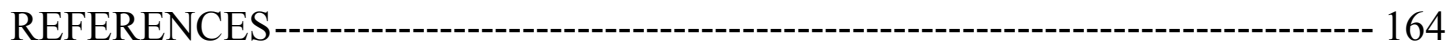

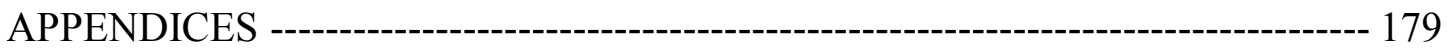

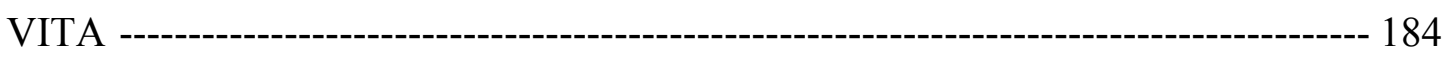




\section{LIST OF TABLES}

TABLE

PAGE

1. Bachelor Degrees Attainment among West Indians, African Americans, Hispanics,

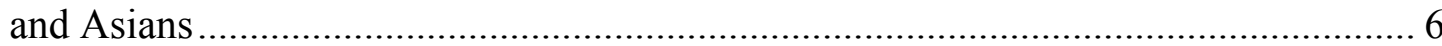

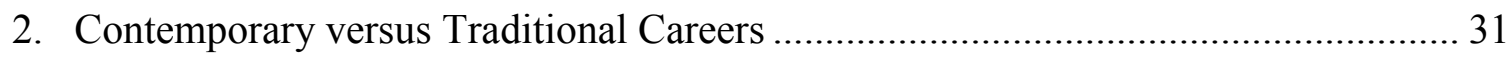

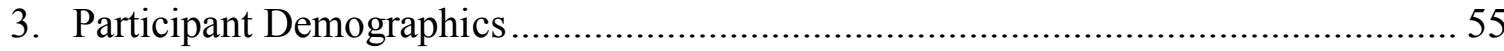

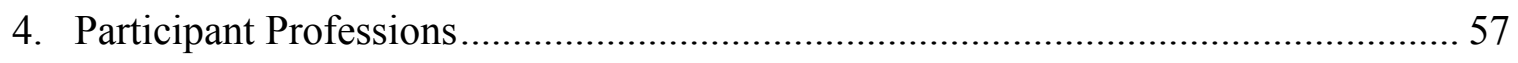

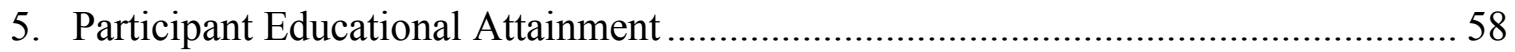

6. Example of Coding Rubric for A prior Code Vocational Personality ....................... 67

7. Career Adaptability Behavior Reported by Participants..................................... 133 


\section{CHAPTER I}

\section{INTRODUCTION}

This phenomenological study explored how West Indian professionals in South Florida perceive their career construction (Savickas, 2002, 2005). The aim of the study was to understand the processes West Indian professionals use to integrate into the U.S. occupational structures. This chapter begins with the background to the study, problem statement, purpose, and research questions. Next, the theoretical framework, significance of the research, delimitations of the study, definition of terms, and organization of the study are discussed.

\section{Background to the Study}

Approximately 2.8 million immigrants from the West Indies live in the United States (U.S. Census, 2000) and about 314,000 reside in the South Florida. The West Indian population in both Miami and Fort Lauderdale represent the second largest West Indian population in the U.S., next to New York area (U.S. Census, 2000). West Indians are driving the growth in Black communities, across Miami and Fort Lauderdale. These Black communities encompass people of African descent including those identifying as African American, African or of other the Diaspora. In fact, between 1990 and 2000, Fort Lauderdale's West Indian community tripled to over 154,000 , accounting for nearly $50 \%$ of the city's total Black community (U.S. Census, 2000). In 2000, Miami's West Indian community increased to about 158, 000 (U.S. Census, 2000) and in 2002 accounted for $25 \%$ of the Black community (U.S. Census, 2002). 
Over 300,000 people surveyed in the Miami-Fort Lauderdale area described their primary ancestry as West Indian (U.S. Census Population Survey [CPS], 2005).

This study focused on West Indian immigrants. For the purpose of this study, West Indians are people from the West Indies, that is, the English-speaking islands/mainland territories of the Caribbean region (Foner, 2001; Henke, 2001; Water, 1999). The term West Indian is often thought to bear a negative connotation because it evokes the colonial "arrogance and ignorance that European settlers brought to this region" (Henke, 2001, p. xvii). In 1492, Christopher Columbus arrived in Hispaniola and mistakenly assumed that he found the western route to India and named this region the West Indies (Henke, 2001). The term Caribbean is often considered more appropriate because of the indigenous Carib Indians who settled in this region and who fiercely attempted to resist European settlers' conquest (Henke, 2001). However, because this study focused on immigrants from the English-speaking Caribbean, where English is the national language, the term West Indian was used to differentiate this group from other groups in the Caribbean (i.e., French, Spanish and Dutch).

West Indians: Who Are They?

The English-speaking region of the Caribbean, formerly colonized by the British, is the home of a diverse group of people known as West Indians. The West Indies consists of many migrant groups who voluntarily and involuntarily (Ogbu, 1991) came from other countries. Voluntary immigrants are immigrant minorities who "generally moved to their present societies because they believed that the move would lead to more economic well-being, better overall opportunities or greater political freedom" (Ogbu, p. 8). 
Involuntary immigrants are nonimmigrant minorities or involuntary minorities "who were brought into their present society through slavery, conquest or colonization" (Ogbu, p. 9). For example, in the West Indies, African slaves involuntarily arrived from West Africa $(\mathrm{Ogbu})$. White settlers, planters, and administrators voluntarily arrived from Europe, and indentured servants voluntarily arrived from India and China (Thomas, 1988). Although West Indians are not a monolithic group, most West Indian immigrants are of African origin (Henke, 2001; Waters 1999) and have traditionally been categorized as Black (U.S. Census, 2000) and voluntary immigrants (Ogbu) in the U.S.

West Indians' migration to the U.S. has forced them into sharing a racial minority group with African Americans. West Indians and African Americans have similar African roots, but dissimilar cultural and historical experiences (Foner, 2001). These experiences have shaped both groups' current perceptions about race, race-relations, and the degree to which the experience of slavery and race permeate their daily interactions in both the U.S. and the West Indies societies (Waters, 1999). According to Waters, there are several social, cultural, and historical reasons for the differing perceptions and experiences between African Americans and West Indians. First, Blacks in the West Indies, unlike their African American counterparts in the U.S., were not systematically disenfranchised and kept from most skilled occupations following emancipation. After emancipation, many West Indians continued to work in the plantation system and eventually acquired land and occupational skills. Land ownership and attaining occupational skills have been identified as "key points of divergence between Caribbean and American black experience" (Waters, p. 33). 
Second, in the West Indies the struggle against racism is less personal and more related to anticolonialism and nationalism, unlike in the U.S. where the struggle against racism is directly personal and often related to skin color. Third, in the West Indies being Black does not mean being a minority, unlike in the U.S. where being Black is tied to being a minority. Fourth, in the West Indies race is a gradation of colors between White and Black, unlike in the U.S. where the social construction of race is a sharp distinction of White and non-White.

Finally, West Indians come to the U.S. as voluntary immigrants (Ogbu, 1991) to improve their economic and educational circumstances (Foner, 2001), unlike African Americans who arrived to the U.S. as involuntary immigrants (Ogbu). Hence, "involuntary immigrants differ from [voluntary] immigrants in their perceptions, interpretations, and responses to" (Ogbu, p. 13) a number of factors such as social barriers, structures of opportunity, and social identity (Ogbu). Despite the difference in each group's immigrant status and history, African Americans and West Indians are often stereotyped and experience racial discrimination in the U.S.

\section{West Indians: U.S. Migration Patterns}

West Indians' migration to the U.S. has occurred in successive waves (Marshall, 1987a). Like most immigrants, West Indians' migration has been based on labor needs, economic trends, and educational opportunities (Levine, 1987). Beginning with World War II around 1940, an estimated 400,000 migrant workers, 17\% of whom were West Indians, came to work in the cannery, agriculture, lumber, and railroad industries in the U.S. (Levine). Some of these migrant workers were recruited to supplement the existing U.S workforce in these industries and others came for economic necessity. 
The second wave took advantage of the Immigration and Nationality Act (1965) that lifted quotas based on national origin and opened the gateway to the U.S. (Thomas, 1988). This wave of immigrants was comprised primarily of single men, who were highly skilled, well-educated, and middle to upper class professionals (Foner, 2001; Waters, 1999). Within the past 3 decades, West Indian immigrants have been individuals from various economic and educational backgrounds and mainly women (Ho, 1999). This group of female immigrants consisted of women who arrived first to seek employment and permanent residency and were followed by the rest of the families (Ho). This femaledriven phenomenon was due to the economic conditions in the U.S. that influenced immigration policy that favored women who were seeking domestic employment (Ho). West Indians: U.S. Workforce Participation and Educational Attainment

West Indians pursue the American dream through their participation in the U.S. workforce (Foner, 2001; Levine, 1987; Waldinger, 2001a). In fact, 33\% of West Indians, who are 16 years and older who participate in the U.S. workforce, work in the educational services and health care and social assistance industries. In Miami-Dade and Broward Counties' workforce this percent is $26 \%$ and $24 \%$ respectively. In these counties, the top three occupations that West Indians who are 16 years and older hold are: (a) professionals and managerial occupations, (b) service occupations (c) sales and office occupations (2006- 2008 American Community Survey [ACS]).

In the U.S., West Indians 25 years and over with Bachelor degrees represented $15 \%$ of all degree holders, compared to African Americans who represented 11\%, Hispanics 9\% and Asian 30\%; the national average was 17\% (2006-2008 ACS). 
In Miami-Dade County, West Indians represented 11\% of Bachelor degree holders, compared to African Americans who represented 10\%, Hispanics 16\%, and Asian 32\%. In Broward County, West Indians represented 13\% of Bachelor degree holders, compared to African Americans who represented 13\%, Hispanics 18\%, and Asian 27\%. In Broward County, the average percent of bachelor degree holders was 19\% and in Miami-Dade County the average percent was $17 \%$. Table 1 shows the comparison of the educational attainment among West Indians, African Americans, Hispanics, and Asians. West Indians' representation in the Black communities, their educational attainment, and relative personal and professional success in the U.S. (Waldinger, 2001a) warrant the need to study this group.

Table 1

Bachelor Degrees Attainment among West Indians, African Americans, Hispanics, and Asians

\begin{tabular}{llllll} 
Region & $\begin{array}{l}\text { Regional } \\
\text { Averages }\end{array}$ & West Indian & $\begin{array}{l}\text { African } \\
\text { Americans }\end{array}$ & Hispanic & Asian \\
\hline United States & $27 \%$ & $15 \%$ & $11 \%$ & $9 \%$ & $30 \%$ \\
Miami-Dade County & $17 \%$ & $11 \%$ & $10 \%$ & $16 \%$ & $32 \%$ \\
Broward County & $19 \%$ & $13 \%$ & $13 \%$ & $18 \%$ & $27 \%$ \\
\hline
\end{tabular}

Source: Based on (2006-2008) American Community Survey.

\section{Problem Statement}

Although West Indians' patterns of migration, workforce participation, and level of education are often well documented (Bureau of Labor and Statistics, 2005; Levine, 1987; Marshall, 1987; Thomas, 1988; U.S. Census, 2002; Waldinger, 2001b), little is known about their careers. 
The term career refers to the individually perceived sequence of attitudes, behaviors, and patterns associated with work-related experiences and activities (Hall, 1976), resulting in the development of a vocational behavior over time (Savickas, 2002). Vocational behavior refers to the responses that an individual makes in selecting and adapting to an occupation and the changes in that individual's responses or behavior over time (Savickas, 2002). Understanding these responses is essential when assessing individuals' career development needs or providing career counseling (Savickas, 2005). Despite the importance of understanding individuals' vocational behavior, little is known about West Indian professionals' vocational behavior when selecting and adapting to an occupation upon their immigration to the U.S. What is known and often reported are the dominant occupations that West Indian professionals gravitate toward in the U.S. workforce rather than their processes of selection and adaptation to their professions.

Furthermore, West Indian professionals' careers are often not explicitly reported in the literature because Black natives and immigrant groups' (i.e., West Indians, Africans, and African Americans) experiences are often homogenized (Ogbu, 1991; Phinney, 1996). For this reason, West Indians have been labeled as "invisible immigrants" (Bryce-Laporte, 1994; Foner, 2001). As noted in Ellison's (1992) novel, Invisible Man, Black foreigners experience a double invisibility that entails being black and foreign. However, Marshall (1987b) contends that Black foreign women, specifically, experience a triple invisibility: as a Black, a foreigner, and a female. West Indians' invisibility in the literature creates not only a gap about their specific personal experiences, but their vocational behaviors as well. 
This gap may be attributed to the fact that West Indians are often seen as a "model minority" group, that is, the belief that this group is successful, hard working, loyal, does not complain (Waters, 1999), and therefore does not warrant special attention. This gap may also be attributed to the fact that unlike Hispanics, West Indians have not yet emerged as a politically influential group, and therefore do not garner special attention.

Exploring West Indian professionals' perceptions of their careers increases our understanding of their specific interpersonal and interpretive career processes and the likelihood that their career and developmental needs as immigrants will be better served. This exploration may also provide a unique perspective of the traditional and monolithic view of Black employment experiences. Understanding West Indian professionals' career responses and experiences is particularly important because, as immigrants and a growing segment of the Black community, their social and economic integration into their host society become major indicators of their survival and success. This understanding not only provides an insight into West Indian professionals' careers and developmental processes, but helps to portray a more comprehensive range of their experiences (i.e., social, and occupational, and personal ) within American society.

\section{Purpose of the Study}

The purpose of this phenomenological study was to explore how West Indian professionals in South Florida perceive their career construction (Savickas, 2002, 2005). The aim of the study was to understand the processes West Indian professionals used to integrate into the U.S. occupational structures. 


\section{Research Questions}

Creswell (2003) contends that the primary research question in qualitative study should relate to the "specific qualitative strategy of inquiry" (p. 106). The primary research question of this phenomenological study is: How do West Indian professionals perceive their career construction?

Secondary questions are:

1. What factors do West Indian professionals believe influence their vocational behavior?

2. What career adaptive mechanisms do West Indian professionals report using to facilitate their integration into the U.S. occupational structures?

3. What processes do West Indian professionals report using to integrate into the U.S. occupational structures?

\section{Theoretical Framework}

Savickas's (2005) theory of career construction states that careers do not simply unfold, but are constructed based on one's self-concept and social realities. According to Savickas (2005):

The process of career construction is essentially that of developing and implementing vocational self-concepts in work roles. Self-concepts develop through the interaction of inherited aptitudes, physical make-up, opportunities to observe and play various roles, and evaluations of the extent to which the results of role-playing meet with the approval of peers and supervisors. Implementation of vocational self-concepts in work roles involves a synthesis and compromise between individual and social factors. (p. 45) 
Career construction represents the what, why, and how of vocational behavior: (a) vocational personality, (b) life themes, and (c) career adaptability. Vocational Personality

Vocational personality refers to individuals' career-related abilities, values, and interests representing the what in their career construction (Savickas, 2005).

It emphasizes the occupational content of career, the intrinsic influences on career development, and the context in which individuals live or derive career influences (Patton \& McMahon, 2006). Vocational personalities are formed in one's family and often rehearsed through activities, such as household chores, games, hobbies, reading, and enforced by teachers, role models, and the community (Savickas). For example, some families expect their children to only focus on what they consider professional careers, such as medical doctors, lawyers, and engineers, as these professions tend to be associated with prestige. This expectation is often common in immigrants or ethnic families because of the strong desire to achieve the American dream (Chope, 2008).

\section{Life Themes}

Life themes refer to individuals' career stories or narratives about tasks, transitions and traumas revealing the why of vocational behavior and the private meaning that guides career choices (Savickas, 2005). A common life theme among some ethnic minorities, in professional roles, is the preference of a mentor who is of similar ethnicity and who provides not just psychosocial support, but career-related support (Ragin \& Cotton, 1999). Individuals use life themes to make meaningful choices and adjustments to work roles. Life themes also provide contexts for the meaning of a career and the dynamics of its construction. 
By combining and organizing life themes, career patterns emerge and become a fundamental way for individuals to see themselves and what is important to them. Patterns are the primary unit of meaning in career construction theory.

\section{Career Adaptability}

Career adaptability refers to individuals' career-related coping mechanisms or processes representing the how in their social and occupational integrations. For many immigrants, entrepreneurship is often an adaptive mechanism to combat structural barriers in the primary labor market and was found to be an important factor in the economic and social integration of West Indians emigrating from the West Indies (Waldinger, 2001a; Water, 1999). Career adaptability emphasizes the occupational process of career (Savickas, 2005), including the developmental task or career decisionmaking processes that individuals employ from prepuberty, late teens, and early twenties to when an occupational commitment is made (Ginzberg, 1972). This developmental task is driven by adaptation to an environment rather than by an internal maturation process. Internal maturation process refers to sequential movement of an individual through a series of life stages (i.e., growth, exploratory, establishment, maintenance, and decline stages; Super, 1980, 1990).

Individuals use four global adaptive dimensions to manage critical tasks, transitions, and traumas as they construct their careers: (a) career concern, (b) career control, (c) career curiosity, and (d) career confidence (Savickas, 2005). Career concern involves concern about one's vocational future in terms of time perception, anticipation, and orientation (Savickas). 
Career control involves the control over one's vocational future in terms of decisionmaking, assertiveness, locus of control, autonomy, and self-determination (Blustein \& Flum, 1999). Career curiosity refers to inquisitiveness in exploring the fit between self and work, information-seeking, and self-knowledge. Career confidence refers to the strength and tenacity to pursue a career (Savickas). Each of the four dimensions includes specific sets of attitudes, beliefs, and competencies, which represent the ABCs of career construction (Savickas).

\section{Evaluation of the Theory}

Savickas's (2002) career construction theory, and its three components of vocational personality, career adaptability, and life themes, simply "tells how the self of yesterday became the self of today and will become the self of tomorrow" (p. 58). This level of introspection concerning the evolution of one's career and self-concept is a trend that is clearly emerging in the career development literature (Patton \& McMahon, 2006). Savickas $(2002,2005)$ has been credited as one of the preeminent career development specialists responsible for the paradigm shift from "testing and telling" to the eliciting of stories, whether developmental or drawn from recent experiences (Chope, 2008). This paradigm shift is also indicative of an era of do-it-yourself career management. Within this self-directed career management era, individuals play a greater role in their own careers and the many personal, cultural, social and environmental contextual factors that they have to consider. Despite the theory's utility, it has also been critiqued for its operational applicability and specificity.

Some scholars believe that although the theory is easy to apply to mainstream research, it lacks the "operational specificity found in other theories" (Swanson \& Gore, 
2000, p. 241). Another critique of the theory is its use. Some scholars believe that more often than not, the theory is used retrospectively to explain and interpret research findings, not to structure a study prospectively (Hackett, Lent, \& Greenhaus, 1991). Despite this criticism, Savickas (2002) believes that the theory successfully provides a cogent framework for post hoc interpretation and integration of empirical facts.

Application of the Theory

Within the past decade there have been important applications and extensions of career construction theory. The theory was extended and applied to gender (Cook, 1994) and sexual orientation issues (Dunkle, 1996). Certain aspects of the theory have also been applied outside the U.S., for example, in South Africa (Stead \& Watson, 1998) and Australia (Smart, 1998). Smart examined the career concerns of Australian men and women and found that individuals who were in the midst of a career change were less satisfied with their jobs and career development than those who were in stable career patterns. Although recycling through a new career is often viewed as normal development, the findings of that study suggest a greater support for people who are managing their careers in the current climate of massive layouts and high unemployment. Stead and Watson examined the concepts of career maturity (also known as career adaptability; Savickas, 2005) and role of resilience in South Africa's career research educational programs. The authors concluded that to better serve this population, progress needs to be made toward the indigenization of career research and counseling.

Significance of the Study

Savickas's (2005) theory of career construction is considered one of the critical career theories that view people as self-organizing and self-directed (O’Doherty \& 
Roberts, 2000). However, more needs to be learned about Savickas's (2005) theory within the context of career construction among immigrants who are professionals in the U.S. This study makes theoretical contributions to Savickas's (2005) career construction theory by extending the three key tenets of the theory to the immigrant population of West Indian professionals. Another theoretical significance of this study is the use of this theory as a prospective framework to interpret and analyze the data. This application of the theory is significant because some scholars believe that more often than not, the theory is used retrospectively to explain and interpret research findings, not to structure a study prospectively (Hackett, Lent, \& Greenhaus, 1991).

This study extends the human resource development (HRD) research on career development by providing a phenomenological framework for comprehending career construction. This framework augments the objective views of career (i.e., career path, careers ladder, and compensation, etc.) and public and normative frameworks (i.e., race, class, gender, sex, etc.) often used in HRD to comprehend or discuss the concept of career development.

The significance of this study to the field of HRD is the use of a subjective perspective that includes exploring nationality, cultural values, and the personal meaning of career to understand vocational behavior and its development. The findings of this study will also enable HRD practitioners to become more aware of the perceived sequence of attitudes, behaviors, and patterns associated with West Indian professionals' work-related experiences.

This knowledge will help HRD practitioners to develop and implement career development activities (i.e., training, mentoring, coaching, incentives, etc.) that address 
some of West Indian professionals' cultural specificities, hence enhancing their employability and success. At the organizational level, this knowledge could be useful in increasing retention and performance.

\section{Delimitations of the Study}

Given the five criteria to participate in this study, there are delimitations to this study. Although West Indians migrate to and live in other urban areas within the U.S., this study focused on West Indian of African descent who live and work in South Florida. In addition, this study focused on individuals who completed at least part of their secondary education in the West Indies. Furthermore, West Indians, who attained college degrees in the U.S., were the focus of this study. Finally, this study only focused on West Indian professionals, as defined in this study.

\section{Definition of Terms}

Boundaryless career refers to "opportunities that go beyond any single employer" (DeFillippi \& Arthur, 1996, p. 116).

Career is the individually perceived sequence of attitudes, behaviors, and patterns associated with work-related experiences and activities that span the course of a person's life (Hall, 1976).

Career adaptability refers to individuals' career-related coping mechanisms or processes representing the how in their social and occupational integrations (Savickas, 2005).

Career concern refers to concern about one's vocational future in terms of time perception, anticipation, and orientation (Savickas, 2005). 
Career confidence refers to the strength and tenacity to purse a career (Savickas, 2005).

Career control refers to the control over one's vocational future in terms of decision-making, assertiveness, locus of control, autonomy, and self-determination (Blustein \& Flum, 1999; Savickas, 2005).

Career construction refers to how individuals acquire knowledge, skills, and abilities based on their self-concept and social realities (Savickas, 2005).

Career curiosity refers to inquisitiveness to explore the fit and possibilities between self and work, information-seeking, and self-knowledge (Savickas, 2005).

Career development is "the process by which an individual becomes aware, explores, understands and makes a commitment toward various aspects of his/her career. The process may involve a number of behavioural actions including the giving and receiving of information, the experiencing of feelings, working through decisions, and selecting choices among alternatives" (Chakiris \& Fornaciari, 1984, p. 75).

Career success is the self-perception of the individual that his/her need for achievement have been achieved (Lau \& Shaffer, 1999).

College degree refers to an Associate level degree and above (i.e. Bachelor's, Master's and Doctorate degrees)

Composite textural description refers to the collective or universal description of the participants' experiences of a phenomenon (Moustakas, 1994). In this study, the descriptions are illustrated with verbatim excerpts from the transcript. 
Contextual factors refer to any events, circumstances, or value systems (i.e., cultural, social, sociopolitical, and environmental) that influence individuals' career behaviors, decision-making process, and outcomes (Savickas, 2005).

Family unit includes other kinship not just the traditional American concept of a nuclear family (i.e., mother, father, and children; Henke, 2001).

Human resource development (HRD) refers to "any process or activity that... has the potential to develop adults' work-based knowledge, expertise, productivity, and satisfaction, whether for personal or group/team gain, or for the benefit of an organization, community, nation, or, ultimately, the whole humanity" (McLean \& McLean, 2001, p. 313).

Individual textural description refers to the participants' descriptions of their experiences or what is experienced (e.g., conveyed through thoughts, feelings, and expectations; Moustakas, 1994). In this study, the descriptions are illustrated with verbatim excerpts from the transcript.

Involuntary immigrants refers to nonimmigrant minorities or involuntary minorities "who were brought into their present society through slavery, conquest or colonization" (Ogbu, 1991, p. 9).

Life themes refer to individuals' career stories or narratives about tasks, transitions, and traumas, revealing the why of vocational behavior and the private meaning that guides career choices (Savickas, 2005).

Organization development involves the construction of new and creative organizational solutions to improve performance problems and organizational inefficiencies (Gilley, Eggland, \& Gilley, 2002). 
Professional refers to a person who is in a specific occupational field that is based on a unique body of knowledge and a core set of competencies (i.e., certified public accountants, doctors, lawyers, or teachers; Queeney, 2000).

Psychological contract refers to the relationship or reciprocity between employee and employer in terms of unwritten and implicit expectations (Rousseau, 1995).

Relational contract refers to the exchange between employer and employee that focuses on socio-emotional exchanges, such as the long-term exchange of loyalty for job security, training and development, and financial rewards (Rousseau, 1995).

Training and development involves the development of new knowledge and skills that may result in performance enhancement (Gilley et al., 2002).

Transactional contract refers to the exchange between employer and employee that focuses on specific monetary economic exchanges, such as the short-term exchange of time worked for money or advancement (Rousseau, 1995).

Vocational personality refers to individuals' interface with occupational careerrelated abilities, values, and interests representing the what in their career constructions (Savickas, 2005).

Voluntary immigrants refers to immigrant minorities who have "generally moved to their present societies because they believed that the move would lead to more economic well-being, better overall opportunities or greater political freedom" (Ogbu, 1991, p. 8).

West Indian refers to a diverse group of people from the Caribbean whose history was impacted by British and European colonialism. 
West Indies refers to the English-speaking Caribbean, which consists of the following islands/mainland territories, often categorized under three broad entities: (a) all 15 members of Caribbean Community and Common Market (CARICOM; Antigua and Barbuda, Bahamas, Barbados, Belize, Dominica, Grenada, Guyana, Jamaica, St. Kitts and Nevis, St. Lucia, St. Vincent and the Grenadines, Suriname, Trinidad and Tobago, and Montserrat), but not Haiti or Dominican Republic ; (b) UK dependences (Anguilla, British Virgin Islands, Cayman Islands, the Turks and Caicos, and Bermuda), and (c) the U.S. Virgin Islands (St. Croix, St. John, and St. Thomas).

\section{Summary}

Chapter 1 addressed the background to the study and the problem statement. This section also described the purpose of the study, research questions, and theoretical framework. The significance of the research, delimitations of the study and definitions of terms were also discussed. In chapter 2, a review of the literature relevant to organizational career development and individual vocational behavior is presented. In chapter 3 , the phenomenological framework is discussed, followed by my autobiography and assumptions related to the study. Next, sampling criteria and procedures for data collection, data analysis, and data management, and integrity measures are discussed. In chapters 4 and 5 , the findings of the study are discussed, and in chapter 6 , the implications and recommendations for future research are presented. 


\section{CHAPTER II}

\section{REVIEW OF THE LITERATURE}

Careers are composed of attitudes, behaviors, and patterns associated with workrelated experiences and activities (Hall, 1976), resulting in the development of a vocational behavior overtime (Savickas, 2002). There are two perspectives of careers in vocational psychology, one that focuses on vocational behavior over one's life span and the other on career development within the organizational setting (Savickas, 2002, 2005).

In this chapter, a review of the relevant literature on career development within an organization and vocational behavior within a social context is presented. The chapter is divided into two major sections: (a) organizational context of career and (b) social context of career.

The section on the organizational context focuses on careers within the organizational system and is discussed within the discipline of HRD. Human resource development (HRD) refers to "any process or activity that... has the potential to develop adults' work-based knowledge, expertise, productivity, and satisfaction, whether for personal or group/team gain, or for the benefit of an organization, community, nation, or, ultimately, the whole humanity" (McLean \& McLean, 2001, p. 313).

The section on the social context of careers focuses on the sociological perspective of career and emphasizes the societal factors that influence career behavior, processes, and experiences. These factors include the influences of family, spirituality, community, and other adaptative factors relating to migration (i.e., language, loss of status, acculturative stress, etc). 
Organizational Context of Career: A Human Resource Development Perspective

This section begins with career development as a component of HRD, followed by a discussion of career development research in HRD. The section concludes with a discussion of the organizational trends that influence career development.

\section{Career Development as a Component of Human Resource Development}

Mc Lagan (1989) defines career development as an arrangement between individual career planning and organization career-management processes, whereas Gutteridge (1984) defines career development as the outcomes created by the interface between individual career planning and institutional career management. Career development is also viewed as "the outcome of the individual's career planning and the organization's provision of support and opportunities" (Simonsen, 1997, p. 7). These definitions, like many career development definitions in HRD, reflect the mutual relationship between the individual and the organization

Career development, like all other HRD activities, should fit into the overall HRD strategy. Often, "many performance problems are career related" because employees tend to "feel trapped, stagnated, overlooked in their jobs or occupations" (Gilley et al., 2002, p. 57). Hence, the goal of organizational career development is to encourage employees to examine future career paths, analyze their abilities, and better match their needs with the needs of the organizations (Gilley et al.). Organizational career development refers to the interaction between individual planning and institutional career management processes (Gutteridge \& Otte, 1983). This interaction is often beneficial for both the organization and the employee. 
Some career development programs and activities within the organization include job rotation and programs aimed at retraining, mentoring, professional development, and certification of employees.

However, effective career development programs require that HRD practitioners gain the commitment of both the employees and the organizational leaders. At the organizational level, this commitment involves effectively executing the organization's responsibilities to enhance the career development systems and processes. These responsibilities include: (a) establishing an internal job system, (b) developing mentoring programs, (c) using senior managers as career counselors, (d) planning and developing career development workshops, and (e) developing long-term human resource planning processes, such as succession planning and developmental plans (Gilley et al., 2002).

At the individual level, this commitment involves taking full responsibility for one's career awareness, and career planning (Gilley et al., 2002). By accepting these responsibilities, employees are likely to (a) fully assume their role in managing their careers, (b) identify their abilities, interests, and strengths, (c) and become familiar with the organization, allowing them to aggressively pursue career opportunities (Zenger, 1981). Both levels of commitment can be achieved if HRD professionals work as mediators between the employee and the organization to ensure that both parties are taking responsibility for their respective roles in the career development process.

A commitment to the career development process can also be achieved if HRD professionals revisit their roles and functions in the career development process and methods they use to evaluate career development programs (Preskill \& Donaldson, 2008). 
Conlon (2003) also argues that HRD must alter its functions from training to learning in order to partner with other organizational systems to support employee attraction and retention. He also believes that today's version of career development must adapt to meet social justice needs of new immigrants, poor youth, victims of discrimination, people with disabilities and low economic status, and others who face obstacles in their career development. This adaptation involves broadening the focus of inquiry beyond the individual to include importance factors that contribute to an understanding of one's career development experiences, such as the role of family, community, history, sociocultural and political events, economic conditions, ethnic background, and community structure and size (Vondracek, 2001). Vondracek, Lerner, and Schulenberg (1983) called for a developmental-contextual approach to career development that focused on a life-span conception of vocational development. This approach is dynamic interactive and offers a relational perspectives of the many contextual factors that affect individuals' personal and professional lives and incorporates several disciplines ( i.e., of sociology, psychology, and counseling) that influence career development.

\section{Career Development Research in Human Resource Development}

Within the past decade, most of the research on career development within the field of HRD has focused on strategies and outcomes and the need to revive career development importance in the field of HRD. This insight is due to the limited scholarship in the area of career development compared to the scholarship on training and development. Given that immigrants are a growing segment of the U.S. population and contributing to the growing cultural diversity among professionals in U.S. workforce, understanding immigrants' perceived attitudes, behaviors, and patterns associated with 
their work-related experiences is more important than ever in order to gain knowledge of their career processes and dynamics.

Research on career development has focused on the different types of career strategies essential to achieve career success. Career success has been defined as a way for individuals to fulfill their needs for achievement and power (Lau \& Shaffer, 1999). It has also been defined as "positive psychological or work related outcomes or achievements that the individual accumulates as a result of work experiences" (Seibert, Crant, \& Kraimer, 1999, p. 417).

Career success represents objective and subjective components. The objective component includes salaries, promotions, and company status (Poole, Langan-Fox, \& Omodei, 1990).These indicators of career success, which are relatively observable and verifiable, are often associated with career success in the U.S. On the other hand, the subjective component includes individual perceptions of job satisfaction, self-knowledge, job stability, values, goals, and aspirations (Seibert et al., 1999). Immigrants tend to measure their career success based on their level of personal adjustment to their careers and employment status, both of which are associated with the subjective career (Bhagat \&London, 1999; Tharmaseelan, 2008). This is not to say that the objective career is less important than the subjective career as both components are critical when assessing one's career success or outcomes (Greenhaus, 2003; Poole \& Langan-Fox, 1993). However, these components are not the only criteria that scholars use to assess career success or outcomes or to determine" why are some people more successful in their career than others?" (Poon, 2004, p. 374). 
When assessing West Indians' career success and mobility in the U.S., some scholars have use cultural and structural explanations, rather than the subject-objective career to answer Poon's (2004) question (Forner, 2001; Waldinger, 2001a; Waters, 1999). For example, the cultural explanations for West Indians' success and mobility generally imply that this group's values, beliefs, and behavior explain their successes (Waters). An example this cultural explanation of West Indians success or mobility is their propensity toward valuing education, working hard, and having dual income earning households. In contrast, the structural explanations for West Indians' success or mobility generally view their behaviors not primarily as reflections of their inner values or beliefs, but as responses to their environment (Waters).

Examples of the structural explanations include West Indians' majority status in the Caribbean, which provides role models, is often credited for their optimistic attitudes and the belief that anything is possible. Other structural explanations of West Indian success include the arguments or findings that: (a) immigrations is a selective process and only the best and brightest migrate; (b) West Indians accept low-wage and lowstatus jobs that native-born do not want, and (c) the reported preference of some employers to hire foreign-born over native-born Blacks (Waters). There is no doubt that the distinction between the cultural or structural explanations of West Indians' success is somewhat arbitrary based on the reciprocity of culture and structure (environment). However, understanding cultural and structural explanations of success among West Indians may provide a boarder context to explore the process of mobility and assessment of career outcomes and success. 
Kim and McLean (2008) found that educational attainment was a factor in career success, rather than age, length of work experience, and employment level. However, one's efforts to achieve career success can be diminished by organizational culture and social norms (i.e., ethnic stereotypes and racial discrimination, etc.). A study found that organization's culture functioned as moderator between the protégé and mentor relationship and the protégé's career advancement possibilities (Apospori, Nikandrou, \& Panayotopoulou, 2006). This finding was particularly true in collective cultures, where good relationships with superiors, similarity in personalities, seniority, and loyalty are valued. Ismail and Rasdi (2007) found that a male dominant culture created many challenges for women academics in Malaysia. To overcome these challenges, many women used networking as a career strategy and credited social capital to their ultimate success.

McDonald and Hite (2008) found that work-life balance was an integral part of participants' definition of success as well as the strategies they used to attain success. The study identified three major strategies that the participants used to attain success: (a) pursuing training and education opportunities, (b) networking, and (c) taking the initiatives at work.

The authors concluded that individuals perceive career success as a fluid concept that changes over the course of their career journey. Mihail (2008) identified another four types of career strategies that employees used to attain career success: (a) enhancing employability, (b) engaging in career planning, (c) building up social capital through networking, and (d) mentoring. 
Although Mihail's (2008) four career strategies may seem appropriate for all employees, for immigrants, these career strategies may involve unique strategic actions or specific compromises. For many immigrants, enhancing their employability may include learning the native language and adapting to work and gender roles of the host society. Engaging in career planning may be perceived as unimportant relative the needs of immigrants' personal adjustment social integration. For example, Stebleton (2007) contends that traditional decision-making models based on Western models that promote long-range career planning may not be useful for African students because of complex decisions, such as balancing work-life concerns and multiple identities. Hence, African students tend not to take a planful approach to career planning because of the external factors that dictate their future (Stebleton). A planful approach refers one's lack of career concern or career indifference that is often reflects planfulness and pessimism about the future (Savickas, 2005).

Furthermore, for some immigrants building up social capital through networking and mentoring may involve first addressing their own socialization process, values, and cultural norms. A comparative study of African Americans, Black immigrant women from Africa and the Caribbean found that background socialization and racial socialization dictated each groups' informal networking patterns (McIntosh-Alberts, 2001). Although each group reported networking within and outside their racial group, the groups differed in the kind of networking support they sought. African women sought career-related support; whereas, African American and Caribbean women sought social and psychosocial. In fact, career success or advancement is more closely associated with career-related mentoring than psychosocial support (Ragins \& Cotton, 1999). 
The study also reported some differences in networking patterns based on race, culture, and racial resocialization. In terms of networking for career advancement, each group had different perspectives based on their respective cultural groupings. In regards to informal networking with male superiors, each group shared similar perspectives. However, networking with White peers and superiors revealed two distinct perspectives. African Americans' perceptions were shaped by the history of race relation in the U.S. (socialization); whereas, Africans and Caribbean immigrants' perceptions were shaped by the process of resocalization.

The study reported three levels of relating to Whites across all three groups, some were :(a) high close-mindedness, (b) high open-mindedness, and (c) in the middle. The findings of this study provide insight in the complexity of human interaction and affirm Conlon's (2003) argument that today's version of career development, including career strategies and measures of success, must adapt to meet social justice needs of diverse groups and others who face obstacles in their career development.

In addition to addressing the social justice needs of diverse groups and others, the career development component of HRD must also remain prominent in research and practice. McDonald and Hite $(2005,2008)$ contend that the career development component of HRD needs reviving and often draws the short straw within the HRD professional community.

Scholars attribute this neglect to HRD's: (a) primary focus on the individual, performance improvement, and organizational learning (Swanson \& Holton, 2001; van Dijk, 2004); (b) failure to ask questions, establish outcomes, and make connections between HRD and career development theories (Egan, Upton, \& Lynham, 2006); and (c) 
limited endeavors to methodically evaluate career development initiatives and programs (McDonald \& Hite, 2005; Preskill \& Donaldson, 2008). Based on the current volatile employment conditions, (i.e., mass corporate downsizing, rampant outsourcing, and fierce global competition), the revival of career development in HRD is more critical than ever. This revival is critical because some scholars claim that downsizing and globalization have altered the traditional career arrangement between the employer and the employee (Donohue, Donohue, \& Grimmer, 2007; Patton \& McMahon, 2006; McDonald \& Hite, 2008; Storey, 2001; Thijssen, Van Der Heijden, \& Rocco, 2008) and that immigrants may need specific career interventions to cope with these changes.

\section{Organizational Trends Influencing Career Development}

One of the major trends attributed to influencing organizational career development is the transformation of the employee- employer relationship (Donohue, Donohue, \& Grimmer, 2007; Patton \& McMahon, 2006; McDonald \& Hite, 2008; Storey, 2001; Thijssen, et al., 2008). The traditional career arrangement between and the employee and the employer refers to a time when employees provided their skills or services and employers provided salaries, benefits, and lifetime work in return (Collin \& Young, 2000a). The assumptions of job security, stability, and commitment were unchallenged and the employer took full responsibility for employees' development (Savickas, 2000). In contrast, the contemporary arrangement refers to the mutual responsibilities and benefits that employees and employers share within the organization. Employees are expected to assume full responsibility for their development and employers are expected to enhance the career development systems and processes and provide effective leadership. 
The notion of the changing psychological contract is often used to examine the change between the traditional and contemporary employer-employee relationship. Psychological contract refers to the relationship or reciprocity between employee and employer in terms of unwritten and explicit expectations (Rousseau, 1995). Scholars have explored the changing nature of the employer-employee relationship (Conway \& Briner, 2002; Herriot, Manning, \& Kidd, 1997; Maguire, 2002), by drawing upon Rousseau's (1995) distinction between transactional and relational contracts.

Relational and transactional contracts represent two distinct employee-employer relationships. A relational exchange focuses on socio-emotional exchanges, such as the long-term exchange of loyalty for job security, training and development, and financial rewards (Rousseau, 1995) and is indicative of the traditional employee-employer relationship. In contrast, transactional exchange between employer and employee focuses on specific monetary and economic exchanges, such as the exchange of time worked for money or advancement (Rousseau) and is indicative of the contemporary employeeemployer relationship. This notion has been deemed significant in the trend towards boundaryless career.

Boundaryless career refers to "opportunities that go beyond any single employer" (DeFillippi \& Arthur, 1996, p. 116). Within this perspective, individuals are (a) moving across the boundaries of separate employers to seek career opportunities, (b) drawing validity and marketability from outside the present employer, (c) sustaining external networks or information to advance their careers and (d) rejecting career opportunities that conflict with personal preferences or beliefs. 
The boundaryless career is independent from, rather than dependent on, a traditional organizational career arrangement (Arthur \& Rousseau, 1996).

The notion that employees need to be independent from traditional organizational career arrangement is not new. Employees' independence was echoed before in Hirsch's (1987) Pack Your Own Parachute, an early recognition of environmental trends and their cumulative impact on career. Hirsch urged employees to embody the following fundamental principles: (a) cultivate networks to maintain visibility, (b) return recruiters' calls to maintain marketability, (c) avoid overspecialization to maintain generality, (d) avoid long-term and group assignments to maintain credibility, and (e) keep their bags packed to maintain mobility. Fundamentally, the concept of a boundaryless career suggests that people take responsibility for their own career futures (Arthur \& Rousseau, 1996). This contemporary perspective has changed some of the widely accepted wisdom about the traditional career and perhaps this change is permanent. Table 1 shows a comparison of the contemporary and traditional changes in careers.

Table 2

Contemporary versus Traditional Careers

\begin{tabular}{lll} 
Career Issues & Traditional Careers & Contemporary Careers \\
\hline Career control & Organization & Individual \\
Career concerns & Advancement & Growth \\
Career mobility & Low & High \\
Career success & Organizationally driven & Personally driven \\
Career attitudes & Organizational commitment & Professional commitment \\
\hline
\end{tabular}


Some scholars have criticized the concept a boundaryless career (Arthur \& Rousseau, 1996) for immigrant groups. Pringle and Mallon (2003) argue that the concept boundaryless career, which focuses on the individual, has limited applicability to collective cultures because it emphasizes the idea of a self-managed career that may be problematic for immigrant groups from collective cultures (i.e., Africans, West Indians, Asians, and Hispanics; Hofstede, 1980). Individuals from collective cultures tend to focus on the needs of the collective (i.e., family, community, and environment) and strongly adhere to cultural norms, such authority, duty, and expectations (Hofstede, 1980). Richardson (2001) argued that it more effective to explore the meaning of work, both paid and unpaid, rather than the notion of work to an occupational structure. Savickas (2000) emphasized that career and HRD practitioners need to consider the role of work relative to other life roles, including work-family and community interaction.

\section{Social Context of Career}

Whereas organizations are interested in employees' growth and development primarily to avoid organizational stagnation and obsolesce, sociologists are interested in individuals' career choice and development because of the consequence of socioeconomic inequality and mobility (Johnson \& Mortimer, 2002). Therefore, sociologists study the diverse, societal, and microenvironments (i.e., family attitudes and values, community structure, and economic trends, etc.) that influence individuals' vocational behavior and development. In fact, thirty years ago, Bronfenbrenner (1977) asserted that "there has been a hypertrophy of research focusing on the properties of the person and only the most rudimentary conception and characterization of the environment in which the person is found" (p. 16). 
Bronfenbrenner's assertion is grounded in the ecological theory. An ecological approach strives to explain social and physical stimuli that exist in individuals' immediate environment that subsequently impact their behavior and experience.

This section begins with a review of the sociological perspective of career, which entails an integrative discussion of sociological theories, sociologists' contributions and social factors that affect career choice. The section concludes with a discussion of the factors that specifically influence immigrants' career development.

\section{Sociological Perspective}

A sociological approach embraces a broad and complex range of sociological issues relating to career development (i.e., ethnicity, race, class, gender, sexuality, etc; Patton \& McMahon, 2006) Hotchkiss and Borrow (1996) argue that a sociological approach also considers the interplay between individual choices and constraints on those choices that are often imposed by the labor market. One of the major criticisms of the psychological theories, also known as trait and factor theories, is their failure to focus on sociological factors, instead these theories were rooted in the congruence between people's personalities and their occupation. Osipow (1990) suggested that although these theories are some of the most influential theories (i.e., Holland's theory of personality and vocational choice [1985, 1997], Krumboltz's social learning theory [Krumbotlz, 1979; Mitchell\& Krumboltz, 1990]), they all had the same objective, to predict the degree of person and environment fit. However, Patton and McMahon contended that although these theories considered the social, economic, and environmental context, they did not conceptualize the nature of these influences which often act as a contextual medium for individual career decision-making. 
Another criticism of these theories is the assumptions of a positivist worldview. The core assumptions of the positivist worldview is that individual behavior is observable, measurable, and linear; individual behavior can be studied separately from their environment, and individual contexts (e.g., race, class, gender, family, etc.) are less important that human actions (Brown, 2002). Conversely, the core assumptions of the constructivist worldview are that "all behavior, including vocational behavior occurs within a cultural context" and that "individuals are shaped through the differential exposure that occurs according to gender, race/ethnicity, sexual orientation, and disability factors" (Swanson \& Gore, 2000, p. 248). The authors claim that an understanding of human behavior is incomplete without acknowledgment of the sociocultural context in both practice and theory.

The contemporary view of career research and practice is a convergence of both constructivist and positivist views. This contemporary view takes into account that individuals' abilities and interests are embedded in multiple contextual factors s (e.g., class, race, gender, value system, and family; Patton \& Mc Mahon, 2006; Savickas, 2005).

Contextual factors refer to any events, circumstances, or value systems (i.e., cultural, social, sociopolitical, and environmental) that influence individuals' career behaviors, decision-making process, and outcomes (Savickas, 2005). Many scholars have suggested the need to focus on contextual factors (i.e., Collin \& Young, 2000b; Patton \& McMahon; Poole \&Langan-Fox's, 1997) and the benefits of collaborating across theories and disciplines to strengthen and broaden the scope of career research and practice. 
This collaboration is not simply the inclusion of novel contexts or new buzz words or concepts, but the interrelation, organization, and simplification of the existing career knowledge (Savickas, 1995).

The collaboration across theories and discipline is evident in the acknowledgment of the influence of context in the refinement in Super $(1980,1990)$ and Holland's (1959, $1985,1997)$ acknowledgement of the developmental nature of career. This level of collaboration is also evident in the proposed contextual models and research by several other scholars. The concept of time was recognized in Vondracek, Lerner, \& Schulenburg's (1986) work as well the importance of human experiences from multiple levels: biological, individual, organizational, social, cultural, and historical. Vondracek et al. (1986) recognition of the concept of time is essential because time is often perceived differently across cultures. For example, the concept of time in African culture tends to focus on the past and present, rather than the future (Pennington, 1990). Conversely, the concept of time in American culture tend to be linear, finite, and future-orientated (Pennington). These different perceptions of the concept of time may influence how cultural diverse individuals perceive their career planning or paths (i.e., linear or circular) or how they perceive their career decisions-making processes (i.e., the focus on the present or the future). Career counselors who understand different cultures' perceptions of time increase the likelihood of providing effective career counseling to diverse groups.

Finally, self-concept was integrated with a social system perspective by Gottfredson (1981) and later an "at risk" framework was proposed by Gottfredson (1986) that identified a wide spectrum of possible risks influencing career development and the type of compromise that people must make in the career decision-making process. 
Gottfredson's (1986) describes compromise as a significant process that individuals often discover when the time is right, that they may be unable to implement their most preferred choices, hence making a compromise.

Most recently, Savickas (2001), who updated Super's (1990) developmental theory, removed the concept of career maturity and replaced it with career adaptability. Career adaptability focuses on environmental factors that influence individuals' career adaptation; whereas, career maturity focused on the internal maturation process and the sequential movement of an individual through a series of life stages (i.e., growth, exploratory, establishment, maintenance, and decline stages; Super, 1980, 1990).Finally, Patton and McMahon (2006) proposed a system theory approach to career development in an attempt to provide a metatheoretical framework for the integration of career theories and to account for the diversity and complexity of influences on individuals' career development. The authors contend the system theory framework is an ideal approach because it emphasizes parts within a whole system and views the whole system as greater than the sum of its parts.

\section{Sociological Factors as Filters for Understanding Career Development Processes}

Sociologists have made a significant contribution to our understanding of human behavior and the factors that are relevant to career development. Within this perspective, career development is viewed in relation to its contextual or situational determinants (i.e., social status, class membership, economic opportunities, and organizations; Patton \& McMahon, 2006). This is in contrast to the traditional assumption that all individuals, regardless of their ethnicity, class, and social status, have "unfettered capacity and means to make career decisions" (p. 141). 
Some scholars have challenged the assumption that all people have the capacity and opportunity to choose a career (Robert, 1997; Patton \& McMahon, 2006). Robert (1997, p. 145) claims that it "is not choice but opportunity that governs the manner in which young people [or immigrants] make their entry into employment. He also contends that sociocultural and socioeconomic factors often act as filters or barriers to obtain relevant information, affirm or deny held values, pattern role models' behaviors, and to determine whether or not to seek encouragement. Some scholars have used: (a) the family, (b) spirituality, and (b) the community, as filters to understand individuals' career development processes (Chope, 2006; Dik \& Duffy 2009; Shea, Ma, \& Yeh, 2007; Ulrich, Richard, \& Bergin, 2000; Vermeulen \& Minor, 1998).

\section{Family}

Family expectations, values, and attitudes also serve as filters in the career decision-making process. Some scholars believe that the family expectations are perhaps the most significant influences that affect individuals' career development (Duffy \& Dik, 2009; Greenhaus \& Powell, 2006; Schultheiss, 2006). Although the American culture tends to promote individualism over collectivism, an individual's family can influence the development of values, interests, and skills.

Chope (2006) contends that many ethnic families take a more rigid approach to the career decision processes of their children than families that have a greater sense of maneuverability and privilege. Subsequently, ethnic families attempt to protect their children by demanding that they follow the familial instructions (Chope).

The family unit does not only influence career development, but also provides emotional support and social and personal resources (Schultheiss, 2006). 
For many immigrants, including West Indians, the family unit may include other kinship not just the traditional American concept of a nuclear family (i.e. mother, father, and children). According to Henke (2001), West Indian families are flexible and fluid form of kinship that creates a wide social and international network that often supports their educational or career pursuits. For example, it is not uncommon for West Indian families in the U.S. to invite relatives or friends from their homeland to live with them in the U.S. to take care of their children while they pursue a degree or an education. In this case, family support becomes an international affair for the common cause of career development.

Spirituality

Spiritual commitments may also play a critical role in the career decision-making process. Some individuals may believe in a Divine will or specific career plan for their lives. Dik and Duffy (2009) refer to this Divine will as a calling, an orientation toward a particular life domain, such as work or a particular career path, based on a Higher Power directive. The authors believe that the notion of a calling is not limited to spiritual people and consists of: an experience that transcends beyond oneself or a work activity or role that extends one's overall sense of purpose, meaning, and motivation. Some individuals' spiritual teachings may influence they conduct themselves, including their personal and business ethical practices (i.e., treating others fairly and equally). These teachings may also influence individuals' career decisions by requiring them to commit to missionary or charitable work. For example, in the Latter-Day Saints church, young men are asked to devote 2 years to full-time mission work; (Ulrich, et al, 2000). On the other hand, some individuals or groups rely on extrasensory perceptions (ESP) as a mode of knowing or 
decision making. Some of these modes of knowing include traditional healers, spirits mediums, and witchcraft (Constantine, Myers, Kindaichi, \& Moore, 2004). Although research on the role of spirituality in career development is limited, spirituality has been found to be positively related to career development outcomes (i.e., self-efficacy, career adaptability, and job satisfaction (Duffy, 2006; Duffy \& Blustein, 2005, Duffy \&Lent, 2008).

\section{Community}

Community norms may also serve as filters of relevant information for many individuals. Vermeulen and Minor's (1998) examined the rural community as a context of women's career choices and decisions to understand their vocational behavior. The findings of the study indicated that gender roles and beliefs were the pervasive factors in the women's career-decision making processes. Also, 95\% of the women's earliest recollection as children was to be a mother and "every potential occupational choice was measured against a lifestyle that included motherhood" (p. 237). The findings also showed that the lack of exposure to the many career possibilities limited the women's career choices. For example, one woman had an interest in medicine, but was unaware that women could be doctors. Despite being in the top $10 \%$ of her graduating class, she

did not know of any female doctors, did not read about them, and was not encouraged by her family, friends, or community. The authors indicated that rural communities provide different structural and cultural factors than those commonly studied in urban areas, emphasizing the importance of situating individuals within the context of their environment. 
Situating individuals within the context of their environment means career research and counseling need to be inclusive, holistic, and multicultural (Pope, 2003; Savickas, 2005) and must take into account individuals' narratives, artifacts, and hermeneutic phenomenology (Blustein, 2001). Narratives are individuals' stories about their life experiences and life themes (Savickas, 2002) Artifacts are objects or symbols that represent an individuals' culture (Hofstede, 1980).

Hermeneutic phenomenology, a type of qualitative inquiry, asks "what are the conditions under which a human act took place or a product was produced that make it possible to interpret its meaning?" (Patton, 2002, p. 113). Hermeneutic phenomenology informs and reminds career theorists that what something means depends on the context in which it was originally created and the context within which it is subsequently interpreted (Patton, 2002).

\section{Migration as a Factor for Understanding Immigrants' Career Development}

Immigrants are influenced by their career experiences in their home(country of origin) and host countries (Walsh, 2001).Migration means leaving one's home territory, where he or she was born, to live in a new host environment (Tharmaseelan, 2008). Home country culture shapes immigrants' career values, norms, assumptions, perceptions, and strategies (Derr \& Laurent, 1989; Hofstede, 1980). Home country culture also shapes immigrants' view of work life and their role within it. However, immigrants are not a monolithic group and their career experiences may vary among individuals based on acculturation level, educational attainment, immigrant and generational status, race, and ethnicity. 
There are an infinite number of social factors that affect immigrants' lives. The most common factors include, but not limited to: (a) English language proficiency, (b) loss of occupational status, (c) acculturative stress, (d) attitudes of people in the U.S. towards immigrants, and (e) income level and length of time in the U.S.

\section{English Language Proficiency}

English language proficiency affects immigrants’ wages (Tress, 1996) and, therefore, long-term economic mobility, and social integration (Lowell, 2004; Waldinger, 2001a). A 5-year follow-up study of immigrants in Detroit found higher English proficiency reduced their chance for economic instability and career immobility (Becker \& Isaacs, 1996).

Race, Masini, and Sheffey (1996) found that immigrants with low levels of English language proficiency were less likely to secure employment than those with higher levels. Individuals with higher English language proficiency used vocational services more frequently, which helped them, find employment. English language proficiency also decreases personal stress and anxiety. Immigrants who are proficient in English do not experience second language anxiety, which refers to the feelings of anxiety and self-consciousness associated with speaking a second language (Ishiyama, 1989).

\section{Loss of Occupational Status}

Immigrants' career success is affected by the loss of occupational status, a perceived level of occupational prestige. Occupational status is an important source of one's self-concept (Super, 1990). The loss of one's occupational status often results in role shock (Lee \& Westwood, 1996). Role shock is often amplified when a high status 
that is associated with immigrants' home occupational identity, such as teacher, banker, doctor, or mother, is either lost or devalued in the host country (Lee \& Westwood). This loss of status and role shock also heighten feelings of uselessness, frustration, and anger (Westwood \& Ishiyama, 1991). Moreover, immigrants with professional skills and training, who are often lumped with unskilled immigrants, may experience feelings of anger and loss due to their now ambiguous status (Lee \& Westwood).

The loss of occupational status was examined in a study of Turkish professionals who migrated to Canada (Aycan \& Berry, 1996). The findings of the study showed a significant initial drop in mean income and occupational status at the end of the first 6 month in Canada (Aycan \& Berry). By the end of the first year, income and occupational status significantly increased. However, the mean difference between the professionals' occupational status at the end of the first year in Canada and at the time of the study showed no significant change; however, there was an income improvement. The findings also indicated that the professionals' present occupational status was significantly lower than their occupational status in Turkey. The authors attributed factors such as language inefficiency, inability to transfer credentials, and overall psychological well-being to the delay in the participants' adaptation process and outcome may cause acculturative stress. Acculturative Stress

Acculturative stress refers to immigrants' responses to life events that are rooted in the experience of acculturation (Aycan \& Berry, 1996). Acculturative stress is not one's everyday stress or simply difficulties in adaptation; it represents changes in individuals' psychology. According to Graves (1967), this distinction is necessary because not all immigrant groups or individuals within an immigrant group reflect and 
experience a change in their psychology. Acculturative stress results from situations that present demands, opportunities, or constraints (McGrath, 1976; Schuler, 1980), and the total amount of acculturative stress that immigrants experience at any time is a function of all three types of stressors (Bhagat \& London, 1999). Demand stressors are work dynamics or conditions that prevent immigrants from having or doing what they prefer. These stressors often result in conflict with cultural values of the organization and stereotypes. Opportunities stressors are work dynamics that present immigrants with opportunities to be or to do what they desire, such as building new relationships and networks and working within new work processes and reward structures. Although opportunity stressors allow immigrants to do what they desire, learning new working processes and structures may be stressful for many immigrants. Constraint stressors are organizational situations that restrict immigrants from what they desire. This mainly occurs when immigrants attempt to merge into the U.S. culture, while maintaining their culture. Acculturative stress can be particularly important for immigrants because it is a major determinant of their career outcomes.

In the U.S., the acculturation process for Black immigrants is often slower than Eastern Europeans or Hispanic immigrants' acculturation. This slower rate of acculturation is often attributed to the political, economical and racial advantages that other immigrants have and continue to enjoy (Portes \& Zhou, 2003). For example, Cuban and Hungarians political refugee status was said to facilitate a smother process for their adaptation in the U.S. Irish immigrants' adaptation process was facilitated by IrishAmericans who had established an economical foothold in the Boston area (Portes \& Zhou). In addition, many immigrants of European ancestry were able to negotiate their 
ethnic identity and evenly become White; hence, escaping the prejudice that immigrants often traditionally endure. For example, Hispanics and Asians are given "ethnic options" (i.e. the option to claim alternative racial identities, i.e. White); whereas; groups like Africans and West Indians immigrants are given "racial labels" (Waters, 1999). This broad-based racial labeling often compromises and complicates Black immigrants' acculturation process.

Attitudes of People in the U.S.

Immigrants, like other ethnic minorities, are often confronted with the need to navigate and cope with multiple oppressions such as racism, sexism, and other "isms" (Fukuyana \& Ferguson, 2000; Ladson-Billing, 1999, 2000; Rothenberg, 2001). Fukuyana and Ferguson contend that the social fabric of the U.S. is founded on the dominant paradigm that marginalizes people, including immigrants, who are different, while favoring White male, Eurocentric, and Christian values. Racial identity is one of the most profound social stratifications in the U.S. that negatively affects personal identity formation (Sue \& Sue, 1990).

Negative stereotypes are manifested within the larger society as well as within organizations. Some employers and employees may believe that immigrants should not be hired, promoted, and given the opportunity or responsibility to supervise others (Lee \& Westwood, 1996). In addition, some Americans see immigrants as competitors for jobs, housing, and other community services (Lee \& Westwood). These attitudinal barriers compromise immigrants' perceptions of their career control, which is a key dimension of career adaptability (Savickas, 2005). In fact, individuals who perceive 
control over their vocational future are more likely to experience a sense of assertiveness, locus of control, autonomy, and self-determination (Blustein \& Flum, 1999).

Income Level and Length of Time in the U.S

Immigrants who live in the U.S. longer are more likely to have successes or experiences similar to those of U.S. natives (Gozdziak \& Martin, 2004; Lowell, 2004). Hence, the length of U.S. residence is related to immigrants' personal and financial stability and their career mobility. Conversely, immigrants with low incomes may have limited access to education, information, and training (Gozdziak \& Martin). However, immigrants with low relative wages may be more inclined to invest in the skills needed to improve their learning to a greater degree than immigrants with better earnings (Lowell).

\section{Summary}

In this chapter, the organizational and social contexts of career were discussed. The organizational context of career outlined the field of HRD roots in organizational and individual development and role in career development, as well as the current trends and influences on organizational career development. The social context of career outlined a sociological perspective of career that emphasize the contextual nature of career experiences, relating to family, community, and sociocultural, and socioeconomic factors The section on immigrants outlined several factors that characterize immigrants' vocational behavior and how they experience their careers in a new host society.

Chapter 3 explains the phenomenological method of this study. Chapter 4 describes the inductive findings. Chapter 5 describes the deductive and comparison 
findings. Chapter 6 discusses the responses to the research questions, implications, and recommendations for future research. 


\section{CHAPTER III}

\section{METHODS}

This chapter begins with the purpose of the study and the research questions. The phenomenological framework is discussed, followed by my autobiography and assumptions related to the study. Next, sampling criteria and procedures for data collection, data analysis, and data management are described. The chapter concludes with a discussion of integrity measures and limitations of the study.

\section{Purpose of the Study}

The purpose of this phenomenological study was to explore how West Indian professionals in South Florida perceive their career construction (Savickas, 2002, 2005). The aim of the study was to understand the processes West Indian professionals use to integrate into the U.S. occupational structures.

\section{Research Questions}

Creswell (2003) contends that the primary research question in qualitative study should relate to the "specific qualitative strategy of inquiry" (p. 106). The primary research question of this phenomenological study is: How do West Indian professionals perceive their career construction? Secondary questions are:

1. What factors do West Indian professionals believe influence their vocational behavior?

2. What career adaptive mechanisms do West Indian professionals report using to facilitate their integration into the U.S. occupational structures? 
3. What processes do West Indian professionals report using to integrate into the U.S. occupational structures?

\section{Phenomenological Framework}

Researchers use a phenomenological framework when seeking to understand the essence and structure of a phenomenon (Patton, 2002; Schram, 2003) by gaining an indepth understanding of everyday experiences. Included in this understanding, is an aim to reveal important "background factors such as stirrings of pleasure, shaping of judgment or incipient wishes" (Patton, 2002, p. 484) that create individuals' perceptions and enable them to exist in their consciousness. Phenomenological studies begin with a question about the meaning of participants' experiences of a phenomenon (Gibson \& Hanes, 2003). For this study the meaning of the participants' experiences is reflected in the primary question: How do West Indian professionals perceive their career construction? This phenomenological question focuses not on the objects (i.e., events, places, circumstances, or people), but participants' perceptions and the meaning they impose on their vocational behavior. A phenomenological framework enables researchers to explicate how beliefs about real or imaginary objects may be acquired and how individuals experience what they are experiencing (Patton).

Phenomenology is an ideal framework for this study because it is "an essential component of HRD research due to its focus on the complexity and wholeness of human experiences" (Gibson \& Hanes, 2003, p. 182). Complexity and wholeness of human experiences have not received sufficient attention in the HRD literature (Gibson \& Hanes). To fully consider the wholeness of human experiences without personal biases or 
judgment, phenomenological rigor is reinforced by acknowledging one's prejudices and viewpoints about the phenomenon under investigation (Patton, 2002). In this phenomenological study, rigor was partially attained through the epoché process, which entails articulating the researcher's autobiography, assumptions, and journaling process.

Researcher's Autobiography, Assumptions, and Journaling Process Phenomenological researchers recognize the personal significance of the issue under study by employing the epoché process (Moustakas, 1994). Epoché is a process that allows the researcher to look inside to become aware of personal biases and to bracket judgment and presuppositions (Patton, 2002). This study's epoché entails the researcher's: (a) descriptive autobiography, (b) assumptions of West Indians' career experiences and career narratives, and (c) journaling process maintained to promote reflection and self-dialogue. This section begins with the researcher's autobiography, followed by the researcher's assumptions of West Indian professionals' career experiences and career narratives. Next, the researcher's journaling process is discussed. Autobiography

I was born in St. Kitts, an island in the West Indies. When I was 16, my family migrated to Miami. My mother and oldest sister were already living in Miami for about 2 years before the rest of the family arrived. While my mother was away, my father took care of me and my three sisters. This was a typical arrangement between my parents when my mother traveled abroad for work. In the West Indies, it is culturally common for one parent to work abroad while the other parent or other family member takes care of the children. While in Miami, my mother was working and preparing a place for us to 
lessen the impact of the transition. My father was also working to help ease the financial impact of moving to Miami. My parents' work arrangement influenced my perceptions of work, that is, to work hard and to take advantage of every opportunity.

After graduating high school in the U.S., I attended college and was indecisive about the area of study I wanted to pursue. I knew I had to attend college, but was unsure of what occupation would fit me best. Only 2 years in the U.S. and a recent high-school graduate, I was overwhelmed by the many career options that were available to me. I felt unprepared to select a career path. I questioned how others were able to decide on a career path without much thought, while I struggled with this overwhelming decision. This experience prompted my initial interest in the career decision-making and career development processes.

In college, my first decision was to pursue an accounting degree. After some consideration, I decided that becoming an accountant would be a boring and isolating occupation. Next, I decided that working in mass media would be more interesting and I earned a Bachelor of Science in Communication. Although I never worked in the mass media industry, I have been steadily employed in the retail industry in various stores, districts, and regional level positions. Working as a human resource manager and trainer sparked my interest in human resource development, and I earned Master of Science in Human Resource Development. After earning my master's degree, I continued to work in the retail industry, while working as an adjunct instructor. I taught human resource management and career development courses.

With some work experience behind me, I decided to pursue a doctoral degree. My career goal was to prepare myself for a second career either in academia or as a 
consultant. As a doctoral student, my interest in career development continued to grow and lead me to consider the social, cultural and environmental factors that influence career decisions and development. My first graduate research agenda dealt with general diversity issues; later it evolved specifically to the many social constructs that prevent individuals from developing and performing to their full potential. This agenda allowed me to reflect on my own identities as an immigrant, Black woman, doctoral student, and professional and to contemplate the influence of these identities on my personal and professional career behavior and experiences. It is my hope that the exploration of how West Indian professionals perceive their career construction will also shed light on my career behavior and experiences.

Assumptions

My assumptions of West Indians' career construction are:

1. Individuals' place of origin, degree of acculturation, length of time in the U.S., occupation, and socioeconomic status influence their career construction.

2. Individuals may be reluctant to share their negative personal and professional experiences or setbacks that they are still struggling to overcome.

3. Individuals may exaggerate their positive personal and professional experiences to portray a happy ending to their migration experience and to validate the idea that they have achieved the American dream.

\section{Journaling Process}

I maintained a journal to document my reactions, thoughts, and feelings after each interview, while checking transcripts and conducting the analyses. Journaling is a way of getting in touch with oneself in terms of reflection, remembrance, exploration, problem 
solving, and personal growth (Janesick, 2004). Journaling my thoughts also helped to reveal additional biases and assumptions as the research progressed. I began my journal by answering all the interview questions myself. Journaling my responses to the interview questions allowed me to reflect on my own career experiences and to pilot the interview guide and revise questions accordingly. In addition to documenting my responses to the interview questions, I documented my thoughts and my reflections in the journal. My personal journal entries were not included as data in the study; rather these entries served as a medium to reflect on and explore my thoughts and to establish my presumptions. All journal entries were stored in one Word document file, for easy access for review during the data analysis phase.

\section{Sampling Methods}

West Indian professionals were selected from South Florida. South Florida, which includes the Miami- Fort Lauderdale, area, has the second largest West Indian population in the U.S., next to the New York area (BLS, 2005) and represents a diverse group of West Indian nationals. There are over 314,000 West Indians in the Miami-Fort Lauderdale area; these two cities are about 50 miles apart. Of the West Indians who are over 25 years of age and live in the Miami-Fort Lauderdale area, $28.1 \%$ have attained undergraduate degrees, $18 \%$ have graduate or professional degrees, and over $60 \%$ work in management, professional, and related occupations (U.S. Census, 2000). West Indian immigrants have been extremely successful establishing themselves in the upper level of their careers and this feat warrants studying this group.

Criteria and snowball sampling methods were used to identify and select 15 West Indian professionals for this study. Criteria sampling refers to the selection of participants 
who met the predetermined criteria for this study (Patton, 2002). All participants met the following criteria of the study: (a) self identify as a West Indian and of African descent, (b) be born in the English-speaking Caribbean and received at least of their part of their secondary education while in the Caribbean; (c) live and work in South Florida; (d) have earned his/her college degree(s) in the U.S; and (e) be a professional, a person who is in specific occupational field that is based on a unique body of knowledge and a core set of competencies (Queeney, 2000).

Snowball sampling identifies participants of interest by asking people who know individuals who fit the criteria for the study (Patton, 2002). Of the 15 professionals in this study, 12 were recruited through snowball sampling and the three remaining were recruited by the researcher. The researcher relied on friends, family members, and colleagues to identify individuals who met the criteria of the study.

A formal email request was sent to friends, family members, and colleagues to elicit their help to identify potential participants for this study. The email explained the purpose of the study and the criteria that each participant must meet to be eligible to participate in this study. The researcher's friends, family members, and colleagues were then instructed to forward the request to potential participants who they thought met the criteria of this study. Individuals who met the criteria of the study also became valuable resources in identifying others who fit the criteria for the study. Snowball sampling and the researcher recruitment continued until 15 eligible participants were identified. The researcher's immediate family members (i.e., mother, father, and siblings) did not participate in the study in order to maintain a neutral view of the data. 
A characteristic of qualitative research is the use of purposeful sampling, such as snowball and criteria sampling (Patton, 2002). Purposeful sampling allows researchers to study small samples in depth and to select information-rich cases strategically and purposefully. In this study, saturation was achieved within the first 7 of 15 interviews.

The five criteria or the scope of this study may have contributed to data saturation within the first 7 of 15 interviews. The point of saturation or when no new information is forthcoming from new participants (Lincoln \& Guba, 1985; Patton, 2002) varies based on the context and/or parameters of a study. For example, Guest, Bunce, and Johnson (2006) found that saturation was achieved within the first 12 of 60 interviews because of the narrowness of their focus and homogeneity of their sample.

\section{Participant Demographics}

The sample for this study included 15 West Indian professionals, who selfidentified as West Indians and of African descent and who were born in the Englishspeaking Caribbean. All of the participants received at least part of their secondary education while in the Caribbean and earned college degree(s) while living in the U.S. All the participants live in South Florida and are professionals, which is defined as a person who is in specific occupational field that is based on a unique body of knowledge and a core set of competencies (Queeney, 2000). The participants' demographics are discussed in the following section. The participants' demographics include: (a) gender, age, place of origin, and length of time in U.S., (b) and profession, and (c) educational attainment. 
Gender, Age, Place of Origin and Years in the U.S.

Of the 15 West Indian professionals in the study, 10 were women and 5 were men. The participants ranged in age from 31 years to 59 years. The participants' mean age was 44 years. The participants' mean age, when they arrived in the U.S., was 19 years. The participants' average length of time in the U.S was 20 years. The participants' gender, age, place of origin, and lengthen of time in the U.S. are summarized in Table 3. In Tables 3 and 4, the participants are listed in the order in which they were interviewed.

Table 3

Participant Demographics

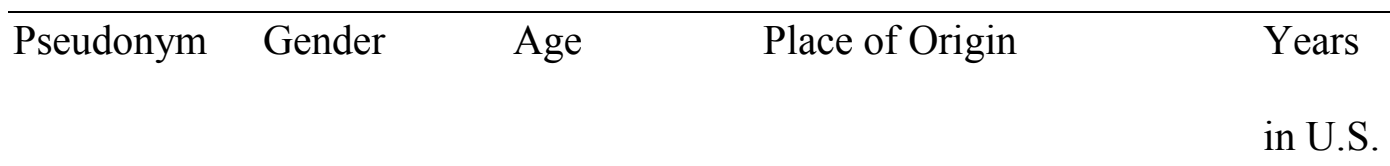

\begin{tabular}{lllll} 
Amy & Female & 37 & St. Croix & 23 \\
Travis & Male & 54 & Guyana & 36 \\
Gareth & Male & 31 & St. Kitts & 12 \\
Jane & Female & 50 & Guyana & 29 \\
Angela & Female & 42 & Jamaica & 26 \\
Connie & Female & 44 & Jamaica & 25 \\
Lena & Female & 38 & Jamaica & 19 \\
Juliet & Female & 53 & Guyana & 33 \\
Harris & Male & 44 & Jamaica & 24 \\
& & & & \\
\hline
\end{tabular}


Table 3 (cont'd)

Participant Demographics

\begin{tabular}{lllll}
\hline Pseudonym & Gender & Age & Place of Origin & Years \\
& & & in U.S. \\
\hline Leah & Female & 45 & St. Kitts & 17 \\
Carla & Female & 33 & St. Croix & 17 \\
Peter & Male & 38 & St. Vincent & 7 \\
Mary & Female & 54 & Jamaica & 33 \\
Pam & Female & 59 & Jamaica & 32 \\
Gerald & Male & 38 & St. Croix & 20 \\
\hline
\end{tabular}

The participants were from five different English-speaking Caribbean islands/mainland territories: Jamaica, Guyana, St. Croix, St. Kitts, and St. Vincent. Six (40\%) participants were from Jamaica. Three (20\%) participants were from Guyana. Three (20\%) participants were from St. Croix. Two (13\%) participants were from St. Kitts. One participant (7\%) was from St. Vincent. The participants from Jamaica represented the largest group (40\%) of professionals in this study. This number is consistent with South Florida's largest West Indian population, who are Jamaicans. Participant Professions

The participants worked in five industries: career services, computer science, education, healthcare, and human resources. With the exception of computer science, the remaining industries are consistent with Census reports that state that West Indian 
immigrants tend to work in sectors such as services, education, and nursing (U.S., Census, 2000). Table 4 summarizes the participants' professions.

Table 4

Participant Professions

\begin{tabular}{ll}
\hline Pseudonym & Professions \\
\hline Amy & Career Services, Counselor \\
Travis & Information Technology \\
Gareth & Information Technology \\
Jane & Nurse, Administrator \\
Angela & Human Resource \\
Connie & Elementary Teacher \\
Lena & Professor/Administrator \\
Juliet & Information Technology \\
Harris & Career Services, Director \\
Leah & Elementary Teacher \\
Carla & Healthcare, CEO \\
Mary & Information Systems, Director \\
\end{tabular}


There were teachers (3), nurses (2), information technology professionals (4), a medical doctor (1), career practitioners (2), a human resources professional (1), an administrator/professor (1), and a healthcare CEO (1).

Participant Educational Attainments

All 15 participants had undergraduate level degrees; there were 15 bachelor's degree holders. Twelve participants had graduate level degrees; there were thirteen master's degree holders. One participant had two master's degrees. Three participants had doctorate degrees. Table 5 summarizes the participants' educational attainments. Table 5

Participant Educational Attainments

Degree types

Number of degrees attained

Bachelors Degree

Masters Degree

Doctorate Degrees
15

\section{Data Collection}

Semi-structured interviews were used to collect the data for this study. This form of research interview was used to obtain descriptions of the world view of participants with respect to interpreting the meaning of the described phenomenon (Kvale). This phenomenological approach seeks to understand each participant's world view and captures a "specific form of human interaction in which knowledge evolves through a 
dialogue" (p.125). According to Rubin and Rubin (2005), "asking everyone the same questions makes little sense in qualitative interviewing" (p.14) because an interview represents a window of a specific time and a social world that is experienced one person at a time, one incident at time (Rubin \& Rubin). Although the phenomenological interview tends to be informal, conversational, and interactive (Rubin \& Rubin), the interview is a conversation that has a structure and a purpose (Kvale).

\section{Interview Guide Construction}

The semi-structured interview guide (see Appendix A) for this study consisted of a sequence of themes to cover and suggested questions. The structure of the guide allowed for changes in the sequences and the form of questions and for the participants to direct the interview based on what they think is important, not what the researcher mandates. "Questions prepared in advanced "may be varied, altered, or not used at all when the [participant] shares the full story of his or her experience of the bracketed question" (Moustakas, 1994, p.114).

The guide consisted of 27 questions that were divided into three themes: (a) background information, (b) employment and education, (c) career influences, experiences, and perceptions (see Appendix A). The first section, background information, consisted of questions about the participants' age, birth place, reasons for migrating, and length of time in the U.S. The second section, employment and education, consisted of questions about the participants' educational and professional attainment. The third section consisted of questions relating to the participants' career influences, experiences and perceptions. 


\section{Interview Administration}

Individuals who identified potential participants for the study were asked to provide the researcher with contact information (i.e., name, phone number, email address, etc.) of potential participants. My first contact and initial screening of potential participants was by email. Potential participants were sent an email to request a brief description of their profile. In an effort to remain transparent, this email also included the researcher's profile. This initial screening email instructed potential participants to answer the following questions to confirm their eligibility to participate in the study, if they : (a) self-identified as West Indians and of African descent, (b) were born in the English-speaking Caribbean and received at least part of their secondary education in the while in the Caribbean, (c) live and work in South Florida, (d) earned their college degree(s) in the U.S. and (e) were professionals, as defined in this study. Individuals who met all five criteria of the study were asked to participate. After agreement, a mutual time and location to conduct the interview was arranged.

The interviews were conducted in a variety of mutual places that the participants and researcher agreed upon. These mutual locations included: (a) local universities' libraries and study rooms, (b) local colleges, (c) local public libraries' study rooms, (d) participants' homes, and (e) the researcher's home. Before each interview, the participants were asked to sign a content letter (See Appendix B). This letter was sent prior to the interview date, via email, for each participant to review ahead of time. Each participant signed two copies of an approved Florida International University Institutional Review Board informed consent release form (see Appendix B). In addition to consenting to participate in the study, this form served as an agreement of anonymity and 
confidentiality of the participants' interview responses. One interview was conducted with each participant. Interviews were conducted in person. Interviews lasted between 45 to 70 minutes and were digitally recorded.

The transcriptionist was instructed to transcribe each audio recording verbatim, that is, prepare full written versions of each interview, including the notations of "unintelligent" phrases or words that she could not decipher from the audio recordings. The transcriptionist was also instructed to discard and delete all resources relating the interviews (audio, recordings, emails about audio recording and all Micro soft Word documents of the transcripts. The transcriptionist reported that to date, all files recordings, transcripts, emails, etc were deleted and removed from any traceable source by an Information Technology (IT) associate and audio tapes were pulled from cassette and shredded. Initially, some of the digital recordings were converted audio tapes because of data capacity issues with the transcriptionist's computer. After this issue was resolved, subsequent recordings were transcribed directly from the digital recordings that were sent to the transcriptionist as email attachments.

The researcher checked each transcript to verify the consistency between the digital recording and the interview transcript. This verification process entailed listening to the recording while reading each transcript (Merriam, 1998). This process also included deciphering as many of the "unintelligent" notations made by the transcriptionist .The researcher anticipated some level of "unintelligent" notations based on the variations of accents among the participants, who were from various islands/main territories in the Caribbean (i.e., Guyana, Jamaica, St. Croix, St. Vincent, and St. Kitts). 


\section{Field Notes}

In addition to interviews, field notes were used to collect data for this study. Field notes or memos are used to record and track analytical insights that occur during data collection (Patton, 2002). Field notes are also an essential part of fieldwork and the beginning of qualitative analysis (Patton, 2002).The field notes for this study consisted mainly of information about: interview date, interviewee's name, interview location, and thoughts and facts about the experience, and observations.

The field book entries were obtained primarily from voice memos that the researcher recorded immediately after each interview, typically on the drive home. The researcher recorded her reflections, ideas and preliminary themes to avoid losing any insights. As Patton (2002) said, "repressing analytical insights may mean losing them forever, for there is no guarantee they'll return (p. 406). These recordings allowed me to verbalize important experiences immediately after each interview before writing them in the field note book.

\section{Data Analysis}

Three types of analyses were used to analyze the data: (a) inductive analysis, (b) deductive analysis, and (c) comparative analysis. Inductive analysis involves discovering and identifying patterns and themes in the data (Patton, 2002). Deductive analysis involves a meta-analysis of the data through the lens of an existing framework (Patton). Savickas's $(2002,2005)$ career construction theory was used as the deductive framework, as well as theoretical framework for this study. Comparative analysis involves comparing and contrasting the inductive and deductive themes to identify similar and dissimilar patterns and to answer the research questions (Strauss \& Corbin, 1998). 


\section{Inductive Analysis}

The first analysis of the data was an inductive analysis using Moustakas's (1994) Modification of Stevick-Colaizzi-Keen Method of Analysis of Phenomenological data. This method is comprised of two phases: individual and composite. The individual phase focused on each participant's textural descriptions of the phenomenon; whereas, the composite focused on the collective textural descriptions of all the participants (Moustakas, 1994). In the following section, both phases are discussed.

Individual phase. The transcripts were read a second time as part of this phase and each individual transcript was analyzed using the following the six steps. First, each statement was considered to determine its relevance to the phenomenon and research questions. Second, all relevant statements were coded directly based on their content and context and/or highlighted on the transcript by making notations next to each statement. Third, all relevant/non- repetitive statements are considered as meaning units of experience. Fourth, these meaning units are connected and clustered into themes. Fifth, the meaning units of experience and themes were synthesized into individual textural description or what is experienced (e.g., conveyed through thoughts, feelings, expectations), and are illustrated with verbatim excerpts from the transcript.

Composite phase. In the composite phase, individual textural descriptions were combined to create composite textural descriptions (or portraits) that described what the participants experienced and how they collectively experienced the phenomenon (Moustakas, 1994). For example, the composite textural description or the emergent theme of residing in an ideal environment captured the importance of the environment to the participants in this study. This emergent theme included individual textural 
descriptions such as: New York was "too cold" (Mary, line 153); Chicago was "too windy" (Connie, line 89); and "I had left the cold and was not planning on going back to the cold. So I stayed [in South Florida]" (Travis, line 115). A total of five emergent themes that describe the participants' collective experience of the phenomenon are discussed chapter 4 .

Coding and category development: About half of the codes that were used to code the data (i.e., inductive relevant statements) were created before the audio recordings were transcribed or the transcripts reviewed for analysis. Code creation commenced after listening to over half of interview audio recordings; the codes were then documented in the researcher's code book (initially in an Excel spreadsheet then loaded into NVivo's code book).

Using this qualitative data management tool, I found data management more manageable. The preliminary scan (or listening to the audio recordings) helped me to create and organize the codebook before commencing an in-depth analysis of the data. Listening to each recording before proceeding to the next interview, not only facilitated code creation but also allowed me to determine what follow-up questions to ask and/or refine for subsequent interviews (Rubin \& Rubin, 2005).

Less than a third of the codes were created using key career concepts from the research questions and the literature review in this study, and the career development literature (i.e., career adaption, career influence, and career success, career mobility). The remaining codes were created spontaneously during the reviewing of each transcript. 
All codes were created or determined simply by asking the following question: "What is this expression an example of?" Ryan and Bernard (2003) contend that this is the simplest way of identifying themes in qualitative research.

Themes are classifications of concepts (codes or expressions) that are discovered by comparing one concept against another and represent a similar phenomenon (Ryan and Bernard, 2003). Boyatzis (1998, p.1) defined a theme as "a pattern in the information that at minimum describes and organizes the possible observations and at maximum interprets aspects of the phenomenon (p.1). The themes used in this study were defined to enhance each theme's creation credibility (Boyatzis).

Although the inductive analysis is presented as a systematic phase-by-phase process in this section, the coding and data analysis processes were iterative and reflective processes. For instance, the list of themes was reviewed several times to verify that no two themes shared the same meaning or overlapped. Therefore, some themes were collapsed or combined to create a new theme. For example, the themes consulting, domestic work and owning business were collapsed to create the theme employment patterns. The names of some of the themes were defined and refined to capture the essence of their meaning units. For example, the initial theme person-environment fit was refined as adjustment challenges. This process of collapsing, combining or refining continued until each theme was distinctly different in meaning and essence from the other.

Five themes emerged from the inductive analysis: (a) vocational influences, (b) adjustment challenges, (c) employment patterns, (d) career mobility patterns, and (e) career success perceptions. These themes are discussed in chapter 4 . 


\section{Deductive Analysis}

The second analysis of the data was a deductive analysis using Savickas's (2005) career construction theory as the theoretical framework. Career construction theory consists of three key tenets: (a) vocational personality, (b) life themes, and (c) career adaptability. Career adaptability includes four global adaptive dimensions which are career concern, career control, career curiosity, and career confidence.

Coding process. Each individual transcript was read for the third time, analyzed, and coded using the rubric (see Appendix C). First, each statement was considered to determine its relevance to the seven a priori codes and corresponding definitions and characteristics. Second, all relevant statements were considered as meaning units of experience and documented with the appropriate a priori code or codes (i.e., VP, CA, CCN, CCL, CCY, CCE, and/or LH). For example the meaning unit "my sister-in-law who's a nurse said well, you should become a nurse" was coded as vocational personality (VP). The meaning unit "with a terminal degree... I can become a consultant" was coded as career adaptability (CA).

Coding rubric. A coding rubric was created based on the three tenets and four global adaptive dimensions. A total of seven a priori codes were used to facilitate the coding process (see Appendix C). The coding rubric was divided into four columns. The first column contains the abbreviations of key tenets of Savickas' $(2002,2005)$ career construction theory: vocational personality (VP), career adaptability (CA), career concerns $(\mathrm{CCN})$, career control (CCL), career curiosity $(\mathrm{CCY})$, career confidence $(\mathrm{CCE})$, and life themes (LH). The second column contained the key tenets. The third contained examples of the characteristics of each tenet and the fourth column contains a definition 
of each tenet. For example, Table 6 is an example of how the tenet vocational personality is presented within the coding rubric. A complete list of all the tents is in Appendix C.

The code for the tenet vocational personality is VP. The characteristics of VP include and originate from events such as rehearsed activities, household chores, games, hobbies, reading, and studying. The definition of VP is individuals' career-related abilities, values, and interests that form the basis for the what in their career construction.

Table 6

Example of Coding Rubric for A prior Code Vocational Personality

\begin{tabular}{|c|c|c|c|}
\hline Code & Key Tenet & Characteristics & Definition \\
\hline VP & $\begin{array}{l}\text { Vocational } \\
\text { Personality }\end{array}$ & $\begin{array}{l}\text { Originates from rehearsed } \\
\text { activities, household chores, } \\
\text { games, hobbies, games, } \\
\text { reading, and studying }\end{array}$ & $\begin{array}{l}\text { Individuals' } \\
\text { career-related } \\
\text { abilities } \\
\text { values, and } \\
\text { interest that } \\
\text { form the basis } \\
\text { for the what } \\
\text { in their career } \\
\text { construction }\end{array}$ \\
\hline
\end{tabular}

Comparative Analysis

A comparative analysis was conducted between the findings from the inductive analysis and deductive findings to check for consistency in the findings, look for patterns, and answer the research questions in this study. Five themes emerged from the inductive analysis and were compared to the findings from the deductive analysis. Using NVivo, as a data management tool, the findings that were coded under the tenet vocational personality were examined to determine if the theme vocational influences was reflected 
in the tenet. The comparison was conducted for each of the three tenets of career construction: vocational personality, career adaptability, and life themes. These comparisons are discussed in detail in chapter 5 and are summarized in Figure 3.

\section{Data Management}

Data management refers to how the data are recorded, collected, organized, and protected (Patton, 2002). The audio recording of all participants' interviews were transcribed verbatim by a professional transcriber and saved in a Word document. Each participant's audio recording and transcription was given a specific code to protect his or her identity. Participants were identified by pseudonyms when findings were reported. In accordance with Florida International University Regulation for Thesis and Dissertation Preparation Manual (2007), this material will be stored for 3 years at the researcher's home in locked cabinet. All electronic data files were stored and secured on the researcher's password-protected home computer. Initially, an Excel data base was created to serve as a data management tool to manage participants' contact information and demographic information (i.e., names, age, place origin, profession, length of time in the U.S, age at arrival, etc.). Upon completing all the interviews, the researcher used NVivo as the main data management tool or software for this study. This software served as a tool to probe into the stored data (i.e., field notes, interviews, codes, and concepts) and to organize, retrieve, and visualize the data.

\section{Integrity Measures}

The integrity of qualitative research is evaluated by its "trustworthiness and authenticity" (Patton, 2002, p. 51). Four traditional categories of trustworthiness of a qualitative study are: (a) credibility, (b) transferability, (c) dependability, and (d) 
confirmability (Lincoln \& Guba, 1985). Credibility of data collection was enhanced through member checks (Creswell, 2003; Patton, 2002). Two participants (i.e., Carla and Travis) were contacted to verify and clarify ambiguous descriptions in their transcripts and new information was added as deemed necessary.

Credibility was also enhanced through the journaling process. This process helped me to reflect on my personal and professional experiences, while maintaining an emic perceptive (an outsider's view; Patton, 2002) of the participants' experiences. This emic perceptive allowed me to capture the essence of the participants' experiences while simultaneously portraying their individual truths. An emic perceptive was essential during the data analysis phase of this study because it enabled me to capture the participants' most meaningful and comprehensive experiences (i.e., personal, social, educational, and professional), which are reflected in the five emergent themes of this study: (a) vocational influences, (b) adjustment challenges, (c) employment patterns, (d) career mobility patterns, and (e) career success perceptions.

The process of documenting field notes also enhanced the creditability of this study. Field notes were useful to document my thoughts and observations. These documentations helped me to contextualize the participants' perceptions of themselves, their behaviors and lived-experiences. For example, during one of the interviews, I wrote a note that documented a participant's level of confident and resilient attitude about getting ahead in the U.S. Similar documentations, about other participants, helped to inform and support the use of concepts such as, compromise, self efficacy, self efficacy expectations, and career resiliency in this study. Detail discussions about these concepts, as they relate to the study, are included in chapters 4 and 5 . 
Transferability of findings was enhanced through the inclusion of the participants' verbatim descriptions of their experiences and professional profiles and the researcher's rich descriptions of the participants and their perceptions. These inclusions will help readers determine if the findings can be transferred to their settings (Lincoln \& Guba, 1985).

Dependability, which refers to the consistent application of data analysis procedures (Miles \& Huberman, 1994), was enhanced group consensus or mutual agreement. My major professor and I reviewed the emerged themes and the classification of the themes for consistency and were revised as needed. Disagreements on code assignment or theme classifications were decided through group consensus or mutual agreement, by probing and clarifying my assumptions (Giorgi, 1985). My dissertation major professor provided detail feedback on every aspect of the study. My dissertation committee also provided valuable feedback that improved the overall significance on this study.

Confirmability, the ability of others to audit the study, was enhanced through the use of audit trials. Audits trails are transparencies in the study that describe how data were collected, how categories were derived, and how decisions were made in the inquiry process (Lincoln \& Guba, 1985). An audit trail in this study includes the description of the interview guide and method of administration that describes how the data were collected. Other audit trails in this study include: (a) the descriptions of the inductive and deductive analyses that describe how categories were derived and, (b) the comparative analysis that describe the decision-making process to determine similar and dissimilar concepts. In fact, the comparative pairings (e.g., vocational influences and vocational 
personality) were discussed in terms of shared concept(s) to enhance the transparency of how the comparisons were derived. Audit trails help to authenticate the study's findings and to facilitate intellectual integrity by enhancing the congruency between the results and the data collected (Patton, 2002).

\section{Summary}

This chapter outlined the phenomenological research design used in this study. West Indian professionals who live and work in the South Florida were purposefully selected and interviewed. With the aid of an interview guide, semi-structured interviews were conducted. All interviews were recorded and transcribed verbatim. Data were analyzed using inductive, deductive, and comparative analyses. Integrity measures and limitations to the study were also included in this chapter. The findings from the inductive analysis are discussed in the next chapter. 


\section{CHAPTER IV}

\section{INDUCTIVE FINDINGS}

This phenomenological study explored how West Indian professionals who are living in the U.S. perceive their career construction (Savickas, 2002, 2005) in order to understand the processes they used to integrate and orient themselves to their new society's occupational structures. The findings in this chapter emerged from the inductive analysis of data collected from the participants' interviews and the researcher's field notes. When quotes from the participants' transcripts are used to support the findings, pseudonyms and line numbers from the transcriptions are provided (i.e., Amy, lines 2022). Five themes emerged from the inductive analysis: (a) vocational influences, (b) adjustment challenges, (c) employment patterns, (d) career mobility patterns, and (e) career success perceptions.

\section{Vocational Influences}

Vocational influences refer to any events, circumstances, or value systems (i.e., cultural, social, sociopolitical, and environmental) that influence individuals' vocational behaviors, decision-making process, and outcomes (Savickas, 2005). Vocational behavior refers to the responses that an individual makes in selecting and adapting to an occupation and the changes in that individual's responses or behavior over time (Savickas, 2002). These responses tend to be grounded in an individual's career socialization, that is, the lifelong differential processes and experiences that prepared him/her for the educational, vocational, life-role, and career options that are considered appropriate (Hansen, 2001). 
Participants reported two prevalent social agents that influenced vocational behavior, their: (a) family support system and (b) the school system.

\section{Family Support System}

For the participants, the family system encompasses not just the traditional American concept of a nuclear family (i.e., mother, father, and children), but other kinships (i.e., caretakers, guardians, surrogate parents, aunts, and uncles). It also includes peers and other cohorts (i.e., fellow immigrants and mentors) who influenced the participants' career vocational behavior.

Within the work-family literature and the context of career, the family is said to provide four categories of tangible and emotional support: information (information, advice, and suggestions), instrumental (aid in time, money or other forms of help), emotional (provision of esteem, affection and trust) and appraisal (feedback and affirmation; Greenhaus \& Parasuraman, 1994). For the participants in this study, the family influence on their vocational behavior manifested in three forms: (a) information support, (b) instrumental support, and (c) emotional support.

Information support. Information support refers to the advice and/or suggestions that the participants' families provided about a particular career choice or decision (Greenhaus \& Parasuraman, 1994). All the participants reported being encouraged to go to college and to get an education. However, the most common suggestion from the participants' family members, friends, and community was to consider a career in medicine or law. This shared expression among the participants was so common; it was one of the first of many relevant statements to be assigned a theme in this study (i.e., doctor and lawyer). 
Jane believes that the social cues that she received as a child coupled with her parents' expectations influenced her interest in medicine. She also believes that almost every parent tells his/her child or children to pursue a career in medicine regardless of ability or interest. Jane said:

I always wanted to do medicine and I think part of that was [I was] poor ... as a kid in the Caribbean. I think you're told you're either going to be a lawyer or a doctor and that's part of your introduction. It's like parents see you as only being successful if you're a lawyer or a doctor and so we're told from small. You're going to be a lawyer or a doctor....Everybody tells their kids that, whether they have the ability or not. So somehow that got stuck in my head and I remember doing sciences, four levels biology, chemistry, psychics with English and literature but that was my goal and I was really interested in science. I liked the sciences and so I decided I would do medicine. (lines 103-113)

Although Jane maintained an interest in medicine, after migrating to the U.S., the

financial constraints of migration forced her to pursue a career in nursing.

Connie's mother advised her to become a doctor, not a teacher. Understanding the

financial rewards and prestige of being a medical doctor, Connie's mother was not

enthusiastic about her career choice. Connie said:

When I told her I wanted to be a teacher...in the islands she said, "Why do you want to do that... Why not a doctor? why not a lawyer?... why teaching? You don't need to become a teacher." So she wasn't enthusiastic about the path I wanted to take. (lines 282- 293)

Although Connie was discouraged by her mother, she became an elementary teacher. As

a child, Connie knew she wanted to be a teacher. She said,

I remember I used to stay with my grandma in the countryside and I would use the ackee tree as [a blackboard]...I would get a stick of chalk and I would teach the kids on the ackee. I would write on that ackee tree... I knew that's what I wanted to do. (lines 273-276)

Childhood hobbies or games often create a foundation for future career interest

(Savickas, 2005). 
Connie's mother's reaction to her career as a teacher supports Chope's (2006) assertions about career choices in immigrant families and families of color. He contends that immigrant families often "take a substantially more rigid point of view in the career decision making process of their children than those families who happen to feel that they have more maneuverability and privilege" (p. 57). This rigidity stems from the fact that culturally diverse families try to protect their children from being unsuccessful by demanding that they follow familial instructions or advice about what educational and career goals to pursue (Chope, 2006).

Travis' reaction to his daughter's career in the theater industry also supports Chope's (2006) assertion about immigrants' expectations for their children and provides an insight into Travis' predisposition about a career in either medicine or law. Although Travis' daughter's role in theater involved technical production, rather than stage performance, he said, "I am not big in to art... My wife might be.... [At least] she is on the side of the theater where she runs things" (lines 530-534). Travis described his son, who is an engineer and daughter as "techies" (line 525) like himself. Travis works in the computer science industry.

However, during the interview, Travis wondered if he made the right career choice. Travis believes that engineering is in the blood because his father was a diesel mechanic and his grandfather managed an electrical plant. However, Travis' family members and friends always insisted that he should have been a lawyer because of his debate skills. Reflecting on his career path and some financial hardship that he faced, Travis still questioned if he made the right career choice; he still seems to perceive a career in law as the ideal career choice. 
Travis stated:

Some people say I would've made a good lawyer. It's possible that maybe I should have done some of those things because I look at some of the financial struggles that I have had and I think having gone to law school I probably might not have had them. (lines 481-485)

Amy's brother advised her about her career path. Amy was indecisive about her

career interest, and her brother recommended that she become a lawyer. Amy said:

[My brother and I] had a conversation and he told me it would be cool if all three of us were lawyers... I'm like okay well maybe that's what I'm going to do, but I've always [wanted to work in]... criminal justice. I figured if I don't go to law school I would work with juveniles...but the goal was to...go to law school only because that's what my brother thought that we should've done. Now my sister's in law school. So she ended up keeping her part of the bargain but, I kind of veered off, in a different direction. (lines 307-315)

Amy followed her true passion and pursued a career in criminal justice and career counseling.

Gerald's admiration for his sister informed his career decision. Gerald's career interest in medicine stemmed not from his parents' expectations, but from witnessing the medical challenges that his sister faced as a child. When he was a young boy, Gerald's sister was very ill. He decided that when he grew up, he was going to become a medical doctor and he did.

Carla's decision to be a doctor was influenced by her experiences with her family doctor in St. Croix. Carla appreciated the personal attention she received from her family physician. Her decision to become a doctor remained a viable career option until she migrated to the U.S. and realized that the doctor-patient relationship was not as personal as in her native island of St. Croix. Carla stated:

I really wanted to be a pediatrician and that was based on my experience with my family doctor ...The family practice that we went to was really like the TV show 
type [of] family practice. Everybody knew your name. And it wasn't like a bunch of nurses. It was [the doctor] and his assistant at the desk and that's what I really wanted. Then when I moved up to Miami and I started to see it was different up here. It was a doctor's office, [but] run more like a business center. The few times that I had to go the doctor here, I mean, I saw the doctor for 2 minutes and the rest was the nurse and the assistants. It was very impersonal. I didn't like that and I started to see that was kind of the trend here and I didn't like that. I thought I could do something else that was a little bit more personal. (lines, 103-120)

Carla earned a bachelor's degree in biology and taught high school for several years.

Peter believes that the lack of information about navigating the U.S. system can be detrimental to migrants. He said, "you have to do the research because information is a killer in this country in terms of your career path" (lines 1076-1077). Peter believes that migrants need to inform themselves or seek information about career decisions because it makes the integration process quicker.

Finally, it seems that upon arriving in the U.S., the ideas of becoming a doctor or a lawyer lost its reverence and many of the participants chose careers in other fields, as many other career options became available to them.

Instrumental support. Instrumental support refers to resources or actions that the participants' family or support system provided to facilitate their careers (Greenhaus \& Parasuraman, 1994). Family members and caregivers were instrumental in facilitating the participants' career goals. This facilitation came in the form of migration opportunities to capture the American dream, financial support, social support, devoted cheerleaders, encouragement, and information gathering.

Jane's sister-in-law was instrumental in Jane's career choice. Jane said, "I came to Fort Lauderdale to my sister-in-law. She was a nurse and she brought me here" (lines 3739). Jane credits her sister-in-law for becoming a nurse. She said, "so my sister-in-law 
who's a nurse said well, you should become a nurse and then you can afford to pay for medical school. So that's the only reason I ended up doing nursing" (lines 58-61).

Peter's wife was instrumental in his decision to migrate to South Florida and in helping him to pursue and attain his career goals. Peter's wife was instrumental because she gathered information for him about how to navigate his new environment. Peter said, "I knew courtesy of my wife what I needed to do at my associate level, with the transfer of the courses that I needed to take to do my journalism, and I did just that" (lines 10801083). Peter went on to say that his wife's help saved him a lot of money because he knew actually what to do. He said, "I did not play around...I was able to complete what I had to do within the required time because I specifically chose the stuff that was required" (lines 1083-1086). While in college, Peter said he only took the courses that were required to avoid wasting time and spending extra money.

Mary's friend was instrumental in ensuring that she attained her nursing certification to become a nurse in the U.S. Mary said her friend, who she referred to as her surrogate mother, provided her a place to live and helped her to understand the requirements to become nurse in the U.S. Mary's father was also instrumental in providing the financial resources to support her nursing career. Mary said her parents' financial support was instrumental in her pursuit to become a nurse. Mary wanted to become a nurse and asked her father to send her to nursing school in Jamaica. Recognizing the cost of a good education, Mary's father was adamant about his expectations of success and questioned Mary's seriousness about attend nursing school. He also warned Mary that she will only attend nursing school if her older sister successfully completed her studies. Mary recalled her father saying, "You know, I work 
very hard in England, depending on your sister's success...then you'll go [to nursing school]. If she is not [successful], then I'm not going to spend the money on you" (lines, 34-36).

Mary's mother and father were living in England, while both she and her siblings lived in Jamaica with an aunt. Given the cost of college in Jamaica, Mary's opportunity to attend nursing school was leveraged on her sister's success. Mary's sister was successful in her studies. Mary was able to attend nursing school and realizing the financial commitment of her parents, she also successfully completed nursing school. Mary said:

So I went to nursing school, passed, which is quite good. I had my struggles of course like everything else. I had to realize that either I stay home and study or I party and don't study and have my father kill me because his money's was being spent to send me to school. (lines 67-71)

Mary decided to migrate to the U.S. rather than to England because she felt that her father was too strict.

Amy, Carla, Connie, Travis, and Gareth said that their fathers were instrumental in helping them attain their career aspirations. Their fathers were living in the U.S. and provided the opportunity for them to migrate to the U.S. Amy credited her parents for bringing her and her siblings to the U.S. for a better opportunity. Amy said:

I think it was just my parents, my mom; she wanted to move here to Miami. It wasn't my decision at all...You know we lived in the projects on government housing. So I guess she wanted for us to get out that and to have a better life and situation. So we moved here. (lines 10-22)

The prevailing reasons for migrating were for a better life, educational attainment, and personal and professional opportunities. 
All the participants expressed these sentiments as reasons for their migration to the U.S. and credited various family members and friends as being instrumental in influencing their vocational behavior and attaining their career goals.

Emotional support. Emotional support refers to the family's provisions that the participants believed gave them the tenacity to pursue their career choices. For many of the participants, emotional support came in the form of held attitudes and values about work and career success that provided a foundation for them to successfully respond, adapt, and strive in a new environment.

Connie's husband was her emotional support system. Connie said that her husband provided emotional support when she wanted to quit her job as a cashier in a hospital to pursue her educational goals to become a teacher. Connie said:

I hated the job with a passion because I didn't like the feeling of being looked down on because I didn't come from my country for anybody to look down on me. So therefore this is not for me. So I went home. I would go home every evening [and] I would complain and my husband said, "So what do you really want to do?"...I said, "What I've always wanted - to become a teacher." (lines 253-263)

Connie thought that the doctors and administrative staff had no reason to look down on her or people in her position. She also thought although the job was not what she wanted to do long term, it supported her family. She said, "I made good money. I was able to buy my first house out of it" (lines 246-247). Connie believed that her job as a cashier did not define who she was as a person. 
Jane's husband was her emotional support system. Jane's husband provided emotional support by encouraging her to migrate to pursue her educational and career goals. Jane and her daughter migrated to the U.S., leaving her husband in Guyana for 8 years. Jane said:

My then 1 year old daughter and ... [I] got on a plane and we came and I left my husband behind and made it to Miami. He had intentions of following us. He came 8 years after, which was natural. But that was because I had to finish school. I ended up going to nursing school. I had to finish school [and] get my feet on the ground. During that time, I did send my daughter back because once I got here what I realized [is that] it was hard for me to go to school.... It was a tough period especially after she went back because you're supposed to bond with your kid. Try[ing] to work to put myself through school; I just couldn't manage that [because] I actually came as a visitor. (lines 7-31)

Jane initially came to the U.S. as an international student, which limited her work options and her ability to support herself and her daughter. Not being a permanent resident, Jane found that it was very difficult to take care of her daughter, work, and attend school.

Carla's father was her emotional support system. Carla and her father were the first to migrate before her mother and older brother arrived 6 months later. Carla's parents thought that she was too young to go off to college by herself; therefore, when her father was given an opportunity to move to Miami for work, Carla relocated with him. Carla said:

I moved here actually for college. I started at the University of the Virgin Islands [UVI]. I was 16. My parents wanted me to go to school, but they did not want me to leave home. So when my dad had an opportunity to move to Miami, I moved with him so that I can attend Florida International University [FIU]. (lines 4-9)

Carla was unhappy about moving to South Florida with her father because she wanted to go away to college by herself to get the "college experience" (line 46). She said:

I didn't want to come because I wanted to go away to college by myself, but my parents kept reminding me of my age and they didn't want me to go away. They 
wanted me to start at UVI until they thought I was old enough to leave but I liked it there. I liked it at UVI so I wanted to stay. So when they decided that they were going to move up here and that I should come up with them and go to college here that wasn't in my plans. I had never heard of FIU, there's nothing about Miami that I was interested in. It was really hard for me to come here. (lines 33-43)

Carla's family was able to provide her with the emotional support that she needed to adjust to her new environment and to pursue her educational and professional goals.

Amy, Angela, and Lena also had the emotional support of their entire family, as they migrated as a family unit. Leah had the support of her brothers who were already in South Florida. Gareth had the support of his father, who was already in South Florida. Travis, who came to the U.S. as an international student, had the support of his mother in Guyana and his father was in New York.

Harris' parents and siblings were his emotional support system. Harris was the last family member to arrive in South Florida after continuous encouragement from his parents and sibling to join them. However, Harris was not concerned about leaving Jamaica because he owned and operated a successful insurance company. However, Harris finally gave into his family's persuasion to migrate to South Florida. Harris described his ambivalence to migrate to the U.S. in the following words:

At that point when I came here [to live in Miami], I was the only one who was still in Jamaica fulltime. Most of my family members, parents, and siblings, they lived in the United States. Finally I decided to migrate to be closer with the family. I was working [in Jamaica] and I ran a very successful business. So I didn't have the interest and the energy to be [in the U.S] or even to visit. So my parents, they filed for me ... when they filed I had 6 months to travel on that green card. Well my 6 months expired on October $12^{\text {th }}$ and I came on the last flight [from] Jamaica on October $12^{\text {th. }}$ (lines 11-23)

Harris has fully adjusted to life in South Florida and appreciates the support of family in his pursuit of his career goals. 


\section{School System}

The school system, including its academic structure and ideology, also influenced the participants' vocational behavior. Roberts (1997) believes that the structure of opportunity is inherent in the social structure of the educational institution that individuals are leaving and the occupational institution that they are entering. One of the assumptions of Roberts' $(1977,1997)$ theory of opportunity structure is that individuals stand in varying degrees of social proximity to different types of occupations and that these varying degrees have nothing to do with the individuals' ambitions. Opportunity structure is recognized as a key component of career development.

The school system from which many of the participants emigrated focused on science as the optimal career path, supporting the speculation that the best careers are in medicine or law. Of the 15 participants, 9 were in science-related professions. In chapter 3, Table 4 summarizes the participants' professions. The participants' current professions are a reflection on the educational opportunity structure and ideology of the school system in which they spent their formative school years.

Many of the participants reported being streamed or tracked to the sciences either based on their genuine interest in a science-related career and/or the ability to pursue a science-related career. Pam explains the process of streaming: "in high school they kind of stream you from very early on. If you are [in the] sciences, you move to one stream. If you are in the arts, you go to another stream" (lines 30-37). In some school systems, like the U.S., entire school programs can be assigned based on "vocational", "general", or "academic tracks". Programs can also be assigned based on ability level within specific subjects (i.e., remedial or honors levels). 
Streaming is said to define long-term trajectories framed by organizational structures such as ability grouping and tracking (Johnson \& Mortimer, 2002).

The process of streaming coupled with family expectations may have influenced the participants' vocational behaviors. For instance, Juliet automatically assumed that she was expected to become a doctor because she was streamed to the sciences. She said "at that time you were going to become a doctor or lawyer and since I was in the science stream, I figured I was going to become a doctor. So I had to do biology" (lines 67-69). However, she ultimately had to choose math because she could not afford instruments required for the biology classes. Although this decision altered Juliet's career from medicine to mathematics, she remained in the field of applied science. After migrating to the U.S., Juliet continued to study math and earned a bachelor's degree in math and computer science and a master's degree in computer science. Juliet currently teaches college level math.

Gareth was also on the science track. Gareth was studying agricultural science before he arrived in the U.S. when he was 19. He stated that he was interested in the sciences especially agriculture science. When asked what he liked about agricultural science, Gareth stated that he liked the idea of "managing a farm from both the growing aspect of it and the financial aspect of it" (lines 79-80). However, once Gareth learned that he was moving to the U.S., he eventually lost interest in agricultural science. He stated, "I started to move away from [agricultural science] and started seek[ing] something else" (line 73). Although Gareth felt that agriculture was a practical career path in the Caribbean, he thought that agricultural science was not an appropriate field to pursue in the U.S. 
Once in the U.S., Gareth remained in the field of applied science and earned a bachelor's degree in management information systems where he currently works.

Jane and Mary were also on the science track and both pursued careers in nursing. Travis was also on the science track and later pursued a career in information technology and engineering. Pam was streamed to the science track. She said, "I [was] always very scientific" (line 37). Pam said, "I always did biology, math, chemistry, zoology, botany... I loved the science [because] it is critical thinking" (39-44). Before migrating to the U.S., Pam attained an undergraduate in chemistry and biochemistry and a master's degree in human nutrition; she is currently the CEO of a major hospital. However, realizing that her education was highly skewed towards the sciences, while in the U.S., Pam also attained a master's degree in business (MBA). She said, "the MBA helped to validate and provided a balance that I did not have [because] I was strictly science. I did not do any kind of financial [courses like] accounting, marketing, in any of my undergrad or post grad" (lines 337-339).

Only few participants veered off the science track and pursed careers in other disciplines. Harris said, "my early interest was to be a medical doctor [because] I always enjoyed the sciences and there was this urge to serve [and] I got a lot of encouragement. I received a lot of encouragement from family and friends" (lines 128-137). Despite being encouraged to do medicine, Harris became an entrepreneur. Carla was also on the science track because her "intention was to go to medical school to become a pediatrician" (lines 103-108). As indicated previously, once in the U.S., Carla decided not to pursue medicine. 
Connie, on the other hand, had no interest in the sciences; she completed the courses to meet a requirement. Connie said, "I was a sort of rebellious in the sense that I did not want to take biology... because I did not want to dissect anything... kill anything, [or] touch anything" (lines 49-64). Connie knew that she wanted to be a teacher; therefore, she had no interest in being on the science track. Connie currently works as an elementary teacher.

Of the 15 participants, Gerald was the only medical doctor. Given the focus on the applied sciences during the participants' formative school years, it is only natural that most of the participants came to U.S. with a strong preference for science-related careers (i.e., math, medicine, engineering, computer science, and nursing), as opposed to liberalarts- related careers (i.e., education, music, and fine art).

\section{Adjustment Challenges}

Adjustment challenges refer to the process of creating a personal, social and professional congruency with new and unfamiliar environments and realties. This process adjustment occurred at different levels of the participants' social life. Three themes emerged concerning the participants' social and professional adjustment to their new environment, the participants focused on (a) emphasizing their personal attributes, (b) delaying gratification, and (c) residing in an ideal environment.

\section{Emphasizing Personal Attributes}

Participants emphasized their personal responsibility, personal and professional merit, and social adeptness rather than their race. The participants were unwilling to apply racial criteria in the process of creating their self-identity in the U.S. and to accept their minority status. Minority status refers to the subordinate treatment of ethnic 
minority groups in the U.S by members of the dominant group and by the institutions controlled by members of the dominant group (Ogbu, 1991).

During the interview, Juliet recalled an experience that occurred close to her time of arrival in the U.S. At that time, Juliet was living in Ohio where she worked and attended college. Juliet was asked to head a minority committee; however, Juliet did not consider herself to be a minority. Julie stated, “I don't think in terms of being a minority. I don't act in terms of being a minority. I don't feel that society has done me any wrong. I am not downplaying what American Blacks have gone through" (lines 644-647).

Not fully understanding why she was asked to head the minority committee, Juliet said her first response was, "I wouldn't be able to relate to it" (line 664). The first thought that came to Juliet was, "indeed with God and me we were a majority regardless of race" (lines 665). Juliet did not consider herself to be a minority because of her spirituality and social experiences in her native country of Guyana. Juliet's experience is very typical for the kind of learning curve that West Indians discover very soon after their arrival in the U.S. (Henke, 2001). For example, Connie could not understand why ethnicity questions were part of the job application process when she first arrived. She said:

I didn't realize that when you pick up an application, the first thing they ask you is your ethnicity. [When] I came here, I had no job [and] couldn't find one because I was in [an] area that was predominantly White. (lines 103-111)

Juliet, who is now acutely aware of the racial stratifications in the U.S., said,

I probably would not have phrased it that way or I would've found a more diplomatic way of saying "no thank you" or maybe I might have even done it now. You know, but back then I was just recently up from Guyana. (lines 676678) 
Juliet further stated she was not totally cognizant of all the race issues because of her spirituality beliefs. Juliet stated, "years later I think back on it and it is like, man I must've sounded so arrogant" (lines 686-687).

Like Juliet, Travis had to confront his minority status. Travis' entry into the U.S was through Missouri as an international college student. Travis recalled that he lived in a fraternity house with "55 White guys" (line 580) and that he was the only Black person. During a shopping trip with a few of his fraternity brothers, Travis said he experienced what it was to be a minority in the U.S . Travis stated:

I don't know whether you want to shut the tape recorder off, but I'll tell you an interesting story. Probably the first month or first, second month I was there ...We went shopping with the president of the fraternity house, myself, and two other guys were in the car. We were driving down the street and a little Black girl ran across the street, and the president said "gee, we should have hit her [making her]... one less Black person" (lines 582-590).

This experience not only changed Travis' opinion about his fraternity brothers, but also reminded him that he was no longer in Guyana and that getting started in U.S was not going to be an easy process.

Jane's attitude towards working in a White dominant culture exemplifies many of the participants' thoughts about getting started and working in a new environment. Jane said:

We have to have more than the other folks because at the end of the day it's still a White dominant culture. We still for the most part have to figure out that for our careers. They're the ones who are opening the doors for us. I mean ...we have to [do] a little bit more to prove ourselves and I would say to some extent in society we still do. We still have to prove ourselves. (lines 935-951) 
Pam mentioned that she appreciated growing up in the West Indies because it allowed her to escape the "baggage" (line 398) of racial inferiority and discrimination that many African Americans faced in the 1960s. Pam said,

At my age, in the 60s I would've been going through some of the racial issues that were here in the states...And they probably would've left a mark... but I didn't have that. So I came to it with a very naïve kind of approach. I didn't know what it was like. Even if they were discriminating against me I didn't even know. I didn't look for it. I didn't care. (lines 400-409)

Pam also said that she felt secure with herself; therefore, if someone did not like her because she was a Black person, her thought was, "I am smart enough to do what I want" (lines 414-415).

Although the participants seem to deemphasize the relevance of race and emphasize the importance of personal attributes, it is inappropriate to assume that they were less concerned or unaware of the relevance and the role of race in the American society and politics. What the participants seem to reject is the racial identity assigned to them by American society because it intruded on their efforts to view themselves simply as West Indians or another immigrant ethnic group (Henke, 20001).

For Gareth, living among several immigrant groups affected his adjustment. Gareth admitted that he had to get out of his bubble of West Indian friends and build up the confidence to work with people from other cultures and races. Gareth felt that coming from a place that was "99\% Black" (line 197) made it difficult adjust to the various races and cultures in South Florida. Gareth's solution was to isolate himself from other groups, which made his adjustment even more difficult.

The participants felt that the adjustment process was not only about integrating in to a new environment, but also knowing that they had done everything in their power to 
create a level playing field to compete within the dominant culture. Peter's assessment of living in the U.S. as a Black, a foreigner, and an educated man captured many of the participants' sentiments about having maximum control over their lives.

During the interview, Peter articulated his reasons for pursuing a $\mathrm{PhD}$ and how having a $\mathrm{PhD}$ would increase his personal freedom and ability to compete in the job market in the U.S. I asked Peter why he wanted to pursue a $\mathrm{PhD}$ and he stated:

When you move from one country, one culture to another culture...particularly people of African descent, the more qualified you are... the more you are able to equate yourself with a job that the dominant race may offer to somebody with their masters. What do I mean by that is... if you're a Black person like I am from the Caribbean with a different accent...the doctorate degree may not necessarily get me the job that somebody who's a resident in this culture who is within the dominant race will get. What it will get is some levels of respect that will get me somewhere on the spectrum. (lines 791-803)

Peter believed that his self worth was not reflected in his race or color of his skin, but the skills and other attributes that he possessed.

Mary's adjustment challenge and strategy was to be professionally prepared for many challenges or opportunities. Mary's attitude about her adjustment was very matter of fact, that is, she believed that her "credentials speak for themselves" (lines 559) and that immigrants pay taxes too and have the right to be here.

Mary struggled with a promotion that she received because she felt that based on the community that her organization serves, an African American should have been promoted. She later realized that she had every right to be in charge as well. Mary shared her thought process about coming to terms with this incident:

Why not an African American? They were raised here. The people [we serve] look like them, speak like them. These are people who are going to use our facility but they're not the only tax payers. We have immigrants who are tax 
payers as well and you... we need to have people who look like the people we serve. (lines 534-544)

Mary's struggle was not only internal, but external. She recalled another incident with a newspaper reporter, who was reporting about the organization where she works.

She stated that the report said, "you know what, I spoke to the vice president and she had a Caribbean flavor, and now I'm speaking to the director and she has a Caribbean flavor; what's up with this Jamaican thing” (lines 549-551). Mary was highly annoyed by what she perceived as a negative undertone. Mary worked for many years as a nurse and had a doctorate in public administration. Mary said that her staff also gave her a hard time because they felt that they also had family members who were qualified and that her promotion was a result of favoritism. Mary's response to her staff's attitude about her promotion was, "I always say 'I've paid my dues and I have done all I can do"” (lines 569-573).

\section{Delaying Gratification}

Delaying gratification refers to embracing a sacrifice attitude in order to achieve long term goals. Many of the participants were acutely aware that they had to "start over" in new jobs or "switch over" to different professions, which in many cases required them to return to school to seek new degrees. Peter's attitude exemplified many of the participants' thoughts about getting started in a new country. Peter assumed a "sacrifice up front attitude" (lines 449), which entailed not focusing on the material things that the U.S had to offer, but on educational and professional opportunities. He stated that sometimes new immigrants get "fascinated" by the material stuff and focus on having the "best car", "best chains", "best clothes", and "best brands" (lines 504-505). However, 
Peter contended that he and his wife adopted a sacrifice up front strategy. This strategy also involved paying for his college education from an associate's to undergraduate degree out of pocket to minimize the cost of student loans and taking whatever jobs were available.

An adjustment strategy that West Indian immigrants often used to integrate is delaying gratification and doing what is necessary at the moment (Henke, 2001). In many cases, the participants experienced downward mobility, working in jobs that were socially below their former occupations and/or skill set. For example, Mary migrated as a nurse, but worked as a caretaker. Jane migrated with work experiences as an accountant and international flight attendant, but worked as a housekeeper. Pam migrated as a public health professional with a master's degree, but worked as a nutritional aide in a hospital. Leah migrated as a teacher, but worked as a part time coach. Gareth migrated as a student with 2 years of college experience, but worked at a gas station. Connie migrated as student with college level experience, but worked as a housekeeper. Harris migrated as a successful business man with two college degrees, but worked in a stockroom. Peter migrated as a seasoned television personality, but worked in various service jobs. The remaining participants (Juliet, Travis, Amy, Angela, and Carla) migrated with their parents and went directly to high-school or college before entering the labor force. Residing In an Ideal Environment

The environment (i.e., geography, climate, and diversity) was an important motivator for many participants in terms occupational integration. A common theme that emerged among the participants was the preference of living and working in a warm climate versus a cold climate. The participants wanted to get ahead in their respective 
professions, but they did not want to freeze in the process. This shared attitude among the participants seemed to be a key factor in their vocational behavior, in terms of job relocation and occupational mobility. For example, Travis' experiences, in terms of navigating his career, exemplify several of the participants' attitudes about working in a warm climate that resembles the Caribbean (i.e., a place with many trees, sun, and sand). Travis stated:

On my way home from work one day, I was driving home in the snow and trying to solve a problem. I can work $24 / 7 \ldots$ and I almost nearly died and I said "this is stupid. Why you living in this cold weather, driving?" and so I just packed up and left. While I was in school I had always heard about Fort Lauderdale, Fort Lauderdale, Fort Lauderdale spring break....So I packed up and left. (lines 83-90)

After arriving in Ft Lauderdale from the Midwest, Travis worked for another technology company that eventually relocated its business to the Northeast. Travis said, "they packed up and left and went to Peoria, Pennsylvania, and to me that was kind of stupid. I had left the cold and was not planning on going back to the cold. So I stayed [in South Florida]" (lines 114-116). Although Travis was aware that finding another job may be difficult or that not relocating with the company may negatively impact his career progression and mobility, he decided to stay.

Unlike Travis, Angela relocated from Fort Lauderdale to Boston for a job opportunity. Angela received a promotion that required relocating to the company's corporate office in Boston. At first, Angela thought it was a great opportunity to work at the corporate level; however, she underestimated her ability to transition to a new place. Angela stated:

I think one of my traits is that I am adaptable. I can adapt to different environments...So I think it wasn't as bad as a transition work wise for me... except the fact that I wasn't dealing with people any more... The difficult part was 
I think the area and adapting to the culture of that area...because it is different..I think the culture there is different in a way where people are more reserved... They're courteous but they're not as friendly to me....You understand what I mean by that... And then during the winter time it's difficult because people stay in... so you don't get to know people that well. It was I think unless you found someone that was willing to open their arms to you and say, "oh, you know, come do this, this, and this". You didn't find people as willing to let you in...I was alone. (lines 329-360)

After a year in Boston, Angela abandoned the opportunity that she once sought and relocated back to Ft. Lauderdale to work for another company.

The environment played a major part in the integration process for several participants. For example, Mary thought that New York was "too cold", "too fast", "too loud", "too big"”, and "too city" (lines 153-156). She thought that New Jersey reminded her of the peaceful countryside of Jamaica. Connie thought that Chicago was too "windy" and "cold" (line 89) of a place to live and pursue a life with her family. Lena left her job on Wall Street in New York City because she thought there were not enough trees on Wall Street. Lena said “New York just it's not for me. I'm from the country part of Jamaica. That's just a little too city for me...I do not know what it was, [maybe] not enough trees" (lines 28-30). Peter visited Miami several times to assess the environment before moving to Miami. He said, "I was looking for anyplace that resembles what I had over 30 years in St. Vincent... Whatever seemed to be close to that then I can assimilate into" (lines 170-172).

Juliet shared the same sentiments as Mary. Juliet said, "I knew I was going to leave my job in Ohio... It was either Hawaii, California, or Florida... I knew I did not want to live in New York" (lines 855-888). Juliet went on to say, "I do not like New York. There is no grass. It is all tall buildings and everything" (lines 896-898). Through a 
process of elimination, Juliet left Ohio and decided to live in South Florida. She did not select Hawaii because of the cost of living. California was not selected because of the potential threat of earthquakes and the possibility that it may fall off into the sea. Juliet said, "I figure [California has] earthquake and [can] fall off in to the sea" (line 90).

Juliet and Peter ultimately decided to live in South Florida because of Florida's proximity to the Caribbean. Juliet said that living in South Florida "put me in line to get back to the Caribbean easily" (line 892). Although living in Texas was an option for Peter, he said, "Texas was kind of a far stretch from St. Vincent. I would not get a direct flight from Barbados, which would be my main hub [from St. Vincent] to Miami” (lines 125-131). The factors of geographical proximity to the Caribbean, diversity, and climate were considered as the participants strived not only for successful professional integration, but personal and social integration.

\section{Employment Patterns}

Employment patterns refer to type of work that the participants held over the course of their careers in the U.S. Four employment patterns emerged from the data, including the participants': (a) underemployment upon arriving in the U.S., (b) higher education employment to access educational opportunities, (c) professional employment in their respective occupational fields, and (d) self-employment to control their destiny.

\section{Underemployment}

Underemployment refers to the underuse of the participants' skill set upon arriving in the U.S. For the participants, getting ahead meant doing whatever necessary to integrate into the U.S. occupational and social structures. Many of the participants reported being either underemployed or overqualified for certain jobs that they held. 
Of the 15 participants, 11 had at least 1 year of college education and/or professional careers before migrating to the U.S. For example, Jane said, "I was in my second year of finishing up a degree in biology and a minor in chemistry (lines 51-52). Gareth said, "when I arrived, I had just completed... college down there; actually maybe a couple of weeks after that I came here but after classes ended I came here" (lines 34-36). Juliet said, "I had completed high school...The last 2 years of high school in Guyana are equivalent to the freshman year at university. I'd taken the ordinary level and the advanced levels of GC.... which was given by the University of London" (lines 29-37). Peter said, "I went to the University of the West Indies and I did a diploma in media communications... It's like an undergraduate diploma" (lines 187-193). Pam said, "in Jamaica, I had an undergraduate and a master's" (line 187) degrees. Leah said, "I was a certified teacher from the University of the West Indies" (lines 111-112).

However, despite their educational level and work experiences, many of the participants were underemployed upon arriving in the U.S. Mary, Jane, and Connie reported working as maids and babysitters in order to get ahead or enter the U.S. workforce. The participants reported that these types of jobs were a means to an end; however, the process was not always easy. Connie reported working for a family of five, which consisted of a mother, father, and three boys:

I got a live-in job...cleaning [a house with]... five bedrooms...and mirrors from ceiling to floor for a 150 dollars per week...They loved me because I really [took] care of the children and I did my job to the best of my ability. One day the little boy spat in my face and I said, "You know, I did not come to this country for this."...It's not that I didn't have a green card... I wasn't illegal. So why should I settle for this. I have goals; I've always wanted to pursue my goals. So, why I am settling for this? My goal at the time was to get enough money to the bank to get my husband here....I said, "You know, enough is enough; sorry I am leaving". (lines 170-188) 
Connie felt that she should not have to tolerate this type of treatment because she was a legal migrant with more options than maybe someone who was illegal and had limited work options.

After leaving her live-in job as a maid, Connie said she lived with a "friend of a friend of a friend" and worked three jobs (line 195). She said that all three jobs added up to one job. Connie worked very long hours. She said "I was 98 pounds or something like that because I did not eat... I had no time and food wasn't my priority... When my husband got here, my husband said, ‘you will not work three jobs anymore;" (lines 204-209). Connie's husband arrived 2 years after she came to the U.S.

Jane said, "I pressed more clothes than I wanted to, I babysat, I cleaned houses. I did all the domestic things to put myself through school" (lines 135-137). Mary comically recalled a job where she was taking care of an older couple. After leaving Jamaica as a nurse, Mary arrived in New Jersey. However, she could not work as a nurse because she did not have a social security number to take the state board examination. In the meanwhile, she stayed with a friend and took a job taking care of an older couple. She said:

I was supposed to wash their clothes, cook their food, and babysit them... Honestly, I did not know anything about cooking because when [they] asked to me [cook] pork chops and apple sauce, I'm like, what is that; I never had time to sit and see how my aunt did anything. (lines 108-111)

Mary was familiar with both pork chops and apple sauce, but not as a meal that was served together. She went on to say:

So I had to call my sister in Brooklyn... [to ask her] how do you cook pork chops and apple sauce...She told me how to do it and it came out nice and they enjoyed it, and deep down in my heart the work was not for me because I [had] to work from 8 A.M. to 8 P.M. and because I loved the fashion on Main Street in New 
Jersey I would I took a second job. So I'd work like 24 hours a day but I slept at work....So I wasn't tired. (lines 111-121)

Although Mary was working very hard to support herself and to attain her goal to become a nurse, her father was not happy with her method of achieving her goal. She said:

[My] mom always knew where I was because she would come and visit me. My dad knew [too] but he's was not very happy with what I was doing 'cause he sent me to school to be a nurse [and he questioned] why I was here [working at these jobs]. (lines 122-124)

After working in New York for a period of time, Mary was recruited to Texas as a nurse. Mary's recruitment had stipulations. Mary had to agree to a 2 year work contract in exchange for the opportunity to complete state board certification and a green card; this card allowed Mary to be a U.S. resident.

Pam acknowledged that she was overqualified for her first job in the U.S., but she had to support herself and her family. She said:

I started out working in a hospital. I worked as a diet aide... in the nutrition department...I was overqualified. I mean I really was. I mean it was like going up and working with the patients on their diet. Those were the days when it wasn't electronic. So you had to work with the diabetics diets and the low salt and clear liquid and you had to instruct the patients and find out from them what they needed. Explain to them the diet that they were going to be on... Was I overqualified? Of course I was, but it was a way to start. So I did that for about 6 months at one of the local hospitals. (lines 111-129)

Although many of the participants, including Pam, were underemployed, they used this period of their employment to understand how to exist in and navigate the U.S. workforce.

\section{Higher Education Employment}

Higher education employment refers to work that the participants performed within the context of an educational institution (i.e., college or university). Nine of the 15 
participants reported that they worked at an educational institution as part of their occupational integration in the U.S. Of the nine that reported working at an educational institution, seven participants were working either in a fulltime or part-time capacity at an educational institution (Amy, Travis, Jane, Carla, Lena, Juliet, and Peter) at the time of their interviews for this study. This common employment pattern among the participants did not occur by chance, but was a deliberate attempt by the participants to take advantage of educational benefits that educational institutions offer.

For Amy and Lena, it was not about the money but having access to the opportunities that working at a college or university provided. Although both Amy and Lena had already completed their bachelor's degrees, while in the U.S., they thought that they needed to learn a little bit more, and they focused their attention on working at a college/university. Amy, who was returning to Miami after being away to college, stated:

When...I moved back with my bachelor degree, it just seem like I wasn't finished yet. I didn't learn enough, so I got hired at Miami-Dade College. You know we have tuition waiver, and I just couldn't see myself sitting there and not taking a class... So I started taking classes...I did an associate of science in finance and one in accounting. (lines 818-821)

All the participants were keenly aware of the power of knowledge and the fact that education was the key to getting ahead. Lena knew this very well; she said:

When I was completing my final year [of my bachelor degree], I thought that maybe I needed to do little more. Then I heard that Nova University [was hiring and] if you came here you get your master's for free.... Well if you're full time, you get your tuition for free.... [At the time], I was working at FAU [Florida Atlantic University] ... So I ran down here and got a job that required a high school diploma...Well I wanted a job that required a bachelor's but that was the only opportunity available at the time. So I took it 'cause I was here only for the tuition waiver in my mind. I got here and I started my master's and I actually enjoyed...So I did my doctorate in higher education administration, which I loved. (lines 121-199) 
Lena currently works at an educational institution and continues to use the educational benefits of her employer. The few participants that did not get ahead by working at an educational institution took advantage of their organizations' or employers' tuition reimbursement programs.

Professional Employment

Professional employment refers to work that is performed in a specific occupational field that is based on a unique body of knowledge and a core set of competencies (i.e., teacher, consultant, information technology, professor, and physician). Consistent with the criteria of this study, all the participants were professionals. However, they were not only professionals in one occupational field, but several. Most of the participants simultaneously navigated two or more careers. Lena was a professor/administrator and consultant. Juliet was an information technology consultant and a college math instructor. Jane was a nurse, a consultant, and a university nurse instructor. Travis was an information technology consultant and a university instructor. Mary was a nurse, a legal nurse consultant, a director of a healthcare organization, and a business owner. Connie was an elementary school teacher and owned and operated a tutoring business. Gerald, a medical doctor, worked fulltime in a hospital in South Florida and part time in a hospital in St. Croix, on his off days. Carla was a researcher at a university and a part time instructor. The consensus among the participants was that having multiple careers allowed them to be employable and marketable.

\section{Self-Employment}

Self-employment refers to working for oneself. Self-employment is often a response or strategy to control employment discrimination and to avoid the ceiling on job 
promotions. Seven of the participants were either independent consultants or business owners. Jane, Juliet, Travis, Mary, and Lena were independent consultants. Connie, Mary, and Travis were business owners. These seven participants capitalized on their expertise in their respective professions to secure additional financial stability for themselves and their families. For Travis, consulting was a strategy to supplement his salary; he said, "I am kind of maxed out on my pay scale" (line 212). For Juliet, consulting was a strategy to gain personal freedom and control over her time. Juliet said, "I really like consulting [because] nobody is sitting watching you work" (line 198-199). For Mary, becoming a legal nurse consultant was a strategy to apply her expertise in nursing in new ways (i.e., medical malpractice).

\section{Career Mobility Patterns}

Career mobility refers to the processes that participants used to facilitate their career. Three themes emerged concerning the participants' career mobility: (a) deliberate, (b) unplanned, and (c) opportunistic.

\section{Deliberate}

Deliberate refers to the participants' plan of action or decision-making processes that were specifically implemented, before migrating, to enhance not only their occupational mobility, but a seamless career transition in the U.S. The notion of a transition encompasses important life changes that may be anticipated events (i.e., achieving the American dream) or unanticipated events (non-achievement of the American dream; Schlossberg, 1981). Transition outcome is the balance of the individual's coping assets and liabilities. 
Five of the participants (Harris, Connie, Gareth, Mary, and Peter) were deliberate in their attempts to achieve positive transition outcomes by permanently migrating to the U.S. However, Peter's decision-making processes were most exemplary of deliberate actions and decisions to achieve positive transition outcomes, which are often enhanced through social support (i.e., family and friends; Schlossberg, 1981).

Before migrating to the U.S., these five participants used the following strategies to enhance their seamless transition and positive transition outcomes: (a) attended American college/universities versus Caribbean universities while in the Caribbean, (b) postponed higher education to avoid re-credentialing once in the U.S., (c) changed career interest to match the perceived skill set in the U.S., and (d) vacationed in or visited the U.S. to learn how to navigate the U.S. social and occupational systems before permanently migrating.

Harris, Connie, and Gareth knew at some point that they were going to migrate to the U.S. and made specific decisions about their education. Before permanently migrating to the U.S, none had been to the U.S. The participants knew they were migrating because a family member (i.e., mother and/or father) started the process of legally filing migration documents for them to live in the U.S.

Harris' deliberate action was to attend an American University while in Jamaica to ensure that his credentials were transferable and accepted in the U.S. Harris stated,

I did my diploma at [the] University of the West Indies, and I did my bachelors at Northern Caribbean University. It's the longest serving institution in Jamaica. It's liberal arts. But the difference with the University of the West Indies and Northern Caribbean University is that the University of the West Indies are more aligned to the British Educational system. 
Northern Caribbean University was aligned with America. So they were sanctioned...so coming here I had plans if I came here to do my master's without having to have my degree validated. (lines 90-107)

Harris earned an associate degree in biology and bachelor's degree in business from Northern Caribbean University and his strategy worked. Unlike many immigrants, Harris did not have to go through the re-credentialing process when he arrived in the U.S.

Connie's deliberate action, with the help of her father, was to postpone attending college in Jamaica until she arrived in the U.S. Although Connie desperately wanted to attend college in Jamaica to become a teacher, her father insisted that she wait until she came to the U.S to avoid the process of re-credentialing and starting all over again. Connie said:

I told [my father] I wanted to go to teachers college in Jamaica; he said it is two different things. So I had to just shrug it off in Jamaica because if I start there then when I get here, I will have to go back to school, so it wouldn't make sense. That's what he said. So I didn't pursue that goal. (lines 293-303)

Connie did not pursue her goal to become a teacher until she arrived in the U.S.; she currently teaches at an elementary school.

Gareth's deliberate action was to change his career interest from agricultural science to computer science, a more marketable field. Upon learning that he was leaving for the U.S., Gareth abandoned his interest in agriculture and started thinking about possible career paths that were more suitable in the U.S., based on his perceptions of the U.S workforce. Gareth stated:

I had so much plans that I actually worked, you know, during the summer at the agricultural department there, and I liked it there, but since it became clear that I was probably not going to stay, I started moving away from that and started seek[ing] something else. But when I came here, I had to access something that was in demand. (lines 58-74) 
Gareth selected computer science as a career path. He said, "computers seemed to be a natural pick for me, a perfect pick for me. So I went that route" (lines 61-62).

The close proximity of the Caribbean to the U.S. allowed Peter and Mary to "check out" their U.S destinations, on several occasions, before making the decision to migrate. While on vacation in the U.S, both participants reported gathering information about how to navigate the U.S. occupational and educational systems. Mary said, "I decided to migrate just to come for a holiday and I liked it, and then I start[ed] putting feelers out how do I get to be nurse in the United States" (lines 73-76). Peter said,

The thing is it wasn't a one shot. It was probably a triple phase process where at first I came to visit. [It] was also part of the decision making process [before my] full move [to the U.S.]. It was for me to determine whether what I see would have been satisfactory. (lines 163-168)

Peter's deliberate action was to visit the U.S several times to get a feel of the country.

During Peter's information gathering phase, he discovered that it was best to attend a junior college for the first years to avoid paying high nonresidential fees at a 4year university. After satisfying the first year of resident period, Peter learned it was best to then transfer to a 4-year college.

Peter believes that new immigrants should attend community college instead of going "straight in to a 4-year college" (lines 1133-1134) to help minimize the cost of getting an education in this country. He further stated that new immigrants should be careful to avoid the stigma associated with community colleges, like he did. Peter said, "when one goes for a job interview... nobody cares if a person attended either a community college or a university" (lines 1136-1140). According to Peter, his approach to gathering information was a "triple phase process" (line 163). On his three visits to the 
U.S., Peter claimed that he was looking for three things: the diversity of South Florida, his sense of "comfortability" in a new environment, and the "proximity" of South Florida to St. Vincent (lines 165-170).

For Mary, two trips to New York gave her an opportunity to gather information about how to become a nurse in the U.S. and how to achieve her career goals. Based on the information that both participants gathered on their trips to the U.S., they were able to minimize their adjustment period because they had prior knowledge of how to navigate the system. For example, Peter discovered that it was in his best interest to seek fulltime employment at an educational institution because of the tuition waiver, to assume a sacrifice up front strategy, and to reset his expectations to zero.

Despite deliberately trying to achieve positive transition outcomes, some of the participants faced unanticipated professional and occupational experiences. For example, Mary did not anticipate her employer's role in her becoming a U.S. resident and the terms of such an agreement. The trade off was agreeing to a work contract for 2 years. She said:

I went through some tough times moving here. You have to more or less fend for yourself kind of have to do things on your own. You have to get a car. You have to file for yourself and you know the lawyers rip you off here and there and take your money [and then] nothing comes of it. You get frustrated. The hospital files for you, but you have to make sure you pass your exams. (lines 132-137)

After Mary passed her nursing exam and fulfilled the 2-year work contract, she left New York and moved to Houston and eventually moved to South Florida. In Harris's case, he did not anticipate the slow pace of his occupational integration, although he had attained an American degree. Peter admitted to a key oversight in his career plan. 
Although Peter was very strategic about his migration to the U.S, he insisted that he move to the States with the "naivety of the Caribbean" (line 260) in terms of the pace of finding and starting his career.

Peter studied journalism and communication at the University of the West Indies and thought that he would continue his education and career in the same occupational field. While in the U.S., he attained bachelor's degree in journalism and communication only to find out that the structures of journalism and communications in the U.S. were not the same as in St. Vincent. Peter realized that, in the U.S., the radio and television stations were ranked based on demographics and that stations that were in higher market share were the most competitive, in terms of getting a job. Deciding that he wanted to live in South Florida also meant that he was choosing to live in a market that was in the top ten in the terms of market rankings. This also meant that finding a job directly out of college may prove to be difficult, as he later found out.

Peter said, "I would have to go to at least a [market share that is about] 30, which is a little bit lower market share for 2 years and at least try to get to an anchor position there" (lines 278-280). Peter finally decided that it was not worth the time, as his wife was already "grounded in what she was going [to do] and that it would not be fair or too much of a harsh move" (lines 282-284) on the family to try to move everyone to a place such as Mississippi just to fulfill his goal.

Peter's wife was already grounded in school and work because she arrived in the U.S. a few years before Peter. Peter acknowledges that she made his transition and integration very easy because of her knowledge of the U.S. occupational and educational system. 
Unable to relocate for his ideal career, Peter made the decision to pursue his "next best love" (line 287) and returned to college and attained master's in computer science.

Peter's level of determination reflects Eby and Buch's (1995) position about individuals' perceptions of change and life transitions. The authors contend that positive transition outcomes are possible if individuals perceive life changes and challenges as an opportunity to redirect career goals, explore career alternatives, develop new competencies, or find a more satisfying job or career.

\section{Unplanned}

Unplanned refers to those participants who stated that their career mobility was determined by someone's advice and/or some unseen circumstances or events. Carla, Connie, Jane, Leah, and Angela felt that their career paths were unplanned because of someone's advice or unseen circumstances. Carla said "someone told me that with a degree in biology I could teach biology. So that's what I did" (lines 130-131). She attained a temporary certificate from the state and started teaching. Carla recalled that the certificate was "supposed to be temporary for 2 years" (line 133) because that was how long she originally planned on teaching. However, she said that she "ended up doing it for 7 years" (line 135) before moving onto another career path.

In Leah's case, the death of her mother and the stress of the loss were instrumental in her disinterest in economics and her new interest in sports management. Leah said,

It was few months since her death and I just couldn't concentrate, and I took an elective in sports management and realized I loved it and it was calming and relaxing for me at that time of at my emotional state. (lines 60-66) 
Angela said, "I do not think I really 'picked' my career path" (line 98). Angela wanted to be a fashion designer, but the career counselor at her college discouraged her. Angela said, "I remember sitting with the counselor [and] somehow [she] redirected me away from that [and] I ended up doing business" (lines 119-124). Connie has a similar experience. She said:

When I started at Miami-Dade College, I ended up in the wrong classes. The advisor for some reason placed me in the wrong classes. My major was supposed to be elementary education and she put me in early childhood. So she told me to stick with the classes and I stick with the classes and miraculously I got job as a preschool teacher because I was certified. (lines 325-338)

Since this experience, Connie has earned her certification to teach kindergarten to $12^{\text {th }}$ grade.

Mary, Jane, Angela, and Carla also felt that their career advancement resulted from others seeing their potential or sometimes by unplanned events. Mary said her introduction to the intensive care unit (ICU) was by chance. She accepted a new job as a nurse in a hospital and she was assigned to the ICU. Although she had not worked in ICU before, she accepted the position. After successfully completing her assigned duties, she was placed in charge of a nursing unit. Mary said, "I remember the first night I worked in ICU on my own... and I [was] trying to do my best because I wanted to outshine everybody. I was just this person who just would not be second to none" (lines 270-274).

Some of the participants said that other people always saw their potential, even when they did not. Jane said, "I'm fine being at home and doing whatever. But opportunities come. People think you can do stuff. You get a pat on your shoulder. You want to do it" (lines 311-315). Angela said career opportunities tend to fall into to her lap 
because she does not focus on herself or skills. She said, "I'm not a self focused kind of person. I don't dwell on thinking about my skills or thinking about me or self evaluate as often as I probably should" (lines 445-453). On the other hand, Gareth said he was always aware of himself and his skill set and partnered with his boss to learn more. Gareth said:

[My boss said] any time you want to learn anything new [he would help me]. I never showed any disinterest. I always, no matter what it was, I always let them know that I'm willing to learn and be available to the company if they needed me. So I just made myself available. And I think they were happy that I was willing to put myself out there. (lines 402-415)

Gareth credits his willingness to learn new things and a positive relationship with his boss for his career mobility.

Carla said that her supervisor recommended that she pursue her master's degree in leadership because she was a teacher. Plus, her employer offered to pay for her education. This decision allowed her career to progress into leadership roles at her high school where she taught. However, looking back at the time she spent attaining her master's degree and teaching at the school, Carla said those " 2 years went by really fast and looking back at it now I'm like, what did I do...I could've done whatever" (lines 484486). Carla felt that she should have taken this opportunity to plan a new career, given that she only planned to teach for 2 years. Instead, Carla felt that she blindly took her supervisor's recommendation, about pursuing a degree in education leadership, without thinking about her career or future.

\section{Opportunistic}

Opportunistic refers to the participants' tenacity to seize every opportunity in order to facilitate their career mobility. For example, recognizing that her degree only 
allowed her to teach kindergarten through the $6^{\text {th }}$ grade, Connie attained a master's degree in reading that allowed her to teach from kindergarten through the $12^{\text {th }}$ grade. Also, her employer paid for her to return to school. Connie said, "my certification in elementary only gave me the opportunity to teach from $\mathrm{K}$ through 6 . Doing the [masters in] reading helped me to teach from $\mathrm{K}$ through 12 (lines 871-873).

Gareth utilized a leave of absence period to rethink his career and look for a new job. After Gareth's first child was born, he took a family medical leave to help his wife take care of their newborn. While on leave, Gareth thought it was a great opportunity to reevaluate his career plans. He used this time to explore several job opportunities. His plan was to secure a new job, with more money, before his leave of absence was completed. Luckily right before the time was up, Gareth received a call for an interview and got a job.

Lena used her dissertation proposal to propose an educational program in Jamaica. She focused her doctoral education on developing a plan that extended her employer's educational department to Jamaica with the intent to oversee the program upon graduating. The proposal was accepted and implemented. Lena received the position to oversee several educational programs throughout the Caribbean region. Lena said,

I thought that [an] education [department] could benefit being there as well so I wrote my papers and all sorts of stuff with emphasis of having [a department] there and with having a job when I'm finished with my doctorate. (lines 220-223)

Using her expertise in education, Lena again capitalized on another opportunity. Lena was asked to revamp and redesign a new pharmacist training program in order to seek accreditation for the program. In the process of rewriting the program, Lena became 
very familiar with the subject matter of the program and decided to take the pharmacy tech exam and attained a license. She said, "I just did the exam. I mean I'm going to know the whole thing inside out, so why not" (lines 717-718). Lena went on to say, "I mean why waste it and I can't work as a pharmacy tech without it... not that I will ever work as a pharmacy tech, but I can teach in the pharmacy tech program" (lines 739-741).

Lena admitted that she is a "worry wart" about the future and that she wants to be ready for anything (line 545). She said, "that ['s] probably why I'm packing up myself with some much credentials" (lines 780-781). Despite having a doctorate degree, a position as a professor, and an administrative position, Lena also has a real estate license, which she stated came in handy when the real estate market was lucrative. She now has a pharmacy tech license and is currently pursuing a registered nurse degree to get ready for her next role as health administrator at her current organization.

Juliet recognized that the consultants in her department were not very productive or honest; therefore, she decided to become a consultant herself. Juliet said:

When the consultants came in to work for us, I could tell when they were goofing off and weren't really giving us the time for the money... So yeah, I figured that I could do a much better job with it and give people better service and... they would be getting more for their money. (lines 204-209)

Juliet also said that she really likes consulting; she enjoys the freedom of consulting.

Amy, Jane, Harris, and Mary used their employers' education reimbursement programs to advance their careers and to remain competitive. Some participants took advantage of their company-sponsored seminars to improve their credentials. For example, Mary said, "I read lot. I go to seminars [because] hard work and perseverance and commitment get you to where you are" (lines 364-373). 


\section{Career Success Perceptions}

Career success refers to the self-perception of an individual that his/her need for achievement has been attained (Lau \& Shaffer, 1999). In the career literature, career success is often classified as either subjective or objective (Hall, 1976; Lau \& Shaffer, 1999). Traditionally, objective outcomes, such as progression in salary, title, and position, tend to delineate career success; whereas, subjective outcomes such as sense of pride in accomplishments and personal goals tend to express career success (Hall, 1976).

The participants classified their career success mainly in terms of subjective outcomes. This finding was consistent with a study on immigrants' career success (Bhagat \& London, 1999; Tharmaseelan, 2008). Immigrants tend to measure their career success based on their level of personal adjustment to their careers and employment status, both of which are associated with the subjective career (Bhagat \& London, 1999; Tharmaseelan, 2008). The subjective outcomes described by the participants are: (a) taking care of family, (b) feeling pride in accomplishments, and (c) giving back to others.

\section{Taking Care of Family}

Taking care of family refers to the participants' ability to provide financial security and stability and social support for their families. The ability to take care of family was an important criterion that the participants used to measure or evaluate their success. Amy's criterion of her success were "being comfortable [and] not having to worry about where her next dollar is coming from or meal" (lines 713-718). She said that not worrying about how to take care of her family was her idea of success. She said,

I don't think my profession has too much to do with it, but if my profession provides me with... [a peace of mind] to not worry about tomorrow [or] paying bills. So I don't think my profession defines success. (lines, 723-730) 
Jane's criteria for success were "being content with who is, raising a phenomenal daughter... who has a great relationship with her mom, father, sister, and extended family. That is success for me" (lines, 1192-1204). Gareth said, "although having the right job and getting the income probably equates to getting the house and car you want,... family is everything ...and [that's what] drives me" (lines 571-579). Mary said that "success is feeling that joy in you because happiness is temporary...I feel joy for where I am. I feel comfortable in my skin" (lines 754-757). Harris said success was "being able to take care of my family, my boys, [and] my wife, comfortably" (lines 1181-1182).

\section{Feeling Pride in Accomplishments}

Feeling pride in accomplishments refers to the feeling of reward after preserving through life's challenges, constraints, and compromises. The participants' sense of pride emanated mainly from the feeling of overcoming challenging events and experiences. Angela's sense of pride emanated from her job satisfaction, attaining a college education, and her family (i.e., her husband and her two children). She said career success meant "being able to show that she achieved something that was difficult to obtain and being recognized for this accomplishment" (lines, 726-728). However, Angela also stated that success was having a "sense of balance that I'm not sacrificing... my personal values or neglecting certain personal things in order to accomplish [success]" (lines752-755).

Connie's sense of pride emanated from the fact that she was able to migrate to the U.S. and strive despite all her adjustment issues with work, school, and family members. She stated,

Success to me is the path that I've taken [and] the steps. I feel very proud of myself in the sense [of my] achievements, seeing where I came from...even 
though I still feel that I can go further and I will go further ...I feel that...I have actually done pretty well. (lines 969-973)

Connie not only felt a sense of pride in her own accomplishments, but instilled it in her students and her children. Connie stated:

I tell my kids my story all the time, and I tell them that no one owes you anything, no matter where you come from, no one owes you anything. Whatever you put in is what you get out, and I believe that education is the key to anything and reading. To me if you can read, you can do anything else, and that's what I always teach my students, you know, that nobody owes you anything, that you have to really work hard at... I have this motto in my classroom [that] the word can't doesn't live here [but] I can and I will [do]...I also instill the same thing with [my own children] that they all are successful... and I'm very proud of them. (lines 975-985)

Connie's sons are excellent students and she takes great pride in telling their success stories.

Jane said her source of pride stemmed from "try to do better than the day before and help others" (lines 1205-1206). Harris's source of pride was doing what he wanted to do in his personal and professional life and not "being stuck in a job and not feeling empowered" (line, 1189). Harris believes that disempowerment negatively affected his success (line, 1191). To avoid feeling disempowered and to ensure success, Harris decided to go back to school to remain competitive and to "work in an environment that supports movement" (lines, 1196-1202), that is, lifelong learning.

Peter articulated his criteria for success mainly in terms of educational attainment and employability. Employability refers to "the possibility to survive in the internal or external market [and can be expressed as employment outcomes such as] physical and cognitive suitability, learning, flexibility, adaption, and mobility" (Thijssen et al., 2008, p. 167). 
In terms, of educational attainment, Peter wanted to make sure he had the appropriate education and skills to compete in the labor market. Peter said education provided him more "flexibility [especially a] terminal degree [because] if you have a $\mathrm{PhD}$, you can perform certain roles even after meaningful employment with an institution" like become a "consultant or you can work on your own" (lines 830-835).

Of the 15 participants, Peter had the shortest length of time in the U.S., only 7 years opposed to 19 years, which was the participants' average length of time in the U.S. Peter's relatively short length of time in the U.S. may have influenced his criteria for success and his overall sense of accomplishment because of his perceived sense of urgency to establish a sense of financial security and to successfully integrate into in his new environment. Peter said, "I think career success is the achievement of specified goals that could put you at a better place income wise, emotional wise, and educational wise than you were when you started" (lines 574-577). Peter further stated:

When I left St. Vincent, I was at an emotional and educational state that was desirable for that environment. It was okay...but once I got on the plane, I reset that to zero and decided that my ultimate aim is to perhaps get a master's. A doctorate degree will be like icing on the cake. And I probably will pursue it ...In the short term... at least get to the master's level before going in to full time work and redefining a career path. And I think if that is achieved at the end of the time period within reasonable time that defines success. The thing is that not only having it fulfills the success requirement but being able to understand the environment here and understand the need for completing it a very short time and how important that is to your own success. And getting a job as a result of what you have done sort of quantifies what is really success for me and I think so far that I've been able to realize portions of that success. (lines 579-598)

For Juliet, adhering to her spirituality and maintaining her sense of personal freedom were essential to feeling prideful and accomplished. She believed that career success meant "doing want she wants to do without having to please others" (lines 529- 
530). She said that not having to please others also meant not getting an "ulcer" in the

process (line, 530). Juliet said her spirituality allowed her to limit her worries about her

personal or professional future. She further stated:

For me success is just being able to do what I want to do without...getting ulcers or anything. So because I'm not pleasing somebody or anything... I never had these career goals. Like in 5 years from now I'm going to be the president of this company or whatever. I can't think that far ahead, so really it's just going day by day...My ultimate dream I guess if I have one is to be financially stable enough to where I can go from country to country ministering with the different churches helping them set up their computer systems. (lines 529-545)

For Juliet, success also meant using her God given talents to earn enough money in order to help the church and to connect with her spirituality. Although financial stability was important to Juliet, it was only a means to an end.

Mary's source of pride was job satisfaction; she described it as a "rush" (line, 648). She said:

There's just something that just gives me the drive when I see people come in [to the hospital] really very sick to the point of death and to know that I did helped contribute to that person walking out of the hospital. It gives me this rush. (lines, 644-648)

Mary said she always had the tendency to help others. She said, "while I was in high

school, I joined the Red Cross of Jamaica. I always, I gravitate towards sick people, [the] blood, guts, [and] gore" (lines 42-44). She went on to say that she was "born not made" (line, 51) to be a nurse.

\section{Giving Back to Others}

Giving back to others entails helping others reach their full potential. For Harris, giving back entailed leaving his "finger print" (line 1155) or a positive impression on his staff and measuring that mark through feedback. Harris said he wanted to leave a mark 
regardless how small, hence the metaphor of a fingerprint versus a footprint. For Leah, a teacher, giving back meant being a role model for her students, even if it meant teaching her students basic manners. She said,

I had some good role models growing up and I had adults who taught me to be honest and do the right thing and I tell [my students] to do the same thing and it's been working..., just being courteous to others saying good morning, good afternoon, and now it's like a process. They [use to] come in to the room in the morning [and] just walk in. It shocked me. I'm from old school. And I said, "well, excuse me, did you miss something?" They did not know what they missed [like] Good morning, thank you, excuse me, please. These things are not being taught anymore. (lines 325-334)

For Pam, a CEO who reached the pinnacle of her career, giving back meant taking others' success into consideration (i.e., personal and professional fulfillment) and not losing sight of the fact that she has to "to deliver and over deliver" (lines 239).

Pam stated:

I don't have a legacy. I don't have somebody sitting there trying to help me to succeed as in the old boys' network. Unless the people... who I am responsible [for]... are successful and unless they have a sense of achievement for themselves as well, then I can't be successful. I will not be considered to be successful because...I haven't created that environment that allow[s] people to be successful... that's part of my responsibility. My responsibility is to create that environment that will allow us to achieve what we set out to achieve and for each and every person to feel like they're important enough to be part of the team [and] that their objectives can be achieved. (lines 241-317)

Pam further explained the challenges in her career mobility and her determination to be successful.

There is really no old girls network because they're not a lot of us to even form a network to help each other and for some reason, women don't think like that for whatever reason. We don't. I just feel like I just have to... I am determined to succeed. I set my goals and I just go about and... I help other people along the way. I think that's important. (Pam, lines 245-252) 
For Mary, giving back meant giving back to her country by owning and operating a nursing school in Jamaica. She said:

I wanted give back to my country and honestly what we charge to train them there [is not expensive]....It's a labor of love. It is also an investment but that investment is not in forthcoming, maybe for my son... years, years, years from now... And [it is also] leaving a part of my legacy. (lines, 613-628)

Although Mary lives in South Florida, she often visits the school to teach and be a role model for the students. Figure 1 summarizes the five emergent inductive themes.

Figure 1

Five Emergent Inductive Themes

Inductive Themes

Vocational influences (any events, circumstances, or value systems (i.e., cultural, social, sociopolitical, and environmental) that influence individuals' vocational behaviors, decision-making process, and outcomes)

Family support system

School system

Adjustment challenges (the process of creating a personal, social and professional congruency with new and unfamiliar environments and realties)

Emphasizing personal attributes

Delaying gratification

Residing an in ideal environment 
Figure 1 (cont'd)

Five Emergent Inductive Themes

Inductive Themes

Employment patterns (the type of work that the participants held over the course of their careers in the U.S.)

Underemployment

Higher education employment

Professional employment

Self employment

Career mobility patterns (the processes that participants used to facilitate their career)

Deliberate

Unplanned

Opportunistic

Career success perceptions (the self-perception of an individual that his/her need for achievement has been attained)

Taking care of family

Feeling pride in accomplishments

Giving back to others 


\section{Summary}

The inductive analysis was conducted to determine themes in the data that were relevant to the phenomenon and research questions of this study. This analysis involved examining each statement in each participant's transcript. Five themes emerged from the inductive analysis of the data: (a) vocational influences, (b) adjustment challenges, (c) employment patterns, (d) career mobility patterns, and (e) career success perceptions. These themes captured the perceptions of careers and careers experiences. In the next chapter, the deductive and comparative findings are discussed. 


\section{CHAPTER V}

\section{DEDUCTIVE AND COMPARATIVE FINDINGS}

This chapter presents the descriptive findings from the deductive and comparative analyses based on the data collected during the participants' interviews. This chapter is divided in two sections: (a) description of the findings from the deductive analysis and (b) comparison of the findings from the inductive and deductive analyses.

\section{Deductive Analysis}

The deductive analysis was conducted after the inductive analysis. The purpose of the deductive analysis was to explore the participants' interpretive, interpersonal, and intrapersonal processes that they perceived as imposing meaning and direction on their vocational behavior. The deductive analysis was conducted using Savickas' (2005) career construction theory as a theoretical framework to analyze the data. This framework includes Savickas' three tenets of career construction: (a) vocational personality, (b) career adaptability, and (c) life themes.

\section{Vocational Personality}

Vocational personality refers to individuals' career-related abilities, values, and interests representing the what in their career construction (Savickas, 2005). These career-related abilities, values, or interests tend to originate from rehearsed activities such as household duties (i.e., cooking), games, hobbies, reading, or studying (Savickas, 2005). Individuals' vocational personality (i.e., ability, value, and interest) tend to shape the occupational content of their careers, the intrinsic influences on their career development, and the context in which they live or derive career influences (Patton \& 
McMahon, 2006). The analysis of the data revealed that both extrinsic and intrinsic influences were equally influential in shaping the participants' vocational personality. Extrinsic Influence

Extrinsic career influences refers to those influences that the participants described as originating within the context of their family, school, and community or from foreseen or unforeseen circumstances and compromises. These extrinsic career influences are: (a) family expectations, (b) compromises, (c) educational exposure, and (d) occupational status at arrival.

Family expectations. Family expectations (i.e., the drive for educational excellence and occupational success) were influential in terms of educational attainment and career preference. All the participants reported that they were encouraged to pursue college education and to get a "good" job. A good job typically meant a job that has great prestige, decision making authority, and autonomy. Angela recalls her parents' expectations for her future, if she decided to live in her parents' home. Angela said her parents said, "you can stay home... you have a place to stay, but you need to go to school" (lines 851-854). Lena said she hesitated to declare a career choice to her parents and told them what they wanted to hear. Lena said, "I just said law so that everybody would shut up and it was more in keeping to shut them up... I think anything would have shut them up" (lines 616-623).

Educational exposure. Educational exposure, academic programs and academic focus, were also influential in shaping the participants' vocational personality. The participants' vocational personality was shaped by their abilities, not necessarily their interests. In other words, participants reported being streamed into science related 
academic tracks based on their abilities to perform in these disciplines (i.e., biology, chemistry, and physics). A key characteristic of streaming is institutional inertia, the tendency for academic streaming to be self-perpetuating (Kerchoff, 1993), that is, shaping career experiences, opportunities, and career outcomes. Of the 15 participants, 12 reported being streamed towards the science track (Carla, Connie, Gareth, Gerald, Harold, Mary, Juliet, Jane, Pam, and Travis). Of the 12 participants who were streamed towards the science track 8 pursued science-related occupations (Carla, Gareth, Gerald, Mary, Juliet, Jane, Pam, and Travis).

These eight participants' occupational attainment, in the science-related careers, supports the contextual-development model of career development (Schoon, Ross, \& Martin, 2007). This model accounts for socialization experiences in the family and the school environment. The model also assumes that adult occupational attainment can be predicted by family social background, school experiences, individual assets, and earlier career choices. An important part of these school experiences is "exposure to science" (Schoon, at al., 2007, p. 132), that is, the number of science related options taken at school (Farmer, 1997). Teachers' assessments and perceptions of their students' abilities are also essential in the school environment.

Occupational status at arrival. Of the 15 participants only 1 participant did not graduate from high school before migrating to the U.S. Amy was a high school student when she arrived in the U.S. All other participants graduated from high school before migrating to the U.S. and most had professional jobs, such as a high school teacher, an accountant, a nurse, a nutritionist, and a business owner. Therefore, many of the participants migrated with a general idea of what career paths they wanted to pursue. Pam 
worked in a public health sector in various capacities in Jamaica and pursued healthcare as a career in the U.S. Pam said, "I was doing research and then I was working with the [Jamaican] government on their nutrition program for the undernourished children, and I decided I wanted to do an MBA and I came here" (lines 25-27). Juliet worked as a math teacher in Guyana and pursued a career in math and computer science in the U.S. She said,

From the time I came out of high school, I started teaching at [a] high school level in Guyana. So I was teaching there for about 2 years. I actually [taught a] combination of math and science. And a couple of the odd courses because I was the part of the homeroom teachers. So there was a couple of other odd ball courses I had to teach. When I got up here, I went in the university full time. And then when I was doing a master's, I was teaching computer science this time. That was what provided the funding for the master's. I was a TA [teacher's assistant]. So when I graduated with the master's, I went in to programming full time at a private research company. I was there for several years, like over 10 years. (lines 137-156)

Juliet continues to work in computer programming.

\section{Intrinsic Influences}

Intrinsic influences refer to influences that the participants described as originating within themselves or being motivated by self satisfaction. The intrinsic influences that the participants reported were their meaning of work and perception of knowledge in terms of career development. The analysis revealed the participants seem to be most concerned about being competent (i.e., acquiring skills and using their skills set). Rather than having a specific career, job, or title, the participants focused on attaining transferable skills.

Perceptions of work and knowledge. Perceptions of work and knowledge influenced the participants' self-management, career progression and career development. 
Although the world of work was an essential part of the participants' lives; it was peripheral. Competency was central to the participants' perceptions of work and their use of knowledge in the workplace. Work may not have been as central to the participants as competency for several reasons. Immigrants or people of color tend to gravitate to family, community, and spirituality instead of the world of work (Chope, 2006). This gravitation is often due to the ubiquitous nature of racism and discrimination and lack of opportunities in mainstream cultures for many ethnic groups (Chope, 2006). In responses to these barriers, ethnic groups place tend place greater importance on work and family balance. This importance is consistent with the trend of career self-management, which was apparent in the participants' perceptions and meaning of work. Career selfmanagement refers to managing one's own career and being an active agent (Arthur \& Rousseau, 1996). The participants self-managed their careers by being competent (i.e., skills and abilities).

Perceptions of competency. The centrality of competency is also consistent with a protean career. The protean career refers to a career that is driven by self-personal values and self-determination rather than organizational rewards and serving the whole person family and life purpose (Hall, 1976). The protean career is an ideal orientation for immigrants because at its core are the notions of adaptation and survival. These notions are essential not only for successful social and occupational integration and mobility, but economic survival.

Jane said:

It's not about a job or a particular job; it's not because I want to be the next chief nursing officer. It's that I want to be in a role that's going to use my skills and 
talent for whomever I'm serving. When you get in to positions of leadership, it's about who you serve. (lines 730-732)

She also feels that although competency is important, freedom to perform one's job functions is priceless.

Juliet's spirituality defined her meaning of work and how she used her skills.

Juliet said:

I see God as my provider, not this particular job. So I mean I don't have the constraints. I don't necessarily have to stop and think, 'well I might get fired for this,' or whatever now. If I see something that isn't right, I will speak up; I don't really have to preserve anything where I'm concerned. So I mean in terms of mentoring my staff, teaching them everything I know, I don't have any problem with that because they can take my position. Many times people are scared, 'well I'm not going to teach you too much because you might move up in the company and push me out.' I don't have to be concerned about that; I want you to get to the point where you can take my position because then I can move up higher or I can go on to something else, so I don't have any problem with that. (lines 437-454)

Juliet believes that God is in control of her career and that she basically does what is most comfortable.

Some participants reported that once they reached their full potential or reached a career plateau, they started searching for new work. This search was an attempt to keep learning, acquiring new skills, and not being bored. Harris said his fear was being stuck in a job. He said, "my concern may be more in being stuck in a job or in the profession where I don't feel empowered" (lines 1189-1191).

Gareth said, "with this job I probably think it is as far as I am going to get. Even though it has been good to me, I am at a plateau...I have learned everything that I could learn to work their system" (lines 486-507). Connie's sentiments about learning and staying current in one's profession capture all the other participants' drive for new knowledge to remain competent within their respective professions. She said: 
I love school and I also like to better myself. I always feel that I can learn more and the only time you're not learning something new is when you are dead because as they always say in the islands you're never too old to learn. (lines 859863)

Connie believes that her desire to keep learning gave her many job opportunities.

\section{Career Adaptability}

Career adaptability refers to individuals' career-related coping mechanisms or processes representing the how in their social and occupational integration. Individuals use four global adaptive dimensions to manage critical developmental tasks, occupational transitions, and personal traumas: (a) career concern, (b) career control, (c) career curiosity, and (d) career confidence (Savickas, 2005). Career control involves the control over one's vocational future in terms of decision-making, assertiveness, locus of control, autonomy, and self-determination (Blustein \& Flum, 1999). Career curiosity refers to inquisitiveness in exploring the fit between self and work, information-seeking, and selfknowledge. Career confidence refers to the strength and tenacity to pursue a career (Savickas, 2005). Each of the four dimensions includes specific sets of attitudes, beliefs, and competencies, which represent the ABCs of career construction (Savickas, 2005).

The analysis of the data revealed that the participants' used three of the four adaptive dimensions: career concern, control, and confidence. Career concerns manifested as planning for the future through educational attainment and performing meaningful work. Career control manifested as continuous learning (i.e., attaining multiple credentials) and maintaining secondary careers (i.e., consulting and owning businesses). Career confidence manifested as self-efficacy expectations, which refers to the participants' beliefs about their ability to perform a behavior that produces desired 
outcomes (Bandura, 1977). More specifically, the participants were confident that their skill set was transferable to a new environment and could produce desirable career outcomes.

\section{Career Concern}

Career concern involves concern about one's vocational future in terms of time perception, anticipation, and orientation (Savickas, 2005). The participants in this study were aware of the importance to prepare for the future. The participants prepared themselves for the future mainly by attaining college education, returning to school to remain marketable, and seizing every opportunity.

Although the participants did not have a set career plan, in terms of a 5 or 10 year career goals, they anticipated a time when they would be fully integrated into their respective professions and financially stable. In chapter 3, Table 6 summarizes the participants' educational attainment.

\section{Career Control}

Career control involves the control over one's vocational future in terms of decision-making, assertiveness, locus of control, autonomy, and self-determination (Blustein \& Flum, 1999). The participants felt that they were responsible for constructing their careers. Continuous learning (i.e., seeking new credentials and opportunities) was the most common strategy that the participants used to control and construct their vocational future. The participants also took control over their career development by networking, learning from others (i.e., colleagues and friends), attending professional seminars, and serving as board members. 
Attaining the appropriate credentials was important to all the participants. All of the participants had bachelor's degrees. Of the 15 participants, 12 had master's degrees. Three participants had doctoral degrees and two (Carla and Juliet) were actively pursuing doctoral degrees.

Lena's portfolio of educational attainment in many ways reflects not only her decision-making processes, but her attempt to maintain control over her career. Her collection of college degrees also exemplifies many of the other participants' attempts to control their careers.

Lena stated, "I actually started out in hospitality and restaurant management thinking that I was headed straight back to Jamaica in the hospitality industry because that seemed more like me" (lines 102-105). After completing her associate degree, Lena thought the degree was too specific. She stated,

I thought it to be a little bit too specific so when I went to FAU, I thought that marketing would be a little bit more marketable. So I just did marketing. I mean I just need a bachelor's degree. (lines 109-110)

After completing a bachelor's degree in marketing, Lena decided that she "needed to do a little more" (line 113) and earned an MBA and later a doctorate in education. Despite all of Lena's educational attainments, Lena is currently pursuing a bachelor's degree in nursing. This educational pursuit is in preparation for a possible new executive role in a university's medical program. Lena said "right now I can work as a hospital administrator with all of the education that I have. However I'm not unique" (lines 417420).

I asked Lena about volunteering to gain the knowledge and experience that she needed. She insisted that volunteering in a medical environment was not enough; she 
needed practical training in nursing to gain the knowledge and experience. Lena believes that attaining a nursing degree makes her more credible, giving her more control over her career.

Planning for the future and gaining control over their careers were also important to Amy and Jane. Amy works as a career counselor and has a master's degree in criminal justice. Amy is currently pursuing another master's degree in management information system (MIS). I asked Amy why she was pursuing a second master's degree. She said, "I'm doing the MIS program because maybe some type of web training [will be needed] and I do not necessarily have to be there to train the people. I can actually do it from a distance" (lines 765-768). Training was a new job function and an opportunity that Amy was interested in performing at her current job. Jane, who has a doctorate in education, said, "I promised my daughter when I was done with [my doctorate] that I wouldn't go back to school" (lines 783-785). However, later in the interview, Jane confessed that "the MBA has been calling her" (lines 783-785). Jane thought process was, she enjoys learning, so why not learn more about business.

For Peter, planning for the future meant having a long term goal to pursue a terminal degree, which would allow him great flexibility. Peter said, "with a terminal degree... I can become a consultant... If you have a $\mathrm{PhD}$, you can perform certain roles even after meaningful employment with an institution" (lines 765-769). Carla and Juliet were also planning for the futures by actively pursuing doctorates. Travis said that he was thinking about pursuing a doctorate, but he was not sure if it would make a difference for him because he was thinking about retiring very soon. 
Connie's career plan is to transition from teaching elementary school students, who are in the regular academic track, to teaching exceptional students, who are autistic; she believes that a doctorate is the key to her future role. She said, "it would give me more knowledge...[to teach and] study autistic students (lines 944-945).

A lack of career control tends to result in career indecision, the inability to make a career choice or decision (Savickas, 2005). Although the participants were satisfied with their current accomplishments, self determination, and assertiveness to success, their sense of career control grew over time the longer their lived in the U.S.

\section{Career Confidence}

Career confidence refers to the strength and tenacity to pursue a career and the anticipation of success, challenges, and obstacles (Savickas, 2005). The lack of career confidence may result in career inhibition. The participants exhibited career confidence. The participants credited their confidence to the support of friends and family, a drive for success, and the belief that their transferable skill set would make their integration quicker and seamless. The participants were comfortable and confident in their ability to pursue and succeed in their respective professions. This confidence was also grounded in the fact that the participants' belief that their good work ethics, good personalities (i.e., working well with others), and credentials made them competitive.

The participants' credited their tenacity to overcome challenges to their selfefficacy expectations. Self-efficacy expectations refer to an individual's belief about his/her ability to perform a behavior that produces desired outcomes (Bandura, 1977). For example, Carla, Gareth, Juliet, Travis, Mary, and Pam knew they were capable of excelling in the science related careers. Travis attributed his success to his aptitude. He 
said, "the success that I have acquired has been because of my aptitude with math or engineering or with academics" (lines 551-553). However, Travis said that the career planning side of his career has been lacking. He said, "but the other side I think [that is missing is] the planning. It has been lacking" (line 556). Pam's career confidence was evident when she said, “even if they were discriminating against me I didn’t even know. I didn't look for it. I didn't because I think I felt secure within myself, I'm smart enough" (lines 408-415).

Juliet was not aware that girls in the U.S. were not often encouraged to pursue math or science and that most science occupations were male-dominated. Of the four participants who were in the computer science field, three were men and Juliet was the only woman.

During the interview Juliet expressed her thoughts and experiences as a math student in Guyana and as math and computer graduate student at Ohio University. She said, in Guyana "we had to learn math. Everybody learns math. So I mean why I would think that women didn't learn math. We're all girls and we all had to learn it" (lines 712714). Reflecting on her experiences as a graduate student at Ohio University, Juliet said:

Come to think of it, the people that I interacted with at the university in Ohio were either White males or Indian males or women. So it was either White female or White males. There weren't Blacks in at that level. There weren't Blacks in the field now that you mention it; there weren't Blacks in the math area or the science or the computer science area. (lines 820-825)

Juliet said because girls were expected to study math in Guyana, she was confident in her ability to pursue an undergraduate and graduate degrees in mathematics and computer science in the U.S. Juliet's and many of the other participants' self-efficacy affected their thought patterns and partly determined their actions and their decision to engage in a task 
and to put forth effort and perseverance (Bandura, 1977). Table 7 summarizes the career adaptability behavior reported by the participants.

Table 7

Career Adaptability Behavior Reported by Participants

$\begin{array}{lll}\text { Adaptability } & \text { Attitude } & \text { Coping Behavior } \\ \text { Dimension } & \text { Beliefs } & \end{array}$

Concern Cognizant Aware of new environment: exploring and accessing boundaries and barriers to determine career decisions and development Control Decisive Assertive and logical approach: selfmanaging career through competency

Confidence $\quad$ Efficacious $\quad$ Opportunistic and unrestrained: anticipating career mobility and success

The participants were confident in their ability and transferable skill set. They believed that their academic success before arriving in the U.S. coupled with their educational attainment in the U.S. would translate into successful and desirable career outcomes. They also believed that growing up in an environment where professionals of all occupations looked like them also increased not only their career confidence, but personal self-efficacy. 
The participants also believed that the supportive environment of verbal encouragement and emotional support enhanced their career confidence in the U.S.

\section{Life Themes}

Life themes refer to individuals' career stories or narratives about vocational developmental tasks, occupational transitions, and personal traumas revealing the why of vocational behavior and the private meaning that guides career choices (Savickas, 2005). Life themes also provide contexts for the meaning of a career and the dynamics of its construction. The analysis of the data revealed that migration stress and starting over were common challenges for many participants. Other life themes include migration stress associated with leaving family members behind, experiences of discrimination, and acculturation stress. Figure 2 summarizes the deductive findings relating to the four tenets of the career construction.

Figure 2

Deductive Findings

Deductive Findings and Tenets Descriptions

Vocational personality (individuals' career-related abilities, values, and interests, representing the what in their career construction)

Family expectations

Educational exposure

Occupational status at arrival

Perceptions of work and knowledge 
Figure 2 (cont'd)

Deductive Findings

Deductive Findings and Tenets Descriptions

Career adaptability (individuals' career-related coping mechanisms or processes, representing the how in their career construction)

Career concern: manifested as career planning for the future

Career control: manifested continuous learning and educational attainment

Career confidence: manifested as self-efficacy and self-determination

Career compromise: manifested as adjusting in career aspirations to accommodate external reality

Life themes (individuals' career stories about tasks, transitions, and traumas, representing the why in their career construction)

Migration stress

Discrimination

Acculturation stress

Adaptation challenges

\section{Summary}

The deductive analysis revealed that the participants' vocational personality was shaped based on extrinsic influences (i.e., family expectations, educational exposure, and occupational status at arrival) and intrinsic influences (i.e., perceptions of work and knowledge). Career adaptability was critical to the participants' economic and occupation 
integration. The participants used three of the four global adaptive dimensions (i.e., career concern, control, and confidence) as coping strategies. The participants also reported life themes of personal and professional challenges (i.e., migration, discrimination, acculturation stress, and adaptation challenges. In the next section, the findings from the inductive and deductive analyses of the data are compared

\section{Comparative Analysis}

The findings from the inductive and deductive analyses were compared to verify the consistency in the findings, look for patterns, and answer the research questions. The five emergent themes from the inductive analysis were compared with the findings from the deductive analysis. The themes from the inductive analysis were: (a) vocational influences, (b) adjustment challenges, (c) employment patterns, (d) career mobility patterns, and (e) career success perceptions. The deductive findings were analyzed using Savickas' (20005) three tenets of career construction: (a) vocational personality, (b) career adaptability, and (c) life themes. Career adaptability included the four global adaptive dimensions: (a) career concerns, (b) career control, (c) career curiosity, and (d) career confidence.

The comparisons between the inductive themes and deductive findings yielded the following pairings: (a) vocational influences and vocational personality, (b) adjustment challenges and life themes, (c) employment patterns and career adaptability, (d) career mobility patterns and career adaptability, and (e) career success perceptions and career adaptability. These pairings resulted from consistency in findings and patterns across both concepts. 


\section{Vocational Influences and Vocational Personality}

Vocational influences were associated with Savickas' (2005) tenet of vocational personality. Vocational personality refers to career-related abilities, values, or interests that tend to originate from rehearsed activities such as household, games, hobbies, reading, or studying (Savickas, 2005). The family experiences, educational exposure, and rehearsed activities (i.e., Connie playing a teacher and Mary's Red Cross membership) were found to influence the participants' vocational personality.

The comparison of vocational influences and vocational personality was based on the shared concept of career socialization. Career socialization "consist of the life long series of differential processes and experiences through which women and men are

prepared for educational, vocational, and life role options that are considered appropriate for them based on their sex, race, or class (Hansen, 2001, p. 31) Career socialization emerged as a possible reason for some of the participants' career choices, decisions, and selection. For example, the participants credited the family expectations and educational experiences for their heightened interest to pursue a career in either medicine or law. Hence, both systems seem to perpetuate a "doctor-law phenomenon" through the process of socialization. Socialization is a process by which behavior, roles, attitudes, and beliefs are transmitted to the next generation (Hansen, 2001).

\section{Adjustment Challenges and Life Themes}

Adjustment challenges were associated with Savickas's (2005) tenet of life themes. A life theme is a problem or set of problems that the participants wish to solve (Savickas). By solving their problems or challenges, the participants were able move from "preoccupation to occupation" (p. 59). Common life themes in our culture are 
themes of obstacles and overcoming. Some of these include the impoverished child who becomes a wealthy adult, the stuttering child that becomes an actor, or the biracial child who becomes president. Culturally, themes denote an individual's evolution from "weakness to strength, from timidity to confidence, from inhibition to expressiveness, and from poverty to affluence" (p. 59). The participants' life themes included stories of simultaneously navigating their ethnic identity and their minority status and succeeding despite these contradictions. For example, Juliet and Travis came face-to-face with their minority status. Mary and Pam encountered discrimination based on their race and nationality.

The comparison of adjustment challenges and life themes was based on the shared elements of perseverance, overcoming, and career resiliency. Resilience theory suggests that resilient people, despite encountering environments characterized by environmental hardships and extreme stress, were able to lead successful lives (Werner, 1993). In this study, some examples of resiliency also included the participants' evolution from underemployment to professional and self-employment. For example, Mary's transition from a entry level job to director of a health center; Jane's transition from a housekeeper to university instructor; Pam's transition from a nutritional aide to a CEO; Gareth's transition from a gas station attendant to information management manager, and Connie's transition from a housekeeper to an elementary teacher.

Werner (1993) contends that resilient people have specific characteristics, which include: positive temperaments, well-developed cognitive and academic skills, internal locus of control, realistic educational and vocational plans, and tendency to assume responsibility. Byster (1998) identified five guiding principles of career resiliency, 
namely: (a) the need to be the primary architect of one's life, (b) the ability to be motivated by one's core values, (c) the ability to stay competitive in one's field by continuous learning, (d) the ability to connect or integrate into one's community by developing relationships with mentors, job shadowing, and attending job support groups, and (e) the ability to accommodate the changing needs of one's employer while maintaining a clear sense of self and direction.

\section{Employment Patterns and Career Adaptability}

Employment patterns were associated with Savickas's (2005) tenet of career adaptability. Career adaptability focuses on how individuals construct their careers, emphasizing the process of career construction. The how in the participants' career construction primary included strategies of higher education employment, professional employment, and self-employment. Career control was the prevailing adaptive dimension that the participants used to adapt and respond to their environment.

The comparison of employment patterns and career adaptability was based on the shared concept of self-management and expected success career outcomes, such as career mobility. Career self management refers to individuals who regularly gather information and plan for career problem-solving and decision-making (Kossek, Roberts, Fisher, \& DeMarr, 1998). The authors identified job mobility and preparedness and developmental feedback seeking as two main career self- management behaviors (Kossek, et al., 1998). The authors contend that although both are instrumental in obtaining career outcomes, they entail different actions. Job mobility entails more interpersonal behaviors or activities, such as exploration and information collection for subsequent planning and changes in activities. Development feedback involves engaging in learning new skills, 
acquiring new knowledge, and improving performance. Career self -management relates to career adaptability because it signifies that individuals are taking full control or responsibility for their career awareness, career planning, and future.

Figure 3

Comparisons between the Inductive and Deductive Findings

\begin{tabular}{|l|c|}
\hline Inductive Findings & Deductive Findings \\
\hline Vocational influences & Vocational personality \\
Adjustment challenges & Career adaptability \\
Employment patterns & Life themes \\
Career mobility patterns & \\
Career success perceptions & \\
\hline Comparative Findings \\
Adjustment challenges and life themes \\
Employment patterns and career adaptability \\
Career mobility patterns and career adaptability \\
Career success perceptions and career adaptability
\end{tabular}




\section{Career Mobility and Career Adaptability}

Career mobility patterns were associated with Savickas's (2005) tenets of career adaptability, specifically its adaptive dimensions of career confidence, concern, and control. Although the participants were confronted with adjustment challenges and mobility obstacles, they were confident in their ability to adapt to their new environment. The participants' confidence in their mobility manifested as being deliberate and opportunistic about their career progression.

The comparison of career mobility and career adaptability is based on the shared element of correspondence; a tenet of the theory of work adjustment (TWA; Dawis, 2005). Correspondence refers to mutual satisfaction between an individual's requirements and needs of the work environment (i.e., money or good working conditions) and the work environment's needs and requirements of the individual (i.e., skills and ability). When there is a mutual satisfaction and interaction and the needs of both are met, the end result is correspondence. Person-environment correspondence is central to TWA because it relates to the fit between person and environment and the co-responsiveness of person and environment to each other.

Factors that reinforce mutual satisfaction are called reinforcers because they maintain or increase the rate of behavior or mobility, such as achievement, advancement, security, and social status. Dawis (2005) identified four terms used to describe work behavior: (a) celebrity, (b) pace, (c) rhythm, and (d) endurance. Celebrity denotes the quickness with which an individual initiates interaction with the work environment. Pace denotes the level of effort expended in the interaction. Rhythm denotes the pattern of pace in the interaction whether steady, cyclical, or erratic. In this case, the rhythm may 
denote the participants' modes of career mobility (i.e., deliberate, opportunistic, and unplanned). Endurance denotes the length of time the individual remains in the interaction.

\section{Career Success Perceptions and Career Adaptability}

Career success perceptions were associated with Savickas's tenets of career adaptability, more specifically, the adaptive dimension of career confidence and control. The participants used several adaptive strategies to gain control of their environment, such as educational attainment, continuous learning, professional employment, self employment, and working several jobs. However, the participants' perceptions of success were mainly subjective rather than objective (i.e., taking care of family, feeling pride in accomplishments, and giving back to others). This subjective orientation to career success denotes an intrinsic and psychological sense of well-being.

The comparison of career success perceptions and career adaptability was based on the shared element of psychological well-being. Some authors believe that adaptation is a multifaceted phenomenon that comprises of three critical elements (Moghaddam, Taylor, \&Wright, 1993): (a) positive feelings and satisfaction with one's current situation, (b) developmental and positive interpersonal relations with members in one's new environment or host culture, (c) some level of effectiveness in carrying out the necessary task at hand or sense of self efficacy.

These three elements relate respectively to three types of indicators of adaptation that immigrants seek in order to achieve success or positive outcomes (Aycan \& Berry, 1996): (a) psychological adaptation, (b) socio-cultural adaptation, and (c) economic adaptation. Psychological adaptation includes "a sense of well-being and satisfaction with 
regard to different aspects of one's life, and sense of satisfaction relative to groups in the country of origin and in the larger society" (p. 242). Socio-cultural adaptation “emphasizes immigrants' progress in becoming full participants in society and acquiring the skills required to manage everyday situations" (p. 242). Economic adaptation entails a "sense of accomplishment and full participation in the economic life in the [U.S.] "(p. 242).

The main criteria for subjective career success are intrinsic or psychological success and were found to be evident in this study. Individuals' perceptions of success are based on their values, and attitudes (Derr, 1986). An individual's perceptions about success, similar to an attitude, has cognitive (i.e., set of beliefs about career), evaluative (i.e., a sense of preferred or ideal careers), and behavioral components (i.e., a predisposition to behave in certain ways). When immigrants' belief system concerning these components are in opposition to their social realties in their new environment adaptation difficulties may surface.

A study of Turkish immigrants found several factors that influenced immigrants' employment-related experiences, poor psychological health, and adaptation outcomes (Aycan \& Berry, 1996). Employment-related experiences included factors such as, loss of status and mobility status, duration of employment and employment status (i.e., employed, unemployed, or underemployed). Poor psychological health was attributed to acculturative stress, self-concept, and alienation. Finally, adaptation outcomes included psychological adaptation, socio-cultural adaptation, and economic adaptation. The findings of Aycan and Berry's study suggest that work has functions other than providing 
income; it also provides sense of purpose, defines status and identity, and enables and establishes relationship with others in the society (Aycan \& Berry).

In the next section, compromise, an emergent theme that the participants' used as a coping behavior or adaptive dimension is discussed, along with findings related to the limited use of the adaptive dimension career curiosity.

\section{Coping Behavior and Non-Behavior}

The most prevalent coping strategies used by the participants were: career concerns, control, and confidence. The participants did not commonly use career curiosity as an adaptive mechanism. The analysis revealed career compromise as an emergent adaptive dimension that participants used. Career compromise emerged as an adaptive dimension because of the many negotiable events and circumstances that the participants reported encountering in their new environment and their careers. The coping behavior of compromise and non-coping behavior of career curiosity are discussed in this section.

Compromise. Compromise is refers to adjusting aspirations to accommodate an external reality (Gottfredson, 2002). Compromises that involve highly acceptable alternatives are not very complicated. However, when compromises involve the balancing between values and interests to identify the best options, they are seen more as choices than compromises (Gottfredson, 2002). The participants encountered both difficult and minor compromises, as well as choices. For example, for many of the participants, migration was a choice, made primarily by their parents. For others, migrating without the entire family (i.e., parents and siblings) was a compromise. When faced with major a compromise individuals tend to sacrifice interest. Carla sacrificed her 
interest in medicine to avoid entering what she perceived as an impersonal culture of doctor-patient relationship in U.S. Peter sacrificed his interest in journalism to avoid relocating his family. The compromise, as an adaptive dimension, was a common occurrence as the participants navigated their social and professional environments.

Career curiosity. Career curiosity refers to inquisitiveness in exploring the fit between self and work, information-seeking, and self-knowledge (Savickas, 2005). Career curiosity was not a pervasive adaptive mechanism for most of the participants. The participants came to the U.S. already knowing how they wanted to build their careers and remained in the same or similar occupational fields. Because of the lack of inquisitiveness or exploration, some participants (Gareth, Amy, Carla, Peter, Travis, and Angela) reported wasting a lot of time getting started in their new environment and venturing down the wrong career paths. Gareth said, "I wasted a little over year. I wrestled with what I was going to do. I looked at different catalogs. I looked at, you know, the different opportunities as far as degrees and stuff at Miami-Dade College" (lines 317-323). Gareth selected a career in management information only after using a computer for 1 hour. He said, "I probably spent no more than an hour on the computer in my whole life" (lines 322-323).

After arriving in the U.S., Peter said if he had known of the market structure for journalism in the U.S., he probably would have not completed a degree in journalism in the U.S. Peter did not realize that he would have to relocate to a smaller media market in order to increase his chances of becoming an on air personality or a reporter. Relocation was not an attractive option for Peter and his family, who preferred to live in South 
Florida. At the end of his college education, during his internship at a local television station, Peter came to this realization:

I should've done IT or computer science. That would have given me a better springboard for where I am now. It could've been an easier pathway to a new career. I should have just chosen then a new career as opposed to actually doing 4 years because in effect there is nothing I can do with the journalism degree except benefit from the training and the skill sets. (lines 1025-1030)

Peter returned to college and pursued a master's degree in computers and currently works in that field.

Limited exploration may be attributed to information poverty and information biases. Limited exposure to career choices often results in information poverty (Drummond \& Chell, 2001). Information poverty occurs in poor information environments. These environments tend to limit individuals' career choices because alternatives are neither explored nor contemplated (e.g., the common expectation to pursue a career in medicine or law). In these environments, alternatives are neither explored nor contemplated because individuals or societies succumb to information processing biases in their career choices (Drummond \& Chell, 2001).

The lack of career curiosity can result in naiveté about the work and the workplace and an inaccurate self-image. A possible explanation for the limited exploration or career curiosity among some of the participants in this study may have been the lack of financial resources upon arriving in the U.S. Limited resources may have restricted some of the participants from considering different career options because of the need to quickly integrate into the U.S. economic and occupation systems. For many participants, it was definitely less expensive to continue on the same educational/career path than to start a new career path in the U.S. The lack of career curiosity may have also 
resulted from the vast number of career options that were available to the participants when they first arrived in the U.S. Amy, Carla, and Gareth reported being overwhelmed by the many career possibilities.

Another possible explanation for the lack of career curiosity among some of the participants may have been the lack of mentoring before selecting a career path. When new immigrants enter the U.S., new information is often difficult to access because of the new social and occupational systems. Navigating new systems can be confusing and difficult. Most of the participants reported not having mentors. Gerald, who is a medical doctor, reported that he did not fully understand the daily routines of the job and life style beyond the job until he became a doctor in the U.S. Gerald also works as doctor in St. Croix. This was a classic case of information poverty. When I asked about being mentored by senior doctors, Gerald contended that the mentoring he received was mainly academic, rather than real world experiences about the daily routines of the occupation.

\section{Summary}

The comparison of the findings from the inductive and deductive analyses revealed associations between: (a) vocational influences and vocational personality, (b) adjustment challenges and life themes, (c) employment patterns and career adaptability, (d) career mobility patterns and career adaptability, and (e) career success perceptions and career adaptability. The comparison of findings also revealed career compromise as an adaptive dimension that participants also used. In the next chapter, the responses to the research questions and implications for research and practice are discussed. 


\section{CHAPTER VI}

\section{DISCUSSION}

This chapter is divided into three sections: (a) responses to the research questions (b) implications for research and practice, and (c) recommendations for future research.

\section{Responses to the Research Questions}

The discussion begins with responses to the secondary research questions followed by the response to the primary research question to conclude the section. Secondary Research Question 1: What factors do West Indian professionals believe influence their vocational behavior?

Several intrinsic factors (i.e., meaning of work and perceptions of knowledge) and extrinsic factors (i.e., family expectations, school system, and occupations status at arrival) influenced the participants' vocational behavior. These factors influenced the career-decision-making process, altered career paths, and shaped the participants' work preference.

However, individuals are not simply molded like clay by the social systems that influence their vocational behavior. Individuals are systems in their own right, with influences from their own subsystems such as ability, aptitudes, beliefs, self-concept, skills, personality, and values (Patton \& McMahon, 2006). Because individuals are part of a larger system, their life roles exist in relation to this large system (i.e., education institutions, workplace, community groups, family, peers, and the media; Patton \& McMahon, 2006). Therefore, "individuals are relational and construct their sense of self in relation to those around them" (p. 201). The participants' family system provided 
social support in the form of career advice, financial resources, and encouragement and their school system provided an academic structure that served the needs of society and reinforced the importance of having a career. There are several other contexts in which the participants' vocational behaviors can be conceptualized.

Bronfenbrenner (1977) identified four major subsystems that influence human behaviors: macrosystem, microsystem, mesosystem, and the exosystem. The macrosystem refers to "overarching institutional patterns of a culture or subculture, such as the economic, social, educational, legal, and political systems" (p.515). Microsystem "is a pattern of activities, roles, and interpersonal relations experienced by the developing person in a given setting with particular physical and material characteristics" (p.22). Mesosystem "comprises the interrelation among two or more settings in which the developing person actively participates (such as, for a child, the relations among home, school, and neighborhood peer group; for an adult, among family, work, and social life"; (p.25). The exosystem is an extension of the mesosystem and the external context in which both the microsystem and the mesosystem are embedded. Exosystem "refers to one or more settings that do not involve the developing person as active participants, but in which events occur that affect, or are affected by, what happens in the setting containing the developing person"( Bronfenbrenner, p.25). Collectively, all three systems present a person's ecosystem, where "career behaviors evolve from an ongoing interaction between the person and his or her environment" (Bieschke \& ToepferHendey, 2002, p. 356).

Within the context of Bronfenbrenner's (1977) four major subsystems, the factors that influenced the participants' vocational behavior may be explained or expressed as the 
following. The macrosystem may represent the global events that influenced the participants' vocational behavior (i.e., migration and globalization, which has lead to organizational restructuring and a protean orientation to career). The microsystem may represent the social constructs that influenced the participants' vocational behavior (i.e., minority status, ethnicity race, and class). The mesosystem may represent the personal and interpersonal contexts in which the participants construction their careers (i.e, family, school, and work and the interpersonal adaptive processes of career compromise, concern, control, and confidence). Finally, the exosystem may represent the participants' interaction with, experience in and expectations across the other three systems: macrosystem, mircosystem, and mesosystem (i.e., achieving the American Dream, career mobility, career success and social and professional integration). Hence, human behavior is also indicative of the cultural environment and experiences in that environment encountered. Culture "represents a somewhat distinct way of organizing its members' activities relative to their human and nonhuman environments" (Gottfredson, 2002, p.120) and the factors that influence individuals' vocational behavior tends to mobilize and reinforce some mixtures of personality and ability. However, culture "does not create the most basics differences among us (personality, physique, intelligence), but it both constrains and facilitates their expressions" (p. 121).

Secondary Research Question 2: What career adaptive mechanisms do West Indian professionals report using to integration into the U.S. occupational structures?

The participants negotiated their integration in several ways, namely through specific employment patterns: (a) underemployment, (b) higher education employment, (c) professional employment, (c) self-employment, and (d) and educational attainment. 
Underemployment is a common employment pattern for many new immigrants in the U.S. workforce; even if new immigrants' credentials resemble U.S. natives' credentials (Lowell, 2004). To integrate into the U.S occupational structure, many of the participants performed jobs that were either entry-level or part-time. Some of the women performed domestic work (i.e., housekeepers and babysitters) and some of men worked in various service sectors (i.e., retail and computer maintenance).

Working in higher education employment was the most common type of employment among the participants and a strategy to gain access to educational benefits. More than half of the participants reported working in an educational institution (i.e., college or university). Several participants continue to work in higher education in several professional capacities (i.e., instructors, professor, and information technology).

Professional employment was an essential adaptive mechanism because, unlike underemployment, it provided the participants greater personal and professional control over their lives. Self-Employment was an adaptive mechanism to gain personal and professional freedom and to establish a legacy. Consulting and owning private businesses were the common types of self-employment among the participants. Immigrants and ethnic groups tend to seek self- employment as used a strategy to mediate discrimination and the lack of opportunities.

Educational attainment is one of the key indicators of successful immigrant integration (Gozdziak \& Martin, 2004) and the participants were acutely aware of this fact. Continuous learning and acquiring new credentials were hallmarks of the participants' vocational behavior. Educational attainment provides mobility to better paying jobs and the ability to support one's self and family. 
Secondary Research Question 3: What processes do West Indian professionals report using to integrate into the U.S. occupational structures?

The participants used the processes of compromise, control, confidence, and concern for the future to integrate into the U.S. occupational structure. Compromise emerged as a process to control negotiable events and circumstances. Compromise manifested the adjustment of the participants' aspirations to accommodate their external realities (Gottfredson, 2002). For example, the participants' employment in entry-level jobs in order to integrate into society manifested as a compromise. Earning low-wages at higher educational institutions to gain access to educational benefits manifested as a compromise. However, experiential compromise occurs when individual encounter barriers in implementing their most-preferred choices. These barriers include family obligations, hiring practices, and the availability of specific employment.

Although the concept of compromise is not new to the career literature, it emerged as a key process of integration in this study. Gottfredson (2002) contends that the concept compromise has cross cultural career development relevance because it occurs as a function of perceived compatibility between an individual's occupational selfconcept and perceived accessibility of jobs. Perceptions of accessibility are grounded in information seeking and information exposure. The author believes that the notion of accessibility takes into consideration both information that individuals are exposed to and the information they themselves seek.

There are three principles that govern the accumulation and influence of information on accessibility (Gottfredson, 2002): (a) selective attention, (b) need to implement as spur to action, and (c) ease and proximity of search. Selective attention 
refers to attending to information concerning the accessibility of occupations that individuals deem appropriate for themselves and the alternatives within their perceived social space. The more preferred the occupation, the more likely the individual will attend to information about it. For example, Mary's persistence to become a U.S. certified nurse exemplifies her selective attention. Mary visited the U.S. several to learn more about certification progress to become a certified nurse s and worked several entrylevel jobs to sustain her life in the U.S. The need to implement a spur to action refers to attending to information close to the time of implementing one's occupation (i.e., graduation or migration to the U.S.). For example, Carla's indecision about what to do with her biology degree became clear, through advice, near the end of her studies. Her pending graduation forced her to consider an alternative to medical school, which was to become teacher. Ease and proximity of search refers to actively seeking information and advice on the primarily and most convenient sources of information. Hence, parents, family, teachers, colleagues, and others in individuals' social setting play an essential role in shaping one's perceptions of accessibility and suitability.

The participants' career concern for the future manifested as planning for the future roles, establishing contacts, and remaining marketable and employable. The participants' career confidence empowered them to construct their preferred careers and to overcome barriers. The participants' control over their careers afforded them ownership of their chosen futures.

Another process of integration was the participants' minimization of racial discrimination. The most salient intrapersonal process that the participants used to integrate into the U.S. occupational structure was to minimize the implications of racial 
discrimination. The participants were aware of the many attitudinal and structural barriers that exist in the U.S; but worked to succeed despite these barriers. A recent study reported that when West Indian immigrants were faced with the possibility of being tested based on their ability or merit; they increased rather than decreased their performance (Deaux et al., 2007). This increase in performance was attributed to West Indians' tendency to minimize the implications of racism through their behaviors and attributes.

These behaviors and attributes include West Indians' cultural views about their self-concept in relation or interaction with others groups. For example, the findings of two comparative studies that examined Black immigrants' attitudes with African Americans' attitudes found that cultural factors may explain why Black immigrants are less likely to perceive racial discrimination (Phelps, Taylor, Gerard, 2001; Phinney \& Onwughalu, 1996). One study revealed that Black immigrants have more positive attitudes toward other racial groups than African Americans and are less mistrustful of Whites than African Americans (Phelps et al., 2001). The other study revealed that Black immigrants were more likely to identify with the traditional American values, including justice, equal rights, and equal opportunity than African Americans (Phinney \& Onwughalu). The Black immigrants identify with these values because they tend to come from countries where traditional values of justice, equal rights, and equal opportunity are the cultural norm (Phinney \& Onwughalu). Hunter (2008) believes that these findings suggest that certain cultural values enable Black immigrants the ability to minimize racial discrimination. 
Primary Question: How do West Indian professionals perceive their career construction?

West Indian professionals perceive their career construction as the unfolding of their interests, capabilities, and self-concept from childhood to adulthood. The participants' perceived their formative years as the threshold of their vocational development and inception of their vocational personality. The participants perceived their ability to migrate, start over, and make sacrifices as their initial adaptive mechanisms. These perceptions were instrumental in the participants' integration into their new environment. The participants' readiness to take control of their career signified a sense of self-direction and a protean orientation for personal ownership of their future. The participants' readiness also signified a decisive attitude and ability to make career decisions about their vocational pursuits.

Although the participants were decisive in their vocational pursuits, from a developmental perspective, they were not inquisitive in their career exploration. For some participants, the lack of career curiosity limited career exploration and prompted unrealistic aspirations and expectations about certain occupations' rewards, routines, and requirements. A possible explanation for the participants' lack of exploration may be the participants' cognitive styles.

Studies on cognitive style indicate that individuals from cultures whose educational practices encourage uniformity and conformance to paternal authority and social norms tend to have cultural attributes that are associated with a field-dependent cognitive style (Witkin, 1979). Cognitive style is relevant because it relates to career decision-making style, more specifically, to dependent decision-making style. This 
decision-making style may account for the participants' limited career exploration or level career inquisitiveness. Decision-making style refers to a habitual pattern individuals use in decision making or individuals' characteristics model of perceiving and responding to decision-making tasks (Harren, 1979).

Career decision-making style is a key aspect of vocational behavior and career development (Harren 1979; Savickas, 2005; Super 1980). There are several different taxonomic classifications of decision-making tasks; among them is Harren's (1979) taxonomy of career decision-making styles. The classification consists of three styles: (a) rational (making decisions deliberately and logically); (b) intuitively (making decisions based on feelings and emotional satisfaction); and (c) dependent (making decisions based on the expectations and opinions of others).

Harren (1979) suggests that the most effective approach to decision-making is the use of a rational style. The participants were rational and deliberate in their approach to integration into the U.S. occupational structure and to achieve and maintain their career mobility and success. For example, some participants deliberately sought higher education employment to gain access to educational benefits, self employment to gain personal freedom, attended American based university to avoid re-credentialing in the U.S. Some participants used their intuition and spirituality to gain control and balance over their personal and professional life. They also made decisions based others' advice and suggestions in terms of career choice and mobility. Although career curiosity is known to stimulate the exploration of possible selves and occupations, it was not commonly used as an adaptive mechanism. However, the participants' career confidence or convictions mediated their limited career exploration. Their tenacious and efficacious 
attitudes and ability to solve their life themes (i.e., obstacles and challenges) mediated their encounter with relatively minimal negative career transition outcomes.

The participants perceived their vocational development as a birthright or entitlement, influenced primarily by family expectations, school experiences, and cultural norms. The participants' vocational developmental was the hallmark of their vocational behavior, that is, how they adapted and responded to their environment. Career adaptability, which entails distinct attitudes, beliefs, and competencies, influenced the strategies the participants used to align their vocational; self -concept with work. Some of these strategies include, balancing work and family, seizing opportunities, being optimistic, being deliberate in achieving career mobility success, and minimizing racial discrimination.

\section{Implications for Practice}

This study has implications for career and professional development in the fields of career counseling, adult education and human resource development. It contributes to the understanding of West Indian professionals' perceptions of their career construction and the factors that influence their career development. The findings relating to how the participants adapted to and coped with occupational changes and challenges support the need for adult educators and career and HRD practitioners to incorporate contextual factors and various life themes and roles into meaningful theoretical frameworks.

The findings relating to the intrinsic and extrinsic factors that influenced the participants' career decisions imply that educators and practitioners need to consider alternative career decision-making models and assessment techniques that are relevant to 
West Indians and other immigrants. For instance, many of the participants relied on a variety of ways of knowing, including spirituality, faith, family members, or friends, to make career and life decisions. Beyond the immediate family, extended family members and friends were instrumental in the participants' decision-making process. Too often in the career literature, the immediate family's influence is the primary focus (Chope, 2008) rather than extended family members, friends, peers, or colleagues. Furthermore, it was the participants' ability to delay their sense of gratification, minimize racial discrimination, and subjective meaning of success, rather than a traditional career decision-making styles and processes that allowed them to construct relatively successful careers.

These findings support the argument of this study that West Indian professionals' career experiences need to be explicitly reported to understand the specific career selection and adaptation processes of this group. By inquiring about all aspects of their students or clients' life, including family, community, sociocontextual factors, educators and practitioners not only increase their cultural competency, but are more likely to explore and use innovative assessment techniques that are relevant to this group. Examples of innovative assessment techniques include career narratives (Cochran, 1997) or career stories (Savickas, 2005) and career-o-gram (a tool that explores family and historical influences; Thorngren \& Feit, 2001). Based on the findings of this study, these assessment tools or strategies seem most beneficial when individuals need to re-author new stories that reflect their preferred ways of existing and navigating a new environment or society (Stebleton, 2007). These strategies may also encourage immigrants to talk 
about their own stories (Savickas, 2005; Stebleton, 2007), including, issues relating the loss occupational status, acculturation, and negotiating multiple identities.

The findings of this study also supports the agreement that HRD professionals need to revisit their roles and functions of the career development process to better serve immigrants and others who face obstacles in their career development Conlon (2003). This retrospect enables HRD professionals to increase their awareness of immigrants' career development and acknowledge the importance of updating today's version of career development to adapt to meet the social justice needs of minority groups. The findings of this study also support a broader focus of inquiry beyond the individual to include importance factors that contribute to an understanding of one's career development experiences, such as the role of family, community, history, sociocultural and political events, economic conditions, ethnic background, and community structure and size. The findings also imply that vocational behavior is dynamic and relational to many contextual factors that affect individuals' personal and professional lives.

The findings relating to participants' perceptions of competency (i.e., skills and abilities) imply that aptitude and a positive attitude of one's self-concept were influential factors that guided their career choices, including their protean orientation toward career development. Career choice involves selecting one occupation over another and is often constrained by sociocultural factors (Swanson \& Gore, 2000). Because these factors are often structural and attitudinal constraints, limiting access and opportunity, it is important that educators and career and HRD practitioners, and researchers explore the relationship of these factors to career choice. 
The findings also show that a protean orientation, or career self-management, was a common orientation among the participants. For example, the notion of work was not viewed in relation to its occupational structures; instead work was viewed in relation to the participants' personal and professional rewards and accomplishments. Work was a vehicle to exercise the participant's skills and abilities and to acknowledge their selfefficacy. For many of the participants, the American dream was realized though career self-management, self-efficacy, self-reliance, and the use of several nontraditional career decision-making processes to ensure a seamless career transition in the U.S. For the participants, career transition involved more than simply changing career; it also meant changing country. Educators, practitioners, and researchers must consider the context of career transition as it relates to immigrants.

The results of this study suggest that understanding West Indians and other immigrants' vocational behavior (i.e., responses, adaptation, and selection, etc.) is essential to explicate their conscious and unconscious processes, the components and requisite cognitive functions in their career decision-making; hence, the subjective and objective evaluations that these processes and functions produce (Patton \& McMahon, 2006).

Although career decision-making and construction cannot be explained in terms of models that apply to all individuals, Figure 4 shows the contextual factors that informed the participants' career construction. The direction of the arrows indicates the flow of perceived influences that the participants' reported using to construct their careers. 
Figure 4

A Visual Model of West Indian Professionals' Perceived Career Construction

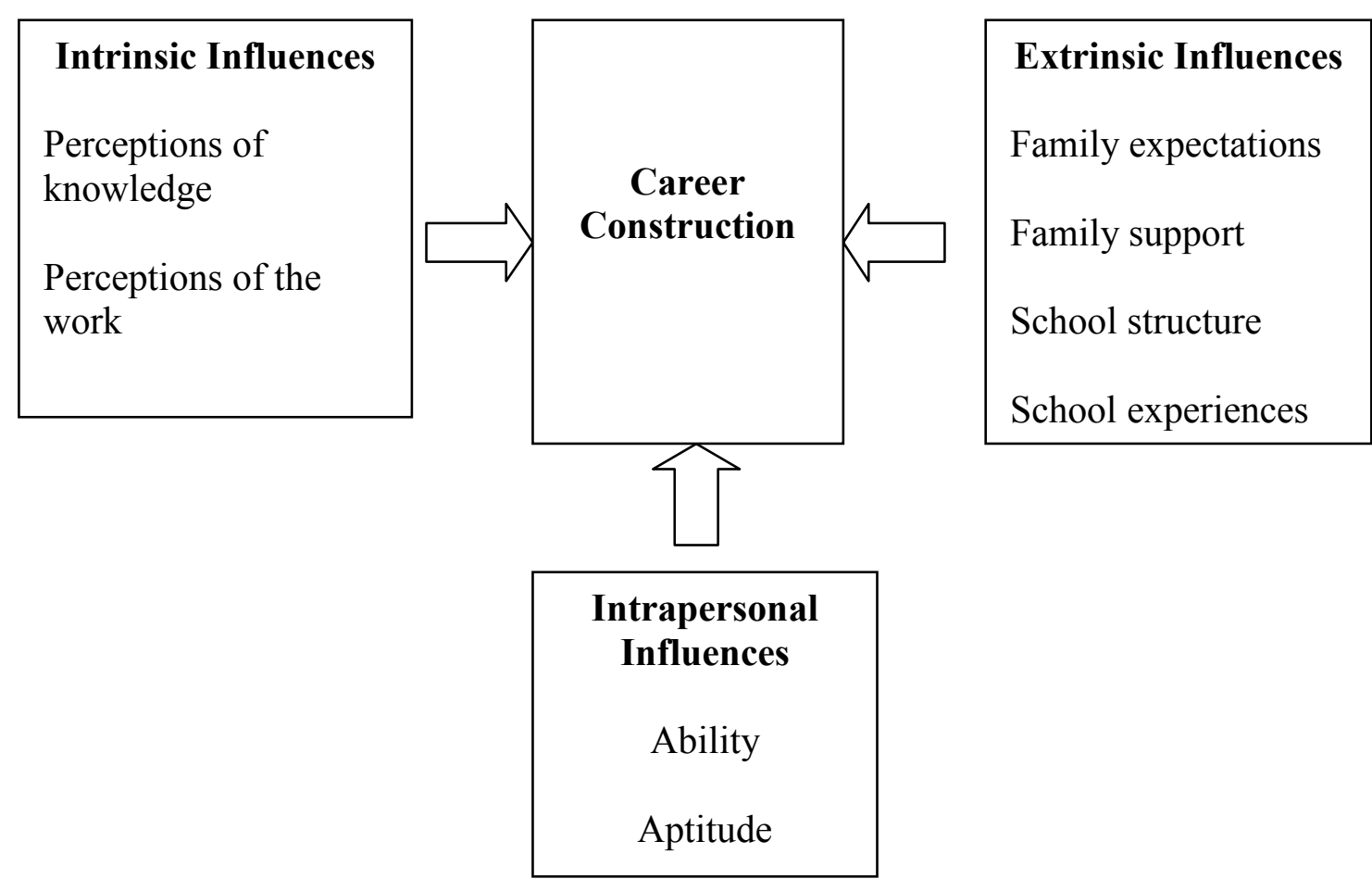

Recommendations for Future Research

Future research on immigrants' career development can build on the findings of this study. The findings in this study are by no means exhaustive and reflect the experiences of the 15 West Indian professionals in this study. Therefore, future research may include the following. First, a survey of a variety of immigrants groups to assess their individualistic and collectivistic orientations towards their career construction and development within the context of Savickas's theory of career construction. Second, an exploration of the influence of culture in career exploration in order to consider the role 
of work relative to other life roles including work-family and community interaction.

Third, an exploration of the influence of migration on career choice order to consider the role of career transition relative to acculturation and occupational integration. Fourth, an exploration of the influence of specific competencies on career exploration and choice in order to consider the role and source of self-efficacy in immigrants' career decisionmaking process, choices, and selection. Finally, an exploration of perceived self-concept across the four emergent employment patterns (i.e., underemployment, higher education employment, professional employment, and self-employment) in this study in order to further understand career identity and career motivation.

\section{Limitations of the Study}

The findings of this phenomenological study must be considered in the context of potential limitations. First, the research design relied on snowball sampling and selfreporting; therefore, the degree of association between the participants' responses and their true values, attitudes, and behaviors, behaviors were not assessed. Therefore, snowball recruitment strategy may have lead to self-selection bias in participants who identified with similar values, resulting in oversampling because of personal friendships and professional relationships. Second, when comparing individuals' perceptions across different professions or industries, the findings may yield different results; therefore, emergent themes from this study are not definitive.

\section{Summary}

Chapter 6 concluded the study with the responses to the research questions, implications for research and practice, and recommendations for future research. This phenomenological study sought to explore how West Indian professionals who are living 
in the U.S. perceived their career construction .The aim of the study was to understand the processes West Indian professionals use to integrate and orient themselves into the U.S. occupational structures. The study identified the influential factors of career choice and development and perceptions of adjustment and career adaptability.

Five themes emerged from the data collected through interviews with the participants. The themes are: vocational influences, adjustment challenges, employment patterns, career mobility patterns, and career success perceptions. The theory career of construction provided significant insights on specific adaptive dimensions that facilitated the participants' occupational integration.

The study provided implications for career counselors, career and human resource development practitioners and researchers. The study also recommended areas of future research that may extend the findings in this study. The study implies that career construction is not culturally neutral and that the exploration of other contextual factors helps to demystify the career construction process. 


\section{REFERENCES}

Alasuutari, P. (1998). An invitation to social research. Thousand Oaks: Sage

Publications.

Apospori, E., Nikandrou, I., \& Panayotopoulou, L. (2006). Mentoring and women's career advancement in Greece. Human Resource Development International, 9 (4), 509-527.

Arthur, M. B., \& Rousseau, D. M. (1996). The boundaryless career. A new employment principle for a new organizational era. New York: Oxford University Press.

Aycan, Z., \& Berry, J. W. (1996). Impact of employment-related experiences on immigrants' psychological well-being and adaptation to Canada. Canadian Journal of Behavioral Science, 28(3), 240-251.

Becker, P. C., \& Isaacs, J. (1996). A new American acculturation study five years later. Journal of Jewish Communal Service, 72, 360-398.

Bernstein, R.J. (1983). Beyond objectivism and relativism. Philadelphia: University of Pennsylvania Press.

Bhagat, R. S., \& London, M. (1999). Getting started and getting ahead: Career dynamics of immigrants. Human Resource Management Review, 9(3), 349-365.

Blustein, D. L. (2001). Extending the reach of vocational psychology: Toward an inclusive and integrative psychology of working. Journal of Vocational Behavior, $59,71-82$.

Blustein, D. L., \& Flum, H. (1999). A self-determine perspective of interests and exploration in career development. In M. L. Savakis \& A. R. Spokane (Eds.), Vocational interests: Meaning, measurement, and counseling use (pp. 345-368). Palo Alto, CA: Davies-Black.

Bronfenbrenner, U. (1977). The ecology of human development. Cambridge, MA: Harvard University Press.

Brown, D. (2002). Introduction to theories of career development and choice. Origins, evolution and current efforts. In D. Brown \& Associates (Eds.), Career choice and development ( $4^{\text {th }}$ ed., pp. 3-23). San Francisco: Jossey-Bass. 
Bryce-Laporte, R. S. (1994). New York City and the new Caribbean migration: A contextual statement. In C. R. Sutton \& E. M. Chaney (Eds.), Caribbean life in New York City: Sociocultural dimensions (pp. 51-69). New York: Center for Migration Studies.

Byster, D. (1998). A critique of career self-reliance. Career planning and adult development journal, 3, 17-27.

Chakiris, B. J., \& Fornaciari, G. M. (1984). Career integration: An understanding of employee roles, work group relation and organization structures. In Z. B. Leibowitz \& S. K. Hirsh (Eds.), Career development: Current perspectives (pp. 75-80). Washington, DC: American Society for Training and Development, Career Development Division.

Chope, R. (2006). Family matters: The influence of the family in career decision making. Austin, Texas: PRO-ED.

Chope, R. (2008). Practice and research in career counseling and development-2007. The Career Development Quarterly, 57(2), 98-173.

Cochran, L. (1997). Career counseling: A narrative approach. Thousand oaks, CA: Sage.

Collin, A., \& Young, R. A. (2000a). Introduction: Framing the future of career. In A. Collin \& R. Young (Eds.), The future of career (pp. 1-17). Cambridge, MA: Cambridge University Press.

Collin, A., \& Young, R. (2000b). The future of career. In A. Collin \& R. Young (Eds.), The future of career (pp. 276-298). Cambridge, MA: Cambridge University Press.

Cook, E. (1994). Role salience and multiple roles: A gender perspective. The Career Development Quarterly, 43, 85-95.

Conlon, T. J. (2003). Development of an operational definition of career development for the $21^{\text {st }}$ century workplace. In S. A. Lynham \& T. M. Egan (Eds.), Academy of Human Resource Development 2003 Conference Proceedings (pp. 489-493). Minneapolis, MN: Academy of Human Resource Development.

Creswell, J. W. (2003). Research design: Qualitative, quantitative, and mixed methods approaches $\left(2^{\text {nd }}\right.$ ed.). Thousand Oaks, CA: Sage.

Dawis, R. V., \& Lofquist, L.H. (1976). Personality style and the process of work adjustment. Journal of Counseling Psychology, 23, 55-59. 
Dawis, R.V. (2005. The Minnesota theory of work adjustment. In R.W. Lent \& S.D. Brown (Eds.), Career developing and counseling: Putting theory to work (pp.323). Hoboken, NJ: John Wiley.

Deaux, K. (2006). To be an immigrant. New York: Russell Sage Foundation.

Deaux, K., Bikmen, N., Gilkes, A., Vetuneac, A., Joseph, Y., Payne, Y., \& Steele, C. (2007). Becoming American: Stereotype type threat effects in Afro-Caribbean immigrant groups. Social Psychology Quarterly, 70, 384-404.

DeFillippi, R., \& Arthur, M. (1996). Boundaryless contexts and careers: A competencybased perspective. In M. B. Arthur \& D. M. Rousseau (Eds.), The boundaryless career (pp.116-132). New York: Oxford University Press.

Denzin, N. K., \& Lincoln, Y. S. (2003). Collecting and interpreting qualitative materials (2nd ed.). Thousand Oaks, CA: Sage.

Derr, C. B., \& Laurent, L. (1989). The internal and external career: A theoretical and cross-cultural perspective. In M. B. Arthur, D. T. Hall, \& B. S. Lawrence (Eds.), Handbook of career theory (pp. 454-471). New York: Cambridge University Press.

Dik, B. J., \& Duffy, R.D. (2009). Beyond the self: External influences in the career development process. The Career Development Quarterly, 58(1), 29-43.

Donohue, W., Donohue, R., \& Grimmer, M. (2007). Research into the psychological contract: Two Australian perspectives. Human Development International, 10 (3), 301-318.

Duffy, R. D. (2006). Spirituality, religion, and career development: Current status and future direction. The Career Development Quarterly, 55, 52-63.

Duffy. R. D., \& Blustein, D. L. (2005).The relationship between spirituality, religiousness, and career adaptability. Journal of Vocational Behavior, 67, 429440.

Duffy, R. D., \& Lent, R.W. (2008). Relation of religious support to career decision self efficacy in college Journal of Career Assessment, 16, 360-369.

Dunkle, J.H. (1996). Toward an integration of gay and lesbian identity development and Super's life-span approach. Journal of Vocational Behavior, 48,149-159.

Drummond, H., \& Chell, E. (2001). Life's chances and choices: A study of entrapment in career decisions with reference to Becker's side bets theory. Personnel Review, 30 (2), 186-202. 
Eby, 1.T., \& Buch, K. (1995). Job loss as career growth: Responses to involuntary career transitions. Career Development. Quarterly, 44(1), 26-42.

Egan, T. M., Upton, M. G., \& Lynham, S. A. (2006). Career development: Load-bearing wall or window dressing? Exploring definitions, theories, and prospects for HRDrelated theory building. Human Resource Development Review, 5, 442-477.

Ellison, R. (1992). Invisible man. New York: Modern Library.

Florida International University Regulations for Thesis/Dissertation Preparation Manual (Fall 07 Edition). Retrieved June 30, 2008, from http://gradschool.fiu.edu/thesis.html

Farmer, H. (1987). Diversity and women's career development. London: Sage Publications.

Foner, N. (2001). Benefits and burdens: Immigrant women and work in New York City. In R. J. Simon (Ed.), Immigrants women (pp.1-20). New Brunswick, NJ: Transition.

Fouad, N. A., \& Byars-Winston, A. M. (2005). Cultural context of career choice: Metaanalysis of race/ethnicity differences. The Career Development Quarterly, 53(3), 223-233.

Fukuyama, M.A., \& Ferguson, A.D. (2000). Lesbian, gay, and bisexual people of color: Understading cultural complexity and managing multiple oppressions. In R. Perez, K. DeBord, 7 K.J. Bieschke (Eds.), Handbook of counseling and psychotherapy with lesbian, gay, and bisexual clients (pp.81-106). Washington, D.C: American Psychology Association.

Gati, I., Krausz, M., \& Osipow, S.H. (1996). A taxonomy of difficulties in career decision-making difficulties questionnaire: Counselee versus career counselor perceptions. Journal of Vocational Behavior, 56, 99-113.

Gibson, S. K., \& Hanes, L. A. (2003). The contribution of phenomenology to HRD research. Human Resource Development Review, 2(2), 181-205.

Gilley, J. W., Eggland, S. A., \& Gilley, A. M. (2002). Principles of human resource development (2nd ed.). Cambridge, MA: Perseus Books.

Ginzberg, E. (1972). Toward a theory of occupational choice: A restatement. Vocational Guidance Quarterly, 20, 169-176. 
Giorgi, A. (1997). The theory, practice, and evaluation of the phenomenological method as a qualitative research procedure. Journal of Phenomenological Psychology, 28 (2), 235-260.

Gottfredson, L. S. (1981). Circumscription and compromise: A development theory of occupation aspirations. Journal of Counseling Psychology, 28, 545-579.

Gottfredson, L. S. (1986). Special groups and the beneficial use of vocational interest inventories. In W.B. Walsh and S. H. Osipow (Eds.), Advances in vocational psychology: Assessment of interests (pp. 127-198). Mahwah, NJ: Erlbaum.

Gottfredson. L.S. (2002). Gottfredson's theory of circumscription, compromise, and selfcreation. In Brown \& Associates, Career choice and development (pp. 85-148). San Franciso, CA: Jossey Bass.

Gozdziak, E. M., \& Martin, S. F. (2004, June 28-29). The economic integration of immigrants in the United States: A review of the literature. Papers prepared for the U.S. -EU seminar: Integrating immigrants into the workforce: North American and European experiences (pp. 1-20). Washington, DC. Congress of the U.S., Department of Labor.

Graves, T. (1967). Psychological acculturation in a tri-ethnic community. South-Western Journal of Anthropology, 23, 337-350.

Greenhaus, J.H. and Parasuraman, S. (1994), "Work-family conflict, social support, and well-being", in Davidson, M.J. and Burke, R.J. (Eds), Women in Management: CurrentResearch Issues, Paul Chapman, London, pp. 213-29.

Greenhaus, J. H. (2003). Career dynamics. In W. C. Borman, D. R. Ilgen, \& R. J. Klimoski (Eds.), Handbook of psychology, industrial and organizational psychology (pp. 220-240). New York: Wiley.

Greenhaus, J.H., \& Powell, G.N. (2006). When work and family are allies: A theory of work family enrichment. Academy of Management Review, 31, 72-92.

Guest, G., Bunce, A., \& Johnson, L. (2006). How many interviews are enough? An experiment with data saturation and variability. Field Methods, 18(1), 59-82.

Guthrie, G. M., \& Tanco, P. P. (1980). Alienation. In H. C. Traindis \& J. G. Draguns (Eds.), Handbook of cross-cultural psychology (pp. 9-61). Boston: Allyn \& Bacon. 
Gutteridge, T. G. (1984). Linking career development and human resource planning. In Z. B. Leibowitz \& S. K. Hirsh (Eds.), Career development: Current perspectives (pp. 22-28). Washington, DC: American Society for Training and Development, Career Development Division.

Gutteridge, T. G., \& Otte, F. L. (1983). Organization career development: What's going on out there? Training and Development Journal, 37(2), 22-26.

Hansen, S. L. (2001). Integrative Life Planning: Critical tasks for career development and changing life patterns. San Francisco, CA: Jossey-Bass.

Hall, D. T. (1976). Career in organizations. Pacific, CA: Goodyear.

Hackett, G., Lent, R. W., \& Greenhaus, J. H. (1991). Advances in vocational theory and research: A 20-year retrospective. Journal of Vocational Behavior, 38, 3-38.

Henke, H. (2001). The new Americans: The West Indian Americans. New York: AMS Press.

Herriot, P., Manning, W., \& Kidd, J. (1997). The content of the psychological contract. British Journal of Management, 8, 151-162.

Hirsch, P. (1987). Pack your own parachute. Reading, MA: Addison -Wesley.

Ho, C. T. (1999). Caribbean transnationalism as a gendered process. Latin American Perspectives, 26(5), 34-54.

Hofstede, G. (1980). Culture's consequences: International differences in work-related values. Beverly Hills, CA: Sage.

Holland, J.L. (1959). A theory of vocational choice. Journal of Counseling Psychology, $6,35-44$.

Holland, J. L. (1985). Making vocational choices: A theory of personality and work environments (2nd ed.). Englewood Cliffs, NJ: Prentice-Hall.

Holland, J. L. (1997). Making vocational choices: A theory of vocational personalities and work environments (3rd ed.). Odessa, FL: Consulting Psychology Press.

Hotchkiss, L., \& Borrow, H. (1996). Sociological perspectives on work career development. In D. Brown, L. Brooks, \& Associates (Eds.), Career choice and development ( $3^{\text {rd }}$ ed., pp.281-334).

Hunter, C.D. (2008). Individualistic and collectivistic worldviews: Implications for understanding perceptions of racial discrimination in African Americans and British Caribbean Americans. Journal of Counseling Psychology, 55(3), 321-32. 
Ishiyama, F. I. (1989). Understanding individuals in transition: A self-validation model. Canadian Journal of School Psychology, 4, 41-56.

Ismail, M., \& Rasdi, R. M. (2007). Impact of networking on career development: Experience of high-flying women academics in Malaysia. Human Resource Development International, 10 (2), 153-168.

Janesick, V. J. (2004). Stretching exercise for qualitative researchers ( ${ }^{\text {nd }}$ ed.). Thousand Oaks: Sage.

Johnson, M. K., \& Mortimer, J. T. (2002). Career choice and development from a sociological perspective. In D. Brown \& Associates (Eds.), Career choice and development ( $4^{\text {th }}$ ed., pp. 37-81). San Francisco: Jossey-Bass.

Kim, N., \& McLean, G. (2008). Stability and dominance in career success orientation in South Korean employees. Human Resource Development International, 11(1), 19-34.

Kirkman, B. L., \& Shapiro, D. L. (2001). The impact of cultural values on job satisfaction and organizational commitment in self-managing work teams: The mediating role of employee resistance. Academy of Management Journal, 44(3), $557-569$.

Krumboltz, J.D. (1979). A social learning theory of career decision making. In A. M. Mitchell, G. B. Jones \& J. D. Krumboltz (Eds.), Social learning and career decision making (pp. 19-49).

Kvale, S. (1996). Interviews: An introduction to qualitative research interviewing. Thousand oaks, CA: Sage.

Ladson-Billings, G. (1999). Just what is critical race theory and what is it doing in a nice field like education? In L. Parker, D. Deyhle, \& S. Villeans (Eds.), Race is ...race isn't: Critical race theories and qualitative studies in education (pp. 7-30). Boulder, CO: West View.

Ladson-Billings, G. (2000). Racialized discourses and ethnic epistemologies. In N. K. Denzin \& Y. S. Lincoln (Eds.), The handbook of qualitative research (2nd ed., pp. 257-278). Thousand Oaks: Sage

Lau, V. P., \& Shaffer, M. A. (1999). Career success: The effects of personality. Career Development International, 2(1), 245-253.

Lee, G., \& Westwood, M. J. (1996).Cross-cultural adjustment issues faced by immigrant professionals. Journal of Employment Counseling, 33, $29-42$. 
Levine, B. B. (1987). Surplus populations: Economic migrants and political refugees. In B. Levine (Ed.), The Caribbean exodus (pp. 5-14). New York: Praeger.

Lincoln, Y. S., \& Guba, E. G. (1985). Naturalistic inquiry. Newbury Park, CA: Sage.

Lowell, L. (2004, June). Immigrant labor market assimilation in the United States: A critique of census data and longitudinal outcomes. Papers prepared for the U.S. EU Seminar: Integrating immigrants into the workforce: North American and European experiences (pp. 1-7). Washington, DC: Congress of the U.S., Department of Labor.

Maguire, H. (2002). Psychological contracts: Are they still relevant? Career Development International, 7(3), 167-180.

Marshall, D. (1987a). A history of West Indians migration: Overseas opportunities and "safety-valve" policies. In B. Levine (Ed.), The Caribbean exodus (pp. 15-31). New York: Praeger.

Marshall, P. (1987b). Black immigrant women in brown girl, brownstones. In C. Sutton and E. Chaney (Eds.), Caribbean New York City: Sociocultural Dimensions (pp.81-85). Staten Island: Center for Migration Studies of new York.

McDonald, K. S., \& Hite, L. M. (2005). Reviving the relevance of career development in human resource development. Human Resource Development Review, 4(4), 418439.

McDonald, K. S., \& Hite, L. M. (2008). The next generation of career success: Implication for HRD. Advances in Developing Human Resources, 10(1), 86-103.

McGrath, J. E. (1976). Stress and behavior in organization. In M. D. Dunnette (Ed.), Handbook of industrial and organizational psychology (pp. 1351-1395). Chicago: Rand McNally.

McIntosh-Alberts, M. (2001). Patterns of informal networking and upward career mobility: A comparative analysis of African American and black immigrant women from Africa and the Caribbean. Dissertation Abstracts International, 62 (12), p. 4346. (UMI No. 3036366)

McLagan, P. A. (1989). The models. A volume in models for HRD practice. Alexandria, VA: American Society for Training and Development.

Mclean, G. N., \& Mclean, L. (2001). If we can't define HRD in one country, how can we define it in an international context? Human Resource Development International, $4(3), 313-326$. 
Merriam, S. B. (1998). Qualitative research and case study application in education. San Francisco: Jossey-Bass.

Mihail, D. (2008). Proactivity and work experience as predictors of career-enhancing strategies. Human Resource Development International, 11(5), 523-537.

Miles, M. B., \& Huberman, A. M. (1994). An expanded sourcebook: Qualitative data analysis. Thousand Oaks, CA: Sage.

Mitchell, L.K. \& Krumboltz, J .D. (1990). Social learning approach to career decision making: Krumboltz's theory. In D. Brown \&L. Brooks (Eds.), Career choice and development: Applying contemporary theories to practice ( $2^{\text {nd }}$ ed., pp.145-196). San Francisco: Jossey-Bass.

Moghaddam, F., Taylor, D.M., \& Wright, S.C. (1993). Social psychology in crosscultural perspective. New York: W.H. Freeman and Company.

Moustakas, C. (1994). Phenomenological research methods. Thousand Oaks, CA: Sage.

Ogbu, J. U. (1991). Immigrant and involuntary minorities in comparative perspective. In M. A. Gibson \& J. U. Ogbu (Eds.), Minority status and schooling: A comparative study of immigrant and involuntary minorities (pp. 3-33). New York: Garland.

O'Doherty, D., \& Roberts, I. (2000). Careers or slide? Managing on the threshold of sense. In A. Collin \& R. Young (Eds.), The future of career (pp. 144-162). Cambridge, MA: Cambridge University Press.

Osipow, S.H. (1990). Convergence in theories of career choice and development. Journal of Vocational Behavior, 36, 122-131.

Parson, F. (1909). Choosing a vocation. Boston, MA: Houghton Mifflin.

Patton, M. Q. (2002). Qualitative research \& evaluation methods ( $3^{\text {rd }}$ ed.). Thousand Oaks, CA: Sage.

Patton, W., \& McMahon, M. (2006). Career development and systems theory $\left(2^{\text {nd }}\right.$ ed.). Rotterdam, The Netherlands: Sense Publishers.

Pennington, D.L. (1990). Time in African culture. In M. K. Astante \& K.W. Astante (Eds.), African culture: The rhythms of unity (pp.123-139). Trenton, NJ: African World Press.

Phelps, R. E., Taylor, J.D., \& Gerard, P.A. (2001). Cultural mistrust, ethnic identity, racial identity, and self-esteem among ethnically diverse Black studies. Journal of Counseling \& Development, 79, 209-216. 
Phinney, J. (1996). When we talk about American ethnic groups, what do we mean? American Psychologist, 51(9), 918-927.

Phinney, J.S., \& Onwughalu, M. (1996). Racial identity and perception of American ideals among African American and African students in the United States. International Journal of Intercultural Relations, 20, 127-140.

Poon, J. M. L.(2004). Career commitment and career success: Moderating role of emotion perception. Career Development International, 9, 374-386.

Poole, M. E., \& Langan-Fox, J. (1993). Contrasting subjective and objective determinants of career success: A longitudinal study. Journal of Occupational and Organizational Psychology, 66(1), 39-55.

Poole, M. E., \& Langan-Fox, J. (1997). Australian women and their careers: Psychological and contextual influences over the life course. Melbourne, Australia: Cambridge University Press.

Poole, M. E., Langan-Fox, J., \& Omodei, M. (1990). Sex differences in subjective career success. Genetic Social, and General Psychology Monographs, 117, 175-202.

Portes, A., \& Zhou, M. (2003). Should immigrants assimilate? In J. Kromkowski (Ed.) Annual editions: Race and ethnic relations (pp.67-83). Guilford, Connecticut: McGraw-Hill/Dushkin.

Pope, M. (2003). Career counseling in the twenty-first century: Beyond cultural encapsulation. The Career Development Quarterly, 52, 54-60.

Preskill, H., \& Donaldson, S. I. (2008). Improving the evidence base for career development programs: Making use of the evaluation profession and positive psychology movement. Advances in Developing Human Resources, 10(1), 104121.

Pringle, J.K., \& Mallon, M. (2003). Challenges for the boundaryless career odyssey. International Journal of Human Resource Management, 14, 839-853.

Queeney, D. S. (2000). Continuing professional education. In A. L. Wilson \& E. R. Hayes (Eds.), Handbook of adult and continuing education (pp. 376-377). San Francisco: Jossey-Bass.

Race, K. E. H., Masini, B. E., \& Sheffey, S. (1996). Linking vocational service to early employment among Soviet refugees. Journal of Jewish Communal Service, 72, 282-289. 
Ragins, B.R., \& Cotton, J.L. (1999).Mentor functions and outcomes: A comparison of men and women in formal and informal mentoring relationships. Journal of Applied Psychology, 84, 529-550.

Richardson, M.S. (2001). New perspectives for counseling psychologists. The Counseling Psychologist, 29, 271-278.

Rivera, L. M., Chen, E. C., Flores, L. Y., Blumberg, F., \& Ponterrotto, J. G. (2007). The effects of perceived barriers, role models, and acculturation on the career selfefficacy and career consideration of Hispanics women. The Career Development Quarterly, 56, 47-61.

Robert, K. (1977). The social conditions, consequences and limitations of career guidance. British Journal of Guidance and Counseling, 5, 1-9.

Rothenberg, P. S. (2001). Race, class, and gender in the United States (5 $5^{\text {th }}$ ed.). New York: Worth Publishers.

Rousseau, D. M. (1995). Psychological contracts in organizations. Thousand Oaks, CA: Sage.

Rowold, J. (2007). The impact of personality on training-related aspects of motivation: Test of a longitudinal model. Human Resource Development Quarterly, 18(1), 931.

Rubin, H. J., \& Rubin, I. S. (2005). Qualitative interviewing: The art of hearing data $\left(2^{\text {nd }}\right)$. Thousand Oaks, CA: Sage.

Savickas, M.L. (1995). Current theoretical issues in vocational psychology: Convergence, divergence, and schism. In W. B. Walsh \& S. H. Osipow (Eds.), Handbook of vocational psychology (pp. 1-34). Mahwah, NJ: Erlbaum.

Savickas, M.L. (2000). Renovating the psychology of career for the twenty-first century. In C. A., Collin \& R.A. Young (Eds.), The future of career (pp. 53-83). Edlinburgh Building: Cambridge University Press

Savickas, M.L. (2001). Towards a comprehensive theory of career development: Dispositions, concerns and narratives. In F.T.L. Leong \& A. Barak (Eds.), Contemporary models in vocational psychology: A volume in honor of Samuel $H$. Osipow (pp. 295-320). Mahwah, NJ: Lawrence Erlbaum.

Savickas, M. L. (2002).Career construction: A development theory of vocational behavior. In D. Brown \& Associates (Eds.), Career choice and development $4^{\text {th }}$ ed., pp. (149-205). San Francisco: Jossey-Bass. 
Savickas, M. L. (2005). The theory and practice of career construction. In S. B. Brown \& W. Lent (Eds.), Career development and counseling: Putting theory and research to work (pp. 42-70). Hoboken, NJ: John Wiley.

Schoon, I., Ross, A., Martin, P. (2007). Science related careers: Aspirations and outcomes in two British cohort studies. Equal Opportunity International, 26, 2, 129-143.

Schram, T. H. (2003). Conceptualizing qualitative inquiry: Mindwork for fieldwork in education and the social sciences. Upper Saddle River, NJ: Merrill Prentice Hall

Schlossberg, N.K. (1981). A model for analyzing human adaptation to transition: Counseling Psychologist, 9, 2, 2-18.

Schuler, R. S. (1980). Definitions and conceptualization of stress in organization. Organizational Behavior and Human Performance, 25, 184-215.

Schulenberg, J. E., Vondracek, F. W., \& Crouter, A. C. (1984). The influence of the family on vocational development. Journal of Marriage and the Family, 46, 129143.

Schultheiss, D.E.P. (2003). The interface of work and family life. Professional Psychology: Research and Practice, 37, 334-341.

Seibert, S. E., Crant, J. M., \& Kraimer, M. L. (1999). Proactive personality and career success. Journal of Applied Psychology, 84, 416-427.

Shea, M., Ma, P., \& Yeh, C. (2007). Development of a culturally specific career exploration group of urban Chinese immigrant youth. The Career Development Quarterly, 56, 56-73.

Simonsen, P. (1997). Promoting a development culture in your organization. Palo Alto: Davis-Black.

Smart, R. M. (1998). Career stages in Australian professional women: A test of Super's model. Journal of Vocational Behavior, 52, 379-395.

Stead, G. B., \& Watson, M. B. (1998). Career research in South Africa: Challenges for the future. Journal of Vocational Behavior, 52, 289-299.

Stebleton, M. (2007). Career counseling with African immigrant college students: Theoretical approaches and implications for practice. The Career Development Quarterly, 55, 290-310. 
Storey, J. (2001). "Fractures lines" in the career environment. In A. Collin \& R. Young (Eds.), The future of career (pp. 21-36). Cambridge, MA: Cambridge University Press.

Strauss, A., \& Corbin, J. (1998). Basics of qualitative research ( $2^{\text {nd }}$ ed.). Thousand Oaks, CA: Sage.

Sue, D. W., \& Sue, D. (1990). Counseling the culturally different: Theory and practice. New York: Wiley.

Super, D. E. (1980). A life-span, life-space approach to career development. Journal of Vocational Behavior, 13, 282-298.

Super, D. E. (1990). A life-span, life-space approach to career development. In D. Brown $\&$ L. Brooks (Eds.), Career choice and development: Applying contemporary theories to practice $\left(2^{\text {nd }}\right.$ ed., pp.197-261). San Francisco: Jossey-Bass.

Swanson, J. L., \& Gore, P. A., Jr. (2000). Advances in vocational psychology theory and research. In S. D. Brown \& R. W. Lent (Eds.), Handbook of counseling psychology ( $3^{\text {rd }}$ ed., pp. 233- 269) New York: Wiley.

Swanson, R. A., \& Holton, E. F., III. (2001). Foundations of human resource development. San Francisco: Berrett-Koehler.

Tharmaseelan, N. (2008). Migrants' adjustment to career: An analysis in relation to Nicholson's Theory. Australian Journal of Career Development, 17(1), 11-19.

Thijssen, J., Van Der Hijden, B. I., \& Rocco, T. (2008). Toward the employability link model: Current employment transition to future employment perspectives. Human Resource Development Review, 7(2), 165-183.

Thomas, C. Y. (1988). The poor and the powerless. New York: Monthly Review Press.

Thorngren, J.M., \& Feit, S.S. (2001). The career-o-gram: A postmodern career intervention. The Career development Quarterly, 49, 291-303.

Tress, M. (1996). Refugees as immigrants: Revelations of labor market performance. Journal of Jewish Communal Service, 72, 263-281.

Ulrich, W. L., Richards, P. S., 7 Bergin, A.E. (2000). Psychotherapy with Latter-Day Saints. In P. S. Richards \& A. E. Bergin, (Eds.), Handbook of psychotherapy and religious diversity (pp. 185-209). Washington: American Psychological Association. 
U.S. Bureau of Labor Statistics. (2005). Labor force characteristics of foreign-born workers. Retrieved June, 10, 2008, fromhttp://bls.gov/news.release/forbrn.nr0.htm

U.S. Bureau of the Census. (2000). Statistical abstract of the United States $2000\left(120^{\text {th }}\right.$ ed.). Washington, DC: U.S. Government Printing Office.

U.S. Bureau of the Census. (2002). March 2002 current population survey: The foreignborn population in the United States. Washington, DC: U.S. Department of Commerce.

U.S. Bureau of the Census. (2005). Current population survey: 2005 annual social and economic supplement. Washington, DC: U.S. Department of Commerce.

Van Dijk, M. S. (2004). Career development within HRD: Foundation or fad? In T. M. Egan, M. L. Morris, \& V. Inbakumar (Eds.), Academy of Human Resource Development Conference Proceedings (pp. 771-778). Bowling Green, OH: Academy of Human Resource Development.

Vermeulen, M., \& Minor, C. (1998). Context of career decisions: Women reared in a rural community. The Career Development Quarterly, 46(3), 230-245.

Vondracek, F. W. (2001). The developmental perspective in vocational psychology. Journal of Vocational Behavior, 59, 252-261.

Vondracek, F. W., Lerner, R. M., \& Schulenberg, J. E. (1986). Career development: A life-span development approach. Hillsdale, NJ: Erlbaum.

Vondracek, F. W., Lerner, R. M., \& Schulenberg, J. E. (1983), The concept of development in vocational theory and intervention. Journal of Vocational Behavior, 23, 179-202.

Waldinger, R. (2001a). Up from poverty? "Race", immigration, and the fate of lowskilled workers. In R. Waldinger (Ed.), Strangers at the gates: New immigrants in urban America (pp. 80-116). Berkeley, CA: University of California Press.

Waldinger, R. (2001b). Strangers at the gates. In R. Waldinger (Ed.), Strangers at the gates: New immigrants in urban America (pp. 1-29). Berkeley, CA: University of California Press.

Walsh, W. B. (2001). The changing nature of the science of vocational psychology. Journal of Vocational Behavior, 59, 262-274.

Waters, M. C. (1999). Black identities. Cambridge, MA: Harvard Press Review. 
Werner, E.E. (1993). Risk, resilience, and recovery: perspective from the Kauai longitudinal study. Development and Psychopathology, 5, 503-515.

Westwood, M. J., \& Ishiyama, F. I. (1991). Challenges in counseling immigrant clients: Understanding intercultural barriers to career adjustment. Journal of Employment Counseling, 28, 130-143.

Young, R., Marshall, S., \& Valach, L. (2007). Making career theories more culturally sensitive: Implication for counseling. Career Development Quarterly, 56(1), 418.

2006-2008 American community survey 3-Year estimates. Retrieved November 30, 2009, from http://factfinder.census.gov/servlet/ datasetmainpageservlet? program $=$ acs 


\section{APPENDIX A}

Semi- structured Interview Guide

\section{Background Information}

1. Where were you born?

2. Tell me about your reason(s) for migrating.

3. Who accompanied you when you first arrived in the U.S.?

3. How old were you when arrived?

4. What city did you migrate to?

5. What was your immigration status upon arrival?

6. How long have you lived in the U.S.?

7. How long have you lived in South Florida?

\section{Education and Employment}

8. Tell me about your educational level when you arrived in the U.S.

9. Tell me about your current educational level.

10. Tell me about your career progression after college.

11. Tell me about your current profession.

12. How long have you been in this profession?

13. Tell me how you came to work in this profession.

14. Do you consider yourself a professional?

\section{Career Influences, Experiences, and Perceptions}

15. Tell me about the people that influenced your career.

16. Tell me about the events that influenced your career.

17. Tell me how your country of origin influenced your career decisions. 


\section{APPENDIX A (cont'd)}

Semi- structured Interview Guide

18. Tell me how the U.S. influenced your career decisions.

19. Tell me about the values, attitudes or beliefs that guided your career choices.

20. Tell me about the transitions in your life that guided your career behavior.

22. Tell me about your support system.

23. How do you maintain a sense of career tenacity to purse your career aspirations?

24. How do you define career failure?

25. How do you define career success?

26. Are there any questions that I did not ask that I should have?

27. Do you have anything you would like to add? 


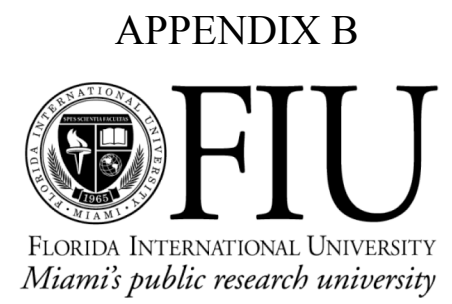

\section{CONSENT TO PARTICPATE IN AN INTERVIEW}

\section{Title: A Phenomenological Exploration of how West Indian Professionals in South Florida Perceive yheir Career Construction}

You are being asked to be in a research study. The investigator of this study is Judith Bernier and she is a student at Florida International University. This study will include 15 West Indian professionals, who live and/or work in South Florida. Your participation will require 1-2 hours of your time to participate in a structured interview. The purpose of the study is to explore your perceptions of your career construction to understand the meaning you impose on your vocational behavior. If you decide to be a part of this study, you will participate in a digitally recorded interview. The face-to-face interview will be guided by a list of questions. You will be asked to answer questions about your perceptions of your career and its development. We do not expect any harm to you by being in the study. You may skip any questions that you do not want to answer. If you get upset or feel discomfort during the interview, you may ask to take a break. You will get no direct benefit from being in the study. Rather, your participation will help to inform us about the contextual factors that influence West Indian professionals' career construction and to provide insights in their career and career development processes. All your responses to the interview questions will remain anonymous and confidential. Your digital voice file and transcribed interview will be identified with a random number, not your name. All of your answers are private and will not be shared with anyone unless required by law. Your data will be compiled with the data of the other participants. I will present the research results as a group. You may ask questions about the study at any time. If you choose not to participate no one will be upset with you. You may choose to stop your participation before you finish the individual interview. If you would like more information about this research after you are done, you can contact me at jbni01@yahoo.com. If you would like to talk with someone about your rights of being a subject in this study, you may contact Dr. Patricia Price, the Chairperson of the FIU Institutional Review Board at 305-348-2618 or 305-348-2494. Dr. Price is the designated person to receive calls from all research participants regarding the rights of human subjects.

Your signature below indicates that all of your questions have been answered to your liking. You are aware of your rights and you would like to be in the study.

$\overline{\text { Signature of Participant }} \quad$ Printed Name $\quad \overline{\text { Date }}$

I have explained the research procedure, participant rights and answered questions asked by the participant. I have offered him/her a copy of this informed consent form.

Signature of Witness

Date 


\section{APPENDIX C}

Coding Rubric

\begin{tabular}{|c|c|c|c|}
\hline Codes & $\begin{array}{l}\text { Key Tenets } \\
\text { of Career } \\
\text { Construction }\end{array}$ & Characteristics & Definitions \\
\hline VP & $\begin{array}{l}\text { Vocational } \\
\text { Personality }\end{array}$ & $\begin{array}{l}\text { Originates from rehearsed } \\
\text { activities, house hold chores, } \\
\text { games, hobbies, reading, } \\
\text { studying, etc. }\end{array}$ & $\begin{array}{l}\text { Vocational personality } \\
\text { refers to individuals' } \\
\text { career-related abilities, } \\
\text { values, and interest that } \\
\text { form the basis for the } \\
\text { what in their career } \\
\text { construction. }\end{array}$ \\
\hline $\mathrm{CA}$ & $\begin{array}{l}\text { Career } \\
\text { Adaptability }\end{array}$ & $\begin{array}{l}\text { Views career development } \\
\text { and construction as } \\
\text { environmental rather than } \\
\text { maturation process. } \\
\text { Reflective of today's } \\
\text { knowledge-based society. }\end{array}$ & $\begin{array}{l}\text { Career adaptability } \\
\text { refers to individuals' } \\
\text { career-related coping } \\
\text { mechanisms or } \\
\text { processes that form the } \\
\text { basis for the how in } \\
\text { their social and } \\
\text { occupational } \\
\text { integration. }\end{array}$ \\
\hline $\mathrm{CCN}$ & Career Concerns & $\begin{array}{l}\mathrm{CCN}, \mathrm{CCL}, \mathrm{CCY} \text {, and } \mathrm{CCE} \\
\text { represent four adaptive } \\
\text { dimensions individuals use to } \\
\text { manage critical tasks, } \\
\text { transitions, and traumas. }\end{array}$ & $\begin{array}{l}\text { Career concern refers } \\
\text { to concerns about one's } \\
\text { vocational future in } \\
\text { terms of time a } \\
\text { perception (Ginzberg, } \\
\text { 1972), anticipation } \\
\text { (Tiedeman,1984) and } \\
\text { orientation } \\
\text { (Crites,1969). }\end{array}$ \\
\hline $\mathrm{CCL}$ & Career Control & & $\begin{array}{l}\text { Career control refers to } \\
\text { the control over one's } \\
\text { vocational future in } \\
\text { terms of decision- } \\
\text { making, assertiveness, } \\
\text { locus of control, } \\
\text { autonomy, and self } \\
\text { determination (Blustein } \\
\text { \& Flum, 1999). }\end{array}$ \\
\hline
\end{tabular}


APPENDIX C (cont'd)

\begin{tabular}{|c|l|l|l|}
\hline Codes & $\begin{array}{c}\text { Key Tenets } \\
\text { of Career } \\
\text { Construction }\end{array}$ & \multicolumn{1}{|c|}{ Characteristics } & \multicolumn{1}{c|}{ Definitions } \\
\hline CCY & Career Curiosity & $\begin{array}{l}\text { CCN,CCL,CCY, and CCE } \\
\text { represent four adaptive } \\
\text { dimensions individuals use to } \\
\text { manage critical tasks, } \\
\text { transitions, and traumas. }\end{array}$ & $\begin{array}{l}\text { Career curiosity refers } \\
\text { to inquisitiveness in } \\
\text { exploring the fit } \\
\text { between self and work, } \\
\text { information-seeking } \\
\text { and self-knowledge. }\end{array}$ \\
\hline CCE & Career Confidence & $\begin{array}{l}\text { Career confidence } \\
\text { refers to the strength to } \\
\text { pursue one's career } \\
\text { aspirations (Savickas, } \\
\text { 2005). }\end{array}$ \\
\hline Life Themes & $\begin{array}{l}\text { Provides meaning to career } \\
\text { construction and formulates } \\
\text { career patterns. }\end{array}$ & $\begin{array}{l}\text { Life themes refer to } \\
\text { individuals' career } \\
\text { stories or narratives } \\
\text { about tasks, transitions, } \\
\text { and traumas. They } \\
\text { reveal the why of } \\
\text { vocational behavior } \\
\text { and the private } \\
\text { meaning that guides } \\
\text { career choices } \\
\text { (Savickas, 2005). }\end{array}$ \\
\hline
\end{tabular}


VITA

\title{
JUDITH DEBBIE BERNIER
}

\author{
Born, Basseterre, St. Kitts
}

1992

Bachelor of Science in Communication

Florida International University, Miami, Florida

2000

Master of Science in Human Resource Development

Florida International University, Miami, Florida

\section{PUBLICATIONS and PRESENTATIONS}

Bernier, J.D. (2002). The complacent acceptance of diversity initiatives: HRD in a culturally diverse environment. Proceedings of Appreciating Scholarship: The First Annual College of Education Research Conference, (pp.14-19). Florida International University: Miami, Florida.

Bernier, J. D. (2002). A critique of diversity initiatives: Adult education in a culturally diverse environment. Proceedings of the $10^{\text {th }}$ Annual African American Adult Education Research Pre-Conference (pp. 40-48). North Carolina: North Carolina State University.

Bernier, J. D , Rocco, T. S., \& Biamonte, J. (2003). Critical race theory: Focusing the lens on Human Resource Development. In S. Neilson \& T. S. Rocco (Eds.), Supporting Interdisciplinary Inquiry: Proceedings of the Second Annual College of Education Conference (pp. 19-24). Miami, FL: Florida International University.

Parsons, M. D., \& Rocco, T. S. Bernier, J. D., Biamonte, J., Batist, C. (2003). Guiding the work of writing: Reflections on the writing process. In S. Neilson \& T. S. Rocco (Eds.), Supporting Interdisciplinary Inquiry: Proceedings of the Second Annual College of Education Conference (pp. 144-149). Miami, FL: Florida International University.

Rocco, T. S., Parsons, M., Bernier, J. D., \& Batist, C. (2003).Guiding the work of writing: Reflections on the writing process. In T. Ferro \& G. Dean (Eds.), Proceedings of the Midwest Research-to-Practice Conference in Adult, Continuing, and Community Education (pp. 174-180). Columbus, OH: The Ohio State University. 
Bernier, J. D., \& Rocco, T. S. (2003). Working in the margins of Critical Race Theory and Human Resource Development. In T. Ferro \& G. Dean (Eds.), Proceedings of the Midwest Research-to-Practice Conference in Adult, Continuing, and Community Education (pp. 13-18). Columbus, OH: The Ohio State University.

Plakhotnik, M, Rocco, T. S., Mc Carley H., Ianinska, S., Bernier, J. D., \& Gonzalez, M. C. (2005). An examination of qualitative empirical studies at the AHRD from 1999-2003: Data collection. In L. Morris, F. M. Nafukho, \& C. M. Graham (Eds.), Proceedings of the Academy of Human Resource Development 2005 Annual Conference (pp. 70-77). Denver, CO: AHRD.

Bernier, J., Rocco, T. S., McCarley H., Plakhotnik, M, Ianinska, S., \& Gonzalez, M. C. (2005). An examination of qualitative empirical studies at the AHRD from 1999-2003: Sampling strategies. In L. Morris, F. M. Nafukho, \& C. M. Graham (Eds.), Proceedings of the Academy of Human Resource Development 2005 Annual Conference (pp. 797-803). Denver, CO: AHRD.

Rocco, T. S., Mc Carley H., Plakhotnik, M, Bernier, J., Ianinska, S., \& Gonzalez, M. C. (2005). An examination of qualitative empirical studies at the AHRD from 1999-2003: Method, rationale for method, data collection, sampling strategies, and integrity measures. In S. Neilson, T. S. Rocco, \& Maria S. Plakhotnik, (Eds.), Proceedings of the Fourth Annual College of Education Conference (pp.111-116). Miami, FL: Florida International University.

Plakhotnik, M, Rocco, T. S., McCarley H., Ianinska, S., \& Bernier, J., (2006). An examination of qualitative empirical studies at the AHRD from 1999-2003: Research Purpose, Research Question(s), and Inquiry Literature Cited. In F. M. Nafukho (Ed.), Proceedings of the Academy of Human Resource Development 2006 Annual Conference (pp. 701-708). Columbus, OH: AHRD.

Bernier, J. D. (2008). Career in Context [Review of the book Career Development and Systems Theory: Connecting Theory and Practice]. New Horizon, 23, 1. 